\title{
Advances in synthetic optically active condensation polymers - A review
}

\author{
S. Mallakpour ${ }^{* 1,2}$, A. Zadehnazari ${ }^{1}$ \\ ${ }^{1}$ Organic Polymer Chemistry Research Laboratory, Department of Chemistry, Isfahan University of Technology, Isfahan, \\ 84156-83111, I. R. Iran \\ ${ }^{2}$ Nanotechnology and Advanced Materials Institute, Isfahan University of Technology, Isfahan, 84156-83111, I. R. Iran
}

Received 19 August 2010; accepted in revised form 12 October 2010

\begin{abstract}
The study of optically active polymers is a very active research field, and these materials have exhibited a number of interesting properties. Much of the attention in chiral polymers results from the potential of these materials for several specialized utilizations that are chiral matrices for asymmetric synthesis, chiral stationary phases for the separation of racemic mixtures, synthetic molecular receptors and chiral liquid crystals for ferroelectric and nonlinear optical applications. Recently, highly efficient methodologies and catalysts have been developed to synthesize various kinds of optically active compounds. Some of them can be applied to chiral polymer synthesis. In a few synthetic approaches for optically active polymers, chiral monomer polymerization has essential advantages in applicability of monomer, apart from both asymmetric polymerization of achiral or prochiral monomers and enantioselective polymerization of a racemic monomer mixture. The following are the up to date successful approaches to the chiral synthetic polymers by condensation polymerization reaction of chiral monomers.
\end{abstract}

Keywords: biodegradable polymers, optically active polymers, polycondensation reaction, amino acids, chiral monomer

\section{Introduction}

Chiral phenomena play significant roles in nature. The synthesis and application of optically active polymers are topics currently attracting much consideration in recent times, due to the wealthy and multifaceted architecture of macromolecular chirality as compared to that of small molecules. Because of unique chiral arrays, nature produces numerous smaller chiral, optically active compounds. Most of the naturally occurring molecules/macromolecules, such as nucleic acids, proteins, and polysaccharides are chiral and optically active. Chirality is essential for life. This situation can be very obviously seen if we look at the chirality of nearly 800 drugs (about $97 \%$ ) derived from natural sources. Only $2 \%$ are racemates and only $1 \%$ is achiral. In the past
30 years, the development of chiral drugs with a single enantiomer (optical isomer) has attracted great attention in drug industries, and the market for chiral drugs has tremendously grown. We are undoubtedly living in a chiral world, because of this fact that our life results from homochiral biosubstances [1-3]. Deoxyribonucleic acid (DNA) is a typical example of a homochiral biopolymer whose chirality derives from two features: (i) the incorporation of enantiopure chiral sugars connecting the achiral chromophoric bases such as adenine, guanine, cytosine and thymine and (ii) the doublestranded, stiff helical conformation arising from complementary base pairing and base stacking in water [4]. Optically active polymers often play important functions as key basic materials for well-

\footnotetext{
${ }^{*}$ Corresponding author, e-mail: mallak@cc.iut.ac.ir
}

(c) BME-PT 
defined high-performance polymers [5]. Recent advances in asymmetric reactions and catalysis as well as in chiral separations have afforded a rapid increase in the number of commercially available optically active compounds and reagents. Both naturally occurring and synthetic chiral polymers and supramolecules have found prosperous applications in chiral chromatographic separations and shown potential uses in chiral catalytic systems, liquid crystals in ferroelectric and nonlinear optical (NLO) devices, electrodes for enantioselective recognition for performing bioelectro synthesis, microwave absorbents, membrane separation technology, optical switches, biomedical equipments and optoelectronics application. A direct and efficient approach for synthesizing chiral polymers is to introduce chiral elements into the macromolecule backbone or the side chains [6-14].

In the history of synthetic polymer chemistry, it seems that one of the most challenging tasks is to construct functional polymeric systems and optically active synthetic polymers that will be as effective as those in living systems [15-18]. Specially, the synthesis of chiral polymers containing amino acids is a subject of much interest, since a high degree of amino acid functionality can lead to polymers with increased solubility and the ability to form secondary structures. The synthetic chiral polymers that have been reported may be categorized into two parts: the first category represents polymers that adopt helical conformations. Such polymers do not contain any chiral center in the main chain or side chain. If a right-handed or lefthanded helical conformation is generated in excess, the polymer can show chiroptical properties. However, the helical conformation is responsible for their optical activity. Helical polymers existing in genes, proteins ( $\alpha$-helix), DNA (double helices), collagen (triple helices), enzymes, and polypeptides are frequently found in nature. They are easily denaturalized by certain physical factors such as heat, ultraviolet irradiation, and high pressure and by other chemical factors such as organic solvents. In contrast, synthetic polymers represent much better stability. Various helical polymers have been synthesized, which include polyisocyanates, polyisocyanides, polychloral, polymethacrylates, polysilanes, polythiophenes, poly(p-phenylene)s, poly(1methylpropargyl-ester)s, poly(phenylacetylene)s and $\operatorname{poly}(\alpha, \beta$-unsaturated ketone) [19-30]. The second one is polymers whose optical activity is derived from main chain or side chain chirality such as: amino-acid-based polymers. Because the amino acids are naturally occurring compounds, synthetic polymers based on amino acids are anticipated to be nontoxic, biocompatible, and biodegradable. On the other hand, synthetic polymers containing amino acid residues in the main chain or in the side chain can be employed for biomedical applications. Possible applications include dentistry, temporary artificial skin substrates, polymer carriers for protein conjugates, drug delivery, gene therapy, tissue engineering, chiral recognition stationary phases, asymmetric catalysts, metal ion absorbents, and biomaterials [31-33]. Chiral recognition of optically active polymers has been utilized in various forms of catalytic and separation chemistry. For example, one of the generally function of chiral polymers is the use as chiral stationary phase in high-performance liquid chromatography (HPLC) for the separation of racemic mixtures [2, 34-38].

Optically active polymers were divided to three types: biopolymers, polymers prepared by almost completely isotactic polymerization by modification of naturally occurring polymer backbones such as polysaccharides and synthetic polymers [2]. Chiral synthetic polymers can be classified as: addition polymers, condensation polymers and cross-linked gels. Addition polymers are including vinyl, aldehyde, isocyanide and acetylene polymers that were prepared via addition polymerization reaction such as poly(acryl amide)s, polyolephynes, polystyrene derivatives, polyazulenes, poly(vinyl ether)s, polymethacrylate, polymethacryloylamine, polychloral, polyisocyanides, polyisocyanates, polyacethylene and polyethers [39-45]. Condensation polymerization continues to receive intense academic and industrial attention for the preparation of polymeric materials used in a vast array of applications [46]. One of application is synthesis of chiral polymers. For this purpose, monomer must be optically active. Cross-linked gels possessing chiral cavities have been prepared and their chiral recognition ability has been studied. The synthesis of gels is based on molecular imprinting technique. Two distinctive methods have been independently developed, that is, (i) polymerizing a monomer having a removable chiral template moiety with a cross-linking agent 
and removing the template groups from the products or (ii) polymerizing a monomer with a crosslinking agent in the presence of a non-polymerizable template molecule and removing the template [2]. This article reviews the synthesis of optically active polymers via polycondensation reaction of chiral monomers.

\section{Synthetic optically active condensation polymers}

\subsection{Polyamides}

Historically, the first study of optically active polymers has been of those available i.e. natural polymers such as proteins, polypeptides, polynucleotides and so on. These polymers are remarkable for their high structural regularity, their ability to take on secondary ordered structures, even in solution, and to undergo order disorder conformational transitions by changes in external conditions (solvent, temperature, $\mathrm{pH}$, etc.). Progress in polymer chemistry has allowed the synthesis of entirely different condensation polymers which one of them is optically active polyamides (PA)s [47].

Many studies concerned with the synthesis and characterization of optically active PAs have been undertaken [48-55], mainly polypeptides and proteins which have been extensively investigated. Synthesis and optical properties of asymmetric PAs derived from composed of optically active cyclic dicarboxylic acids, (+)-(S)- and (-)-(R)-trans-1,2cyclopropanedicarboxylic acids, $(-)-(\mathrm{R})$-trans-1,2cyclobutanedicarboxylic acids, $(+)$-and (-)-trans1,3-cyclopentanedicarboxylic acids and secondary diamines such as trans-2,5-piperazine, piperazine or $\mathrm{N}, \mathrm{N}^{\prime}$-dimethylethylenediamine was reported by Overberger and Shimokawa [56]. Overberger et al. [57] also prepared optically active PAs by interfacial polycondensation reactions of (+)-(S)-trans-2- methylcyclopropanedicarboxylic acid or (+)-and (-)trans-1,2-cyclohexanedicarboxylic acids with rigid spirodiamine, 2,6-diazaspiro[3,3]heptane. They prepared several model compounds, too. These model compounds were ( \pm )-trans-1,2-cyclopropanecarboxylic acid azetidide, (+)-trans-2methylcyclopropanedicarboxylic acid diazetidide, 2,6-di[( $( \pm)$-trans-2-methylcyclopropanecarboxyl]-

2,6-diazaspiro[3,3] heptane and (+)-trans-1,2cyclohexanedicarboxylic acid dipiperidide for studying the conformation of the polymers. The conformations of the polymers and the model compounds were investigated by means of optical rotatory dispersion, circular dichroism (CD) and by hydrodynamic methods.

A series of chiral PAs containing optically active thymine groups as pendants were synthesized from $\mathrm{N}$-acylation of an active diester of N-hydroxy-5norborene-2,3-dicarboxamide, N,N'-(isophthaloyldioxy)-bis(5-norbornene-2,3-dicarboximide), with 1,3-diamino-2-hydroxypropane by Overberger's group [58]. Overberger et al. [59] prepared optically active PAs based on the polycondensation of two new active diesters: the active diesters of 4chloro-1 hydroxybenzotriazole, such as 1,1'-(terephthaloyldioxy)bis(4-chloro-benzotriazole), and 1,1'(isophthaloyldioxy)bis(4-chlorobenzotriazole), with optically active isomers of 2,4-diaminopentane. Dipolar aprotic solvents such as N,N-dimethylformamide (DMF) and dimethyl sulfoxide (DMSO) were used as reaction solvents. The solution polycondensation carried out in solution at room temperature afforded optically active PAs. The aminolysis of the two active diesters was carried out as a model reaction study.

Synthesis of optically active PAs derived from L or $\mathrm{D}$-tartaric acid have been also reported in some cases [60-65] (Figure 1).
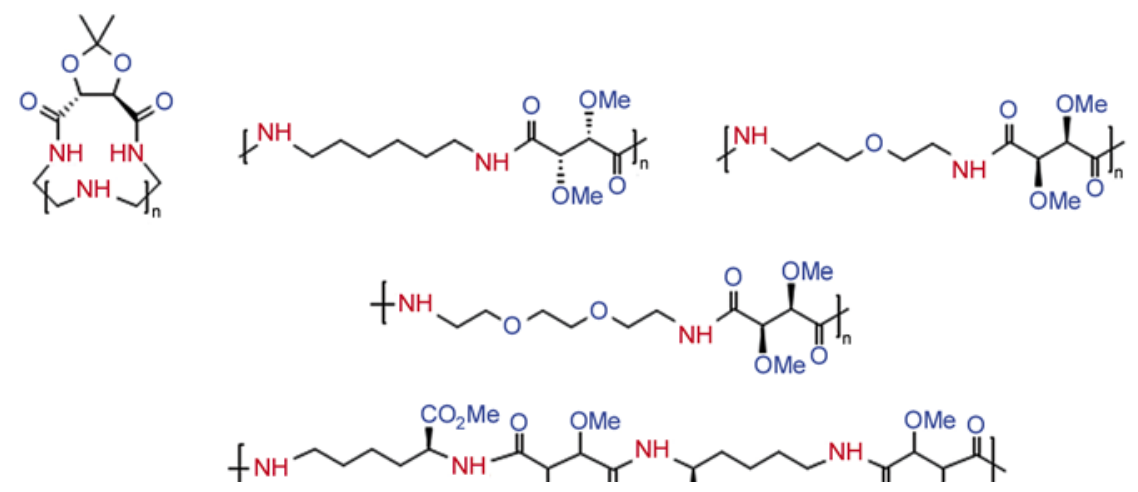

Figure 1. Chemical structures of PAs derived from tartaric acid [60-65] 
A number of optically active PAs containing $\alpha$ amino acids have been prepared. In the case of the synthetic PAs, only those containing the naturally occurring (L)- $\alpha$-amino acids, being structurally close to the natural polypeptides, possess potentially degradable linkages that make them suitable as biomaterials [66-70].

A new polyamidation reaction between $\mathrm{N}, \mathrm{N}^{\prime}$-bistrimethylsilylated diamines and 2,2'-p-phenylenebisazalactones in $\mathrm{N}, \mathrm{N}$-dimethylacetamide (DMAc) was investigated by Katsarava et al. [71]. By the interaction of bisazalactones with $\mathrm{N}^{\alpha}, \mathrm{N}^{\varepsilon}$-bistrimethylsilylated L-lysin alkyl ester, PAs were obtained containing dipeptide links in the main chain. It was shown that these can be transformed into water-soluble polyacids upon saponification of ester side groups.

PAs derived from carbohydrates are the object of current attention, because they are not only optically active, but also for its potential as biodegradable and biocompatible materials [72-77].

Mallakpour and coworkers [78-80] have investigated the synthesis of PAs from the polycondensation reaction of chiral 5-(4-methyl-2-phthalimidylpentanoylamino)isophthalic acid, (2S)-5-(3-phenyl2-phthalimidylpro-panoylamino)iso-phthalic acid and 5-(3-methyl-2-phthalimidylpentanoylamino) isophthalic acid with several aromatic and aliphatic diisocyanates such as 4,4'-diphenylmethane diisocyanate (MDI), toluylene-2,4-diisocyanate (TDI), isophorone diisocyanate (IPDI) and hexamethylene diisocyanate (HDI) under microwave irradiation as well as conventional technique (Figure 2). The resulting aromatic PAs were optically active and soluble in various organic solvents and have good

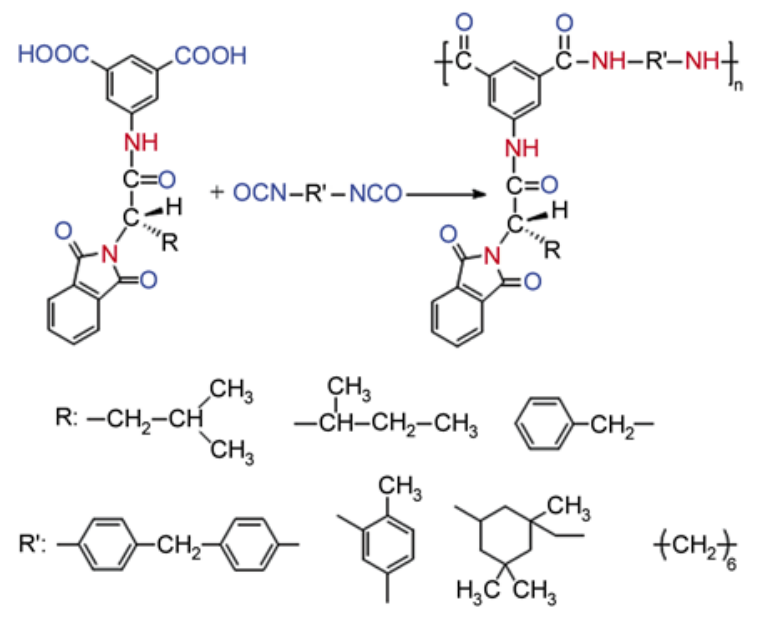

Figure 2. Synthesis of optically active and thermally stable PAs [78-80] thermal stability. Microwave-assisted step-growth polymerization reactions proceeded rapidly compared to conventional solution polycondensation and it was almost complete within a short period of time. The reactions were carried out in the presence of a small amount of dibutyltin dilaurate (DBTDL), pyridine (Py) or triethylamine (TEA) as catalysts and/or under no catalyst conditions. The use of such an organic medium was necessary to induce effective homogeneous heating of the monomers. They obtained comparable results from the viewpoint of yield and inherent viscosity of the polymers with lower reaction time by several orders of magnitude under microwave conditions and straightforward procedure. The polymerization reactions were also carried out in the presence of tetrabutylammonium bromide (TBAB) as a molten ionic liquid (IL) or traditional solvent like1-methyl-2-pyrrolidone (NMP) under microwave irradiation as well as conventional heating conditions by Mallakpour and coworkers[81-83]. In recent years, Mallakpour and coworkers reported on the synthesis and characterization of a new class of wholly aromatic and optically active PAs containing phthalimide and L-leucine pendant groups by condensation polymerization of a bulky diacid, (2S)-5-[4-(4-methyl2-phthalimidylpentanoyl-amino)benzoylamino] isophthalic acid, and several diisocyanates (Figure 3) [84]. Polymerization reactions were performed in the presence of DBTDL as a catalyst and without catalyst in molten TBAB as a green solvent and were compared with polymerization in NMP as a conventional solvent. The resulting polymers were obtained in good yields and inherent viscosities ranging between 0.26 and $0.96 \mathrm{dL} \cdot \mathrm{g}^{-1}$. Amalgamation of the bulky side chain in the PAs, cause an

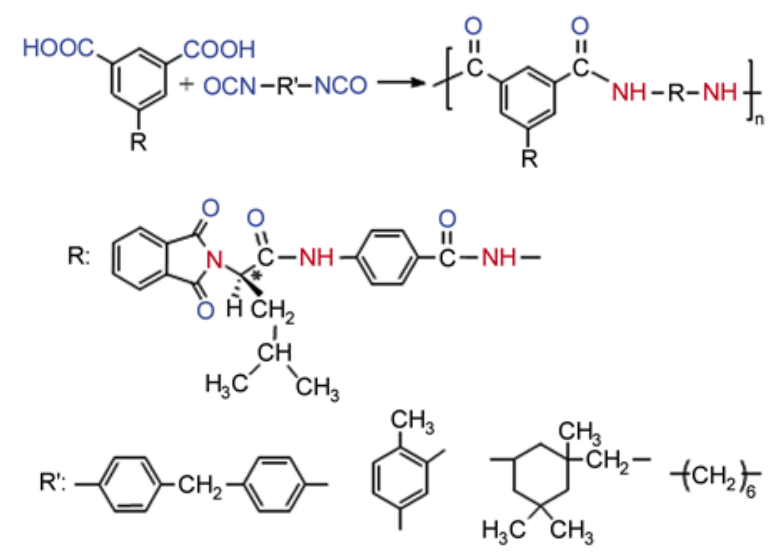

Figure 3. Synthesis of optically active PAs containing phthalimide and L-leucine pendant groups [84] 
increase in the solubility, while maintaining good thermal stability.

The same researchers also synthesized novel thermally stable and optically active PAs with flame retardant properties which were prepared via an oil bath heating method using a mixture of 1,3dipropylimidazolium bromide (as IL) and triphenyl phosphite (TPP) both as reaction media and activator [85]. The main advantage of this polycondensation reaction is that this procedure is a one-pot reaction and use of diacid chloride is not needed. These polymers presented high thermal stability, with the decomposition temperature being above $400^{\circ} \mathrm{C}$, although slightly diminished compared with those of related aromatic PAs which do not contain any pendant groups (Figure 4). The reaction proceeded efficiently with IL/TPP as condensing agent without the need of any additional promoters, which are necessary upon utilizing of traditional organic solvents like NMP. The incorporation of tetrabromophthalimide, and L-phenylalanine groups into PAs backbone gave polymers with good solubility in common organic solvents.

In another study, Mallakpour and Rafiee [86] synthesized novel optically active aromatic PAs from the reaction of new diacid monomer, 5-[3-phenyl-2(9,10-dihydro-9,10-ethanoanthracene-11,12dicarboximido) propanoylamino]isophthalic acid that was successfully synthesized starting from cis9,10-dihydro-9,10-ethanoanthracene-11,12-dicarboxylic acid anhydride and L-phenylalanine and different aromatic diamines by two diverse methods such as: microwave-assisted and conventional heating polyamidation (Figure 5). A highly effective, very fast microwave method was described to syn-

thesize optically active aromatic PAs under microwave heating for only $3 \mathrm{~min}$. Generally, better yields are obtained under faster and cleaner reactions when compared to those from conventional heating. All of these polymers having bulky anthracenic and amino acid functionality in the side chain showed excellent solubility and readily dissolved in various organic solvents. PAs were thermally stable, with $10 \%$ weight loss recorded at $385^{\circ} \mathrm{C}$ in the nitrogen atmosphere, and char yields at $800^{\circ} \mathrm{C}$ higher than $50 \%$ and glass transition temperature $\left(T_{\mathrm{g}}\right)$ above $180^{\circ} \mathrm{C}$.

Because of importance of optically active materials and polymers with amino acid, Mallakpour and Taghavi [87] prepared a series of novel optically active PAs by direct polycondensation of novel chiral dicarboxylic acid, containing a rigid naphthalimide and flexible S-valine pendant group, 5-[3methyl-2-(1,8-naphthalimidyl)-butanoylamino] is ophthalic acid with different diisocyanates in the

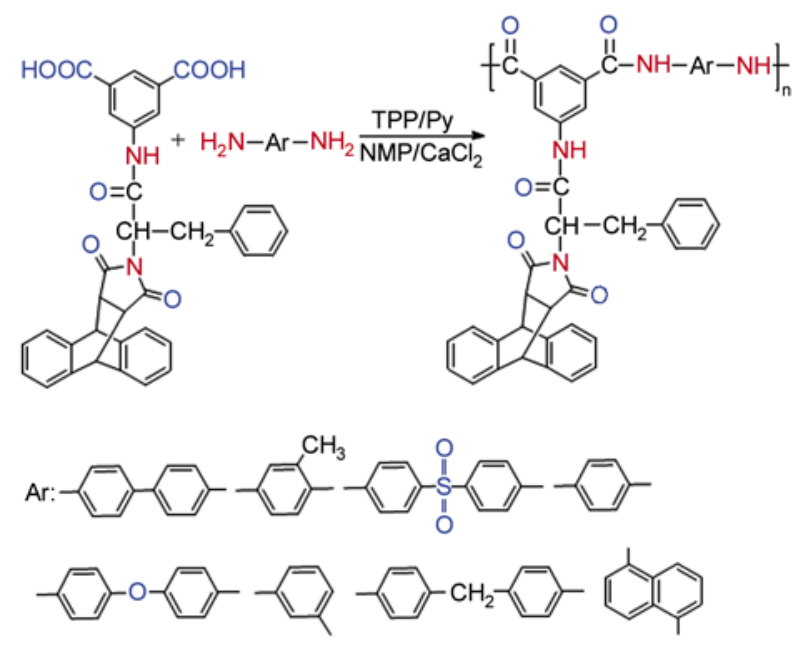

Figure 5. Polycondensation reactions of chiral monomer with aromatic diamines [86]
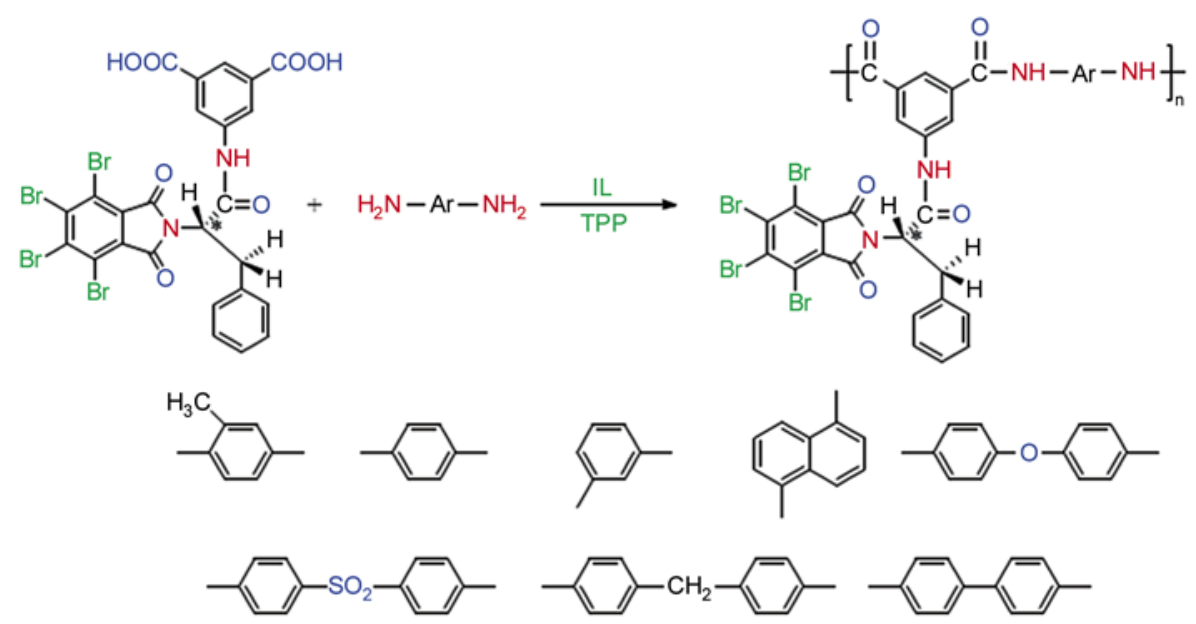

Figure 4. Synthesis of optically active flame retardant PAs [85] 


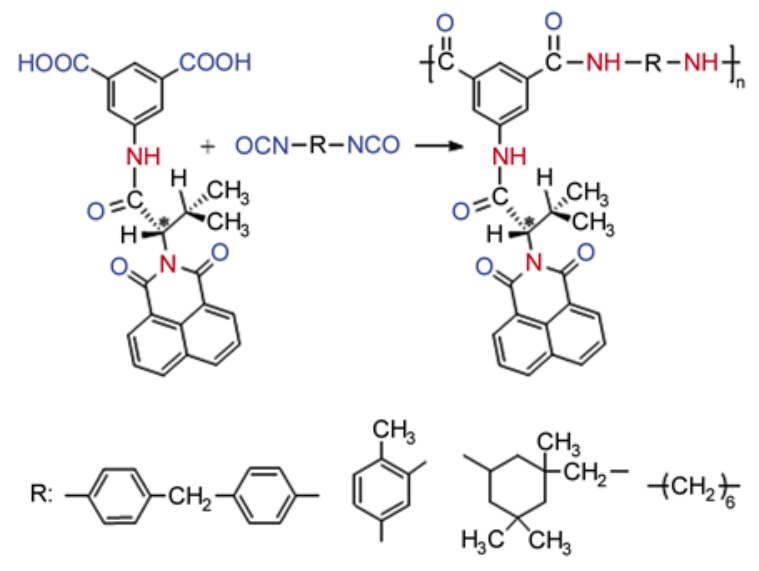

Figure 6. Synthesis of optically active flame retardant PAs [87]

presence of a small amount of ILs that act as a primary microwave absorber as well as conventional heating was carried out (Figure 6). Incorporation of the naphthalimide group into the polymer side chain as well as combination of the aromatic backbone and aliphatic pendant group in the presence of several functional groups remarkably enhanced the solubility while maintaining good thermal stability of the new polymers. The choice of 1,8-naphthalenedicarboxylic anhydride was due to the many derivatives of 1,8-naphthalic anhydride exhibit strong fluorescence emission and serve for this reason as fluorescent dyes and fluorescent whitening agents. They reported for the first time an electrochemical oxidation method based on the adsorptive stripping cyclic voltammetry technique on the multi-walled carbon nanotube-modified glassy carbon electrode for the investigation of electrochemical stability of the resulting polymers in aqueous solution at various $\mathrm{pH}$ values. The resulting polymers have many applications as photoactive materials which can be used in solar energy collectors as electro-optically sensitive materials and for laser activity.

Optically active PAs with asymmetric structure and dipole groups can easily form strong hydrogen bonds between amide groups along the molecular chain and hence can yield crystalline structures with asymmetric modality; as such, they should possess considerable ferroelectric properties. Liu et al. [88] synthesized a series of optically active PAs by polycondensation of various diamines and diacetyl chlorides and studied the dielectric properties of the resulting polymers. They found that these polymers formed a chiral tilted smectic phase and therefore should have ferroelectric properties. This implies that the polymers have asymmetric liquid crystalline structures. Chen et al. [89] reported on the synthesis of a variety of optically active PAs and o-methylated PAs, derived from (-)-anti head-tohead coumarin dimer component. Polymers were absorbed on macroporous silica gel particles and used as chiral stationary phases for direct resolution of racemates having aromatic moiety by HPLC. Preparation and properties of aromatic PAs from 2,2'-bis(p-carboxyphenoxy) biphenyl or 2,2'-bis(pcarboxyphenoxy)-1,1'-binaphthyl and aromatic diamines was investigated by Liou et al. [90]. 2,2'bis(p-aminophenoxy)biphenyl and 2,2'-bis(paminophenoxy)-1,1'-binaphthyl, were synthesized by the reaction of $p$-fluoronitrobenzene with biphenyl-2,2'-diol and 2,2'-dihydroxy-1,1'-binaphthyl, respectively, followed by catalytic reduction. Biphenyl-2,2'-diyl- and 1,1'-binaphthyl-2,2'-diylcontaining aromatic PAs having inherent viscosities of $0.44-1.18$ and $0.26-0.88 \mathrm{dl} / \mathrm{g}$, respectively, were obtained either by the direct polycondensation or low-temperature solution polycondensation of the diamines with aromatic dicarboxylic acids (or diacid chlorides). These aromatic PAs containing biphenyl and binaphthyl units had $T_{\mathrm{g}} \mathrm{s}$ in the range of $215-255$ and $266-303^{\circ} \mathrm{C}$, respectively. This group also prepared [91] new aromatic dicarboxylic acids having 2,2'-bis(p-carboxyphenoxy) biphenyl and $2,2^{\prime}$-bis(p-carboxyphenoxy)-1,1'-binaphthyl by the reaction of $\mathrm{p}$-fluorobenzonitrile with biphenyl-2,2'diol and 2,2'-dihydroxy-1,1'-binaphthyl, respectively, followed by hydrolysis. Biphenyl-2,2'-diyland 1,1'-binaphthyl-2,2'-diyl containing aromatic PAs were obtained with inherent viscosities in the range of $0.58-1.46$ and $0.63-1.30 \mathrm{dl} / \mathrm{g}$, respectively via solution polycondensation of the corresponding diacid chlorides with aromatic diamines. Nozaki et al. [92] prepared two cyclic PAs from glycine and $1,1^{\prime}$-binaphthyls, and their structures were determined by single-crystal X-ray analysis. Conformations of these two cyclic PAs in organic solvents and their interaction with other organic molecules were also studied. Hsiao et al. [93] synthesized two series of novel fluorinated aromatic PAs from 2,2'bis(4-amino-2-trifluoromethylphenoxy) biphenyl and 2,2'-bis(4-amino-2-trifluoromethylphenoxy)1,1'-binaphthyl with various aromatic dicarboxylic acids via phosphorylation polycondensation tech- 
nique and using TPP and Py as condensing agents in the NMP solution containing dissolved calcium chloride $\left(\mathrm{CaCl}_{2}\right)$. All polymerization reactions proceeded homogeneously throughout the reaction and gave clear and viscous polymer solutions. All of the resulting PAs could be cast to transparent, light-colored, and flexible films with moderately high $T_{\mathrm{g}} \mathrm{s}$ and thermal stability. A series of optically active helical PAs were synthesized by Agata et al. [94] via polycondensation of (R)- or (S)-6,6'-diamino-2,2'dimethylbiphenyl with various aromatic dicarbonyl chlorides with an optically active axially dissymmetric diaminobiphenyl compound. The molecular weights of the PAs obtained with the same type of (R)- or (S)-linkages were similar to each other, and also had very similar specific rotation values, with opposite signs. The resulting wholly aromatic PAs were soluble in common organic solvents, and excellent conformational stability of their helical structures was observed at higher temperatures. Liou et al. [95] prepared a series of novel aromatic PAs having noncoplanar biphenylene units in the main chain and bulky naphthyl or phenyl pendant group at 2,2'-disubstituted position from phenyl and naphthyl-substituted rigid-rod aromatic dicarboxylic acids, 2,2'-diphenylbiphenyl-4,4'-dicarboxylic acid and 2,2'-dinaphthylbiphenyl-4,4'-dicarboxylic acid, and various aromatic diamines via direct phosphorylation polycondensation (Figure 7). The introduction of the bulky phenyl and naphthyl-substituted group could increase the solubility and disrupt the copolanarity of aromatic units in chain packing and exhibited excellent thin-filmforming ability and thermal stability.

Among PAs there is a large group of polymers which differ from other PAs in their properties and methods of preparation. This group, called polypeptides or Poly(amino acid)s (PAA)s, is very close in its composition and structure to one of the most important classes of polymeric substances-proteins [96]. PAAs are of substantial commercial interest. As biodegradable polyanionic materials their applications range from slow release agents in agriculture, to detergents, surfactant, metal adsorbents, and cosmetics [97]. PAAs may offer numerous advantages in biomedical applications such as in diagnos-

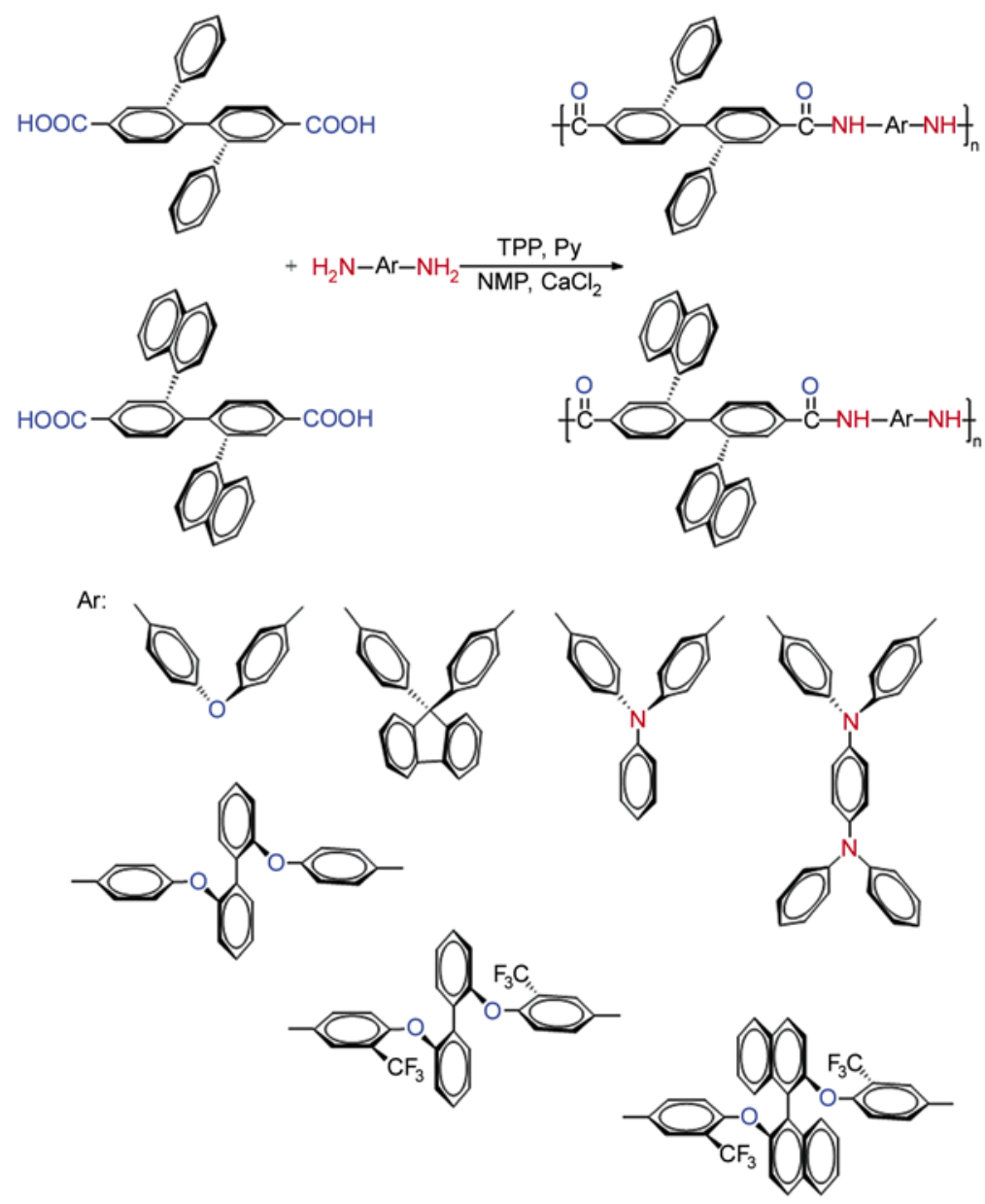

Figure 7. Synthesis of noncoplanar aromatic PAs [95] 
tics, sustained release matrices, microencapsulation, for plasma membrane isolation and chromosomal preparations, carriers for therapeutic protein conjugates and drug delivery systems [98, 99]. PAAs are obtained by the polymerization of amino acids or their suitable derivatives, serving as monomers, and like other synthetic polymers they represent a mixture of macromolecules of varying chain lengths. Recent refinements in the chemical technique of polymerization and the development of new physical methods in polymer chemistry have led to a renewal of interest in the polymers of amino acids. Most of the polymers described in the literature are composed of a single amino acid. A number of copolymers have also been prepared [100]. Many attempts were made to prepare PAAs and much considerable progress has been achieved in the synthesis and study of them. Several studies were carried out in polycondensation of $\alpha$-amino acid derivatives by Frankel and coworkers [101105]. Fasman and Blout [106] studied the synthesis and the conformation of poly-L-serine and poly-oacetyl-L-serine. These materials were synthesized with degrees of polymerization (DP) slightly above 100. Novel derivatives of poly(aspartic acid) conjugated with various amino acids such as $\gamma$-amino butyric acid, leucine, serine, valine, glycine and $\beta$ alanine and their amphiphilic copolymers were synthesized and characterized by Kim et al. [107]. The resulting polymers exhibited biocompatibility by in-vitro cytotoxicity test. These amino acid-conjugated biocompatible polymers had potential applications in pharmaceutical and cosmetic fields as base materials for drug-carrier systems. Yuki et al. [108] prepared a series of $\operatorname{poly}(\beta$-amino acid)s, poly[(RS)- $\beta$-proline $]$ and poly [(R)- $\beta$-proline], by the polycondensation reaction of the p-nitrophenyl esters. They studied conformational properties of polymers.

\subsection{Polyimides}

As polyimides (PI)s possess many desirable attributes, so this class of materials has found applications in many technologies. They have inherently high mechanical properties, good chemical resistance, low dielectric constant and high thermal stability. The high processing temperature of these materials requires dopant molecules to have high thermal decomposition temperatures. Currently, high performance PIs are being widely used for several primary applications in the electronics area as: (1) Fabrication aids such as photoresists, planarization layers and in implant masks; (2) Passivation overcoats and interlevel insulators; (3) Adhesives and underfill materials for micro BGA ( $\mu$ BGA) packaging and flip chip technology; (4) Substrate components. Some of other applications include aerospace, automotive and general engineering. In the aerospace and automotive industry they are used in structural composites and as high temperature adhesives. General engineering applications include high temperature bearings and seals [109, 110].

More recently, optically active PIs have been developed. The synthesis of optically active PIs derived from binaphthyl compounds and dianhydrides was reported [111-113]. Binaphthyls are very important chiral compounds which have been used in polymer systems. The chirality of them is arising from the restricted rotation along the carbon-carbon single bond of the two naphthalene rings. The resulting polymers showed good chiral recognition ability when used as a chiral packing material for HPLC. In $1996 \mathrm{Mi}$ et al. [114] reported on the first synthesis of a type of thermally stable and optically active aromatic PIs possessing (R)-(+)- or (S)-(-)-1,1'-bi2-naphthalene units in the main chain, along with some of their important properties. The key monomers, optically active (R)-(+)- or (S)-(-)-2,2'bis(3,4-dicarboxyphenoxy)-1,1'-binaphthalene dianhydrides ( $5 \mathrm{R}$ and $5 \mathrm{~S})$, were prepared by the reactions of optically active (R)-(+)- or (S)-(amic acid)s and subsequent chemical imidization with acetic anhydride-triethylamine (Figure 8). The solubility of resulting PIs was greatly improved by the incorporation of noncoplanarity in axially dissymmetric 1,1'-bi-2-naphthalene units into the polymer backbone. The optical stability at high temperatures could be expected because the racemization resulting from the rotation around the axis of the two binaphthalene rings would be highly hindered by the long chain stretching out on both sides. This group [115] also prepared new optically active aromatic PIs from (R)-(+)-2,2'-bis(2-trifluoro-4aminophenoxy)-1,1'-binaphthyl monomer with $4,4^{\prime}$-oxydianhydride by one step method. The same researchers [116] performed the similar reaction for the preparation of thermally stable chiral PIs. They 

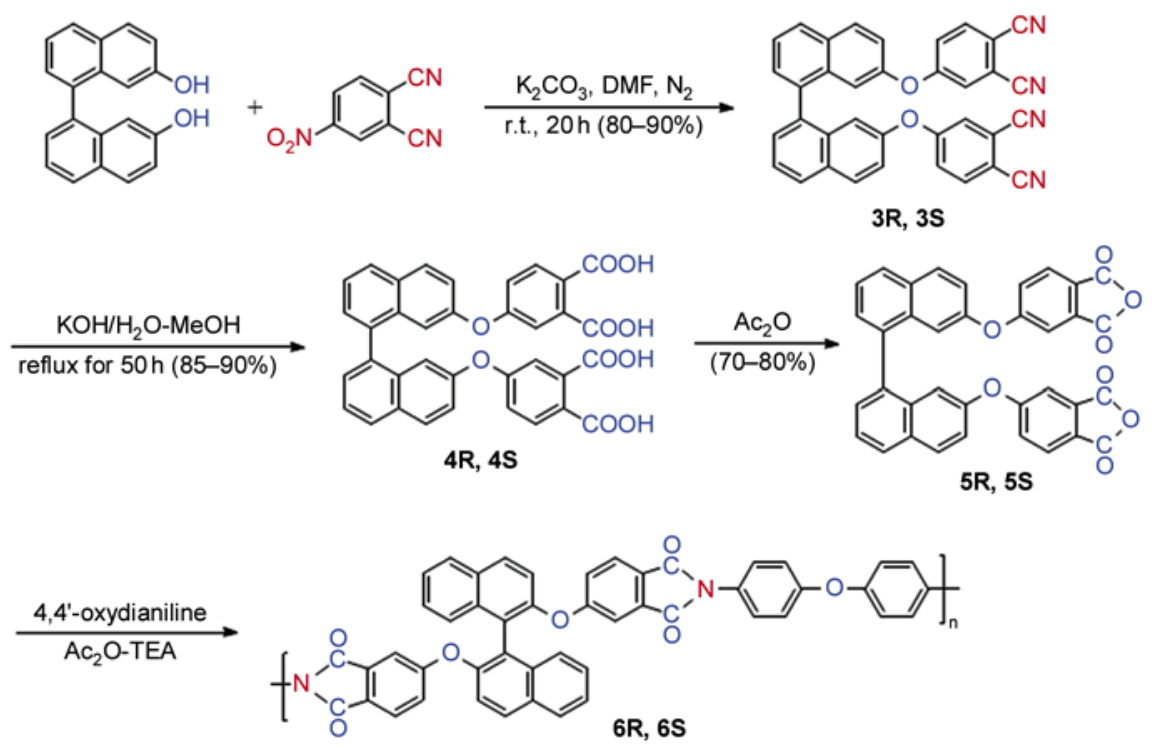

Figure 8. Synthesis of optically active twisted PIs containing 1,1'-bi-2-naphthalene unit [114]

synthesized polymers from condensation of aforementioned monomer with various dianhydrides by using the one-step method. These polymers had glass-transition temperatures of $256 \sim 278^{\circ} \mathrm{C}$ and were optically active with specific rotations ranged from $167 \sim 258^{\circ}$ and their chiroptical properties also were studied.

Liou [117] reported on the synthesis of organosoluble aromatic chiral PIs from 2,2'-bis (3,4-dicarboxyphenoxy)-1,1'-binaphthyl dianhydride. The dianhydride monomer was subjected to the one-step polycondensation with various aromatic diamines, giving moderate molecular weight PIs with inherent viscosities up to $0.67 \mathrm{dl} / \mathrm{g}$. The introduction of bulky, cranked, and twisted noncoplanar binaphthyl-2,2'diyl unit into the polymer backbone highly improved solubility of the PIs in organic solvents. All the PIs showed typical amorphous diffraction patterns and had $T_{\mathrm{g}} \mathrm{s}$ in the range of $280-350^{\circ} \mathrm{C}$, depending on the nature of the diamine moiety. All polymers were stable up to $400^{\circ} \mathrm{C}$, with $10 \%$ weight loss being recorded above $485^{\circ} \mathrm{C}$ in air.

Yigit et al. [118] described chiral synthetic functionalized PIs containing a chiral $(\mathrm{R}, \mathrm{R})$ or $(\mathrm{S}, \mathrm{S}) 1,3-$ bis(p-N,N'-dimethylaminobenzyl)-perhydrobenzimidazol-2-thion unit in the backbone. The reactions were performed between an optically active aromatic dimethylamine and various dianhydrides such as: pyromellitic dianhydride (PMDA), 3,3',4,4'benzophenonetetracarboxylic dianhydride (BPDA), 4,4'-oxydiphthalic anhydride (ODPA) and 3,3',4,4'biphenyltetracarboxylic dianhydride (BTDA) in the

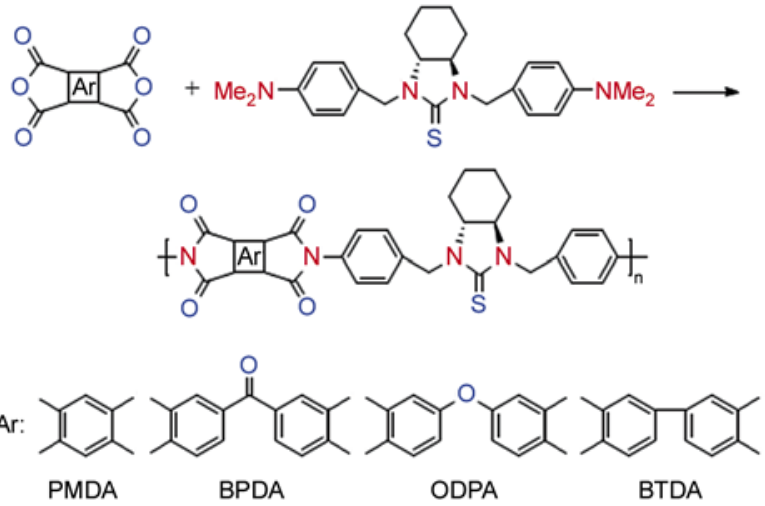

Figure 9. Synthesis route for PIs [118]

presence of the solvent NMP (Figure 9). PIs were soluble in some polar aprotic solvents such as NMP, DMF, DMAc and DMSO and insoluble in apolar solvents such as ether and hexane. The inclusion of chiral groups containing perhydrobenzimidazole groups in the polymer backbone makes the polymer thermally stable with increased solubility. The improved solubility may be attributed to the bulky structure of the monomers, which decreases the interchain interaction owing to the rigid aromatic repeating units. The PIs prepared exhibit excellent properties, with a high potential for optically active polymers.

Kudo and coworkers [119] have reported on the synthesis of constitutionally isomeric head-to-head, head-to-tail and random PIs using an unsyrnmetric alicyclic tetracarboxylic dianhydride. They reported on a first example for the structurally isomeric PIs that show a different physical property (Figure 10). They also prepared optically active alicyclic PIs via 


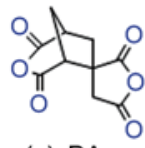

(-)-DAn
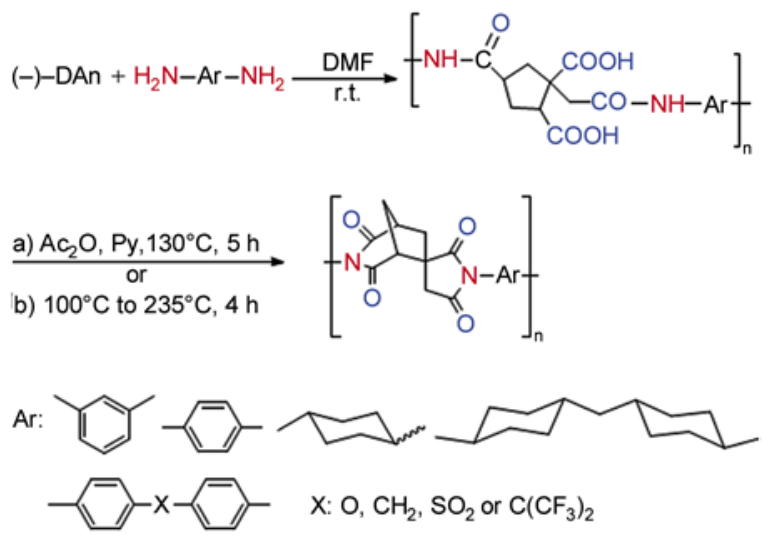

Figure 10. Synthesis of optically active coPIs derived from DAn [119-123]

polycondensation of (-)-[1 $\mathrm{S} *, 5 \mathrm{R} *, 6 \mathrm{~S} *]-3$-oxabicyclo[3.2.1] octane-2,4-dione-6-spiro-3'-(tetrahydrofuran-2',5'-dione) $[(-)$-DAn] with diamines and subsequent chemical or thermal imidization (Figure 10). The dianhydride (-)-DAn was synthesized by an asymmetric Diels-Alder reaction of a chiral itaconic acid derivative as a key step. Colorless or slightly yellow flexible films were obtained for the (-)DAn-derived PIs. The resulting polymers showed good solubility toward dipolar aprotic solvents and Py [120]. Kudo's group also successfully synthesized a series of optically active and soluble PIs having a spiro alicyclic unit in the main chain by the reactions of DAn with several diamines through a general two-step polymerization method [121122]. In another research, they reported on a systematic investigation of the physical properties of coPIs of DAn [123]. The comonomer used in their study was c-3-carboxymethyl-r-1,c-2,c-4-cyclopentane tricarboxylic acid 1,4:2,3-dianhydride (TCAAH), a structural isomer of DAn, which is unsymmetric but does not have a spiro unit (see Figure 10). The refractive indices of coPIs were also studied. They showed the DAn content in the backbone affects various properties of coPI, which might be attributed to its unsymmetric spiro-alicyclic structure. The structure property relationships found here should be universal in principle, and might be applicable to the design and modification of other polymers.
Barikani et al. [124] investigated a new optically active diisocyanate containing methylene groups and a preformed imide ring using the Curtius rearrangement of corresponding diacylazides. The diisocyanate was polycondensed with PMDA, benzophenone tetracarboxylic dianhydride, and hexafluoroisopropylidene diphthalic anhydride to provide three optically active PIs. The introduction of methylene moieties as well as the presence of a preformed imide ring in the polymer backbone improved the solubility of the polymers without too much thermal stability being sacrificed. Synthesis and characterization of new optically active PIs containing L-leucine amino acid residue are reported by Yeganeh et al. [125]. They prepared a new optically active diisocyanate from the reaction of L-leucine and PMDA and subsequent transformation of intermediate imide-containing diacid to diisocyanate via Weinstock modification of Curtius rearrangement using TEA, ethylchloroformate and sodium azide reagents. The solution polycondensation using DMF solvent and appropriate duration and temperature programming which optimized via study of model compound was applied successfully for preparation of PIs from this diisocyanate and three different dianhydrides such as PMDA, 3,3,4,4-benzophenonetetracarboxylic dianhydride, and hexafluoroisopropylidene 2,2-bis(phthalic anhydride). Two different optically active dianhydrides were also prepared by them [126] from the reaction of L-aspartic acid with either PMDA or benzophenone tetracarboxylic dianhydride and subsequent transformation of tetraacids to dianhydrides using thionyl chloride. Twelve novel optically active and soluble PIs having inherent viscosities of 0.18 $0.55 \mathrm{dl} / \mathrm{g}$ were synthesized from the reaction of optically active dianhydrides with different aromatic and aliphatic diisocyanates. These polymers showed acceptable physical properties as well as optical activity.

\subsection{Polyesters}

Recently, Mallakpour and coworkers [127-131] synthesized optically active thermally stable aromatic polyesters (PE)s containing phthalimide group from the reaction of two different diacid monomer with several aromatic diols via direct polyesterification with tosyl chloride $(\mathrm{TsCl}) / \mathrm{Py} /$ 
DMF system as condensing agent. The resulting polymers were obtained in good yields with inherent viscosities ranging between 0.21 and $0.61 \mathrm{dL} / \mathrm{g}$. Thermal gravimetric analysis (TGA) showed that the $10 \%$ weight loss temperature in a nitrogen atmosphere was more than $360^{\circ} \mathrm{C}$, which indicates that the resulting PEs have a good thermal stability. From the chemical point of view the ester group imparts to the polymer's structure increased sensibility to hydrolysis that can cause chain breaking. In addition because of the existence of amino acids in the polymer pendant group these polymers were expected to be biodegradable and were therefore classified under environmentally friendly polymers. More recently this group also synthesized optically active and photoactive aromatic PEs by step-growth polymerization of a chiral diacid containing naphthalimidyl and flexible chiral groups with different diols via direct polyesterification reaction. The resulting polymers show excellent solubility due to bulky pendant groups, good thermal stability with glasstransition temperature around $200^{\circ} \mathrm{C}$, and fluorescence emission phenomena [132].

A series of coPEs based on 2-[(S)-(+)-methyl-1butoxylhydroquinone as the chiral monomer with several nonchiral hydroquinones was synthesized by Fujishiro and Lenz [133] to form a new family of main-chain cholesteric liquid crystalline polymers containing a flexible spacer. Copolymers containing unsubstituted hydroquinone units formed two liquid crystalline phases, one of which was a cholesteric phase, but the other may have been a cybotactic nematic phase. Copolymers with nonchiral substituted hydroquinone units formed only a cholesteric phase. Schwartz et al. [134] reported on the polycondensation of silylated 2,3-isopropylidene D-threitol with a dicarboxylic acid dichloride in o-dichlorobenzene or 1-chloronaphthalene at $180-230^{\circ} \mathrm{C}$ and ten cholesteric coPEs were prepared by polycondensation of mixtures of silylated methylhydroquinone and cis- or trans-1,4:3,6-dianhydro-D-sorbitol (trans: isosorbide, cis: isomannide), or 2,3-isopropylidene threitol with the dichloride of 1,10-bis(4'-carboxyphenoxy)decane. The polymers containing isosorbide units are optically active. The resulting coPEs form a broad cholesteric phase above $200^{\circ} \mathrm{C}$. This approach is also useful for the synthesis of coPEs from diols and diphenols, and thus, allows the preparation of cholesteric
PEs with interesting optical properties. For the first time, Kricheldorf's group [135] investigated a process for the production of optically active PEs based on the polycondensation of 4-carboxycinnamic acid in the form of its acid chloride with chiral spacers in the presence of Py. Difunctional cinnamic acids such as 4-hydroxy- or 4-aminocinnamic acid are useful and interesting components of photoreactive polycondensation. Chiral spacer was synthesized from (R)-3-bromo-2-methyl-1-propanol and 4-mercaptophenol. Three homoPEs were also prepared via polycondensation of 4,4'-dihydroxybiphenyl and 2,5-bis(n-octyloxy)-2,5-bis(dodecyloxy)- or 2,5-(hexadecyloxy) terephthaloyl-chloride by this group [136]. Furthermore, several coPEs were synthesized from 4,4'-dihydroxybiphenyl and mixtures of 2,5-bis-(hexadecyloxy) terephthaloylchloride and 2,5-bis((S)isopentyloxy)terephthaloylchloride. All PEs were characterized by inherent viscosities, elemental analyses, ${ }^{1} \mathrm{H}$ NMR spectroscopy, differential scanning calorimetry (DSC) measurements, dynamic mechanical analyses (DMA), wide-angle X-ray diffraction (WAXD)s powder patterns at various temperatures and optical microscopy. Two liquid crystalline phases were detected for the homoPEs and most coPEs: a viscous sanidic (biaxial nematic) phase and, at higher temperatures, a mobile nematic phase. Sanidic PEs are PEs forming a layered supramolecular structure with the layer planes parallel to the main chain in contrast to the smectic systems where the layer planes are more or less perpendicular. Kricheldorf and coworkers [137] also synthesized a series of chiral PEs by polycondensation of silylated 4,4'dihydroxybiphenyl and mixtures of 2,5-bis(dodecylthio)terephthaloyl chloride and 2,5-bis((S)-2methylbutylthio)terephthaloyl chloride. The resulting coPEs were characterized by elemental analyses, viscosity, DSC and X-ray measurements, and optical microscopy. Depending on the reaction conditions low and high molecular weights were obtained. Bahulayan and Sreekumar [138] investigated chiral PEs with azobenzene moieties in the main chain by the polycondensation of terephthaloyl chloride with isosorbide, which acts as the chiral building unit, and an azobiphenol, bis(4-hydroxyphenylazo)-2,2'dinitrodiphenylmethane or bis(4-hydroxyphenylazo)-2,2'-dinitro-3,5,3',5'-tetramethyldiphenylmethane in a solvent mixture of DMAc and 1,2- 
dichlorobenzene $(1: 4 \mathrm{v} / \mathrm{v})$. These polymers exhibited good thermal properties, had high $T_{\mathrm{g}}$ values and TGA studied showed they were stable up to $400^{\circ} \mathrm{C}$. The polymer chains characterized by helical structures were non-centrosymmetric at the molecular level. But in randomly oriented polymer films obtained by solvent evaporation, non-centrosymmetry may be lost. This group [139] prepared a series of optically active PEs with $\pi$-conjugated donor-acceptor segments was synthesized by the condensation of azobenzene-4,4'-dicarbonylchloride with 1,4:3,6-dianhydro-D-sorbitol $\left([\alpha]_{\mathrm{D}}^{25}=\right.$ $42.5^{\circ}$ ) and biphenolic chromophores, bis(4-hydroxyphenylazo)-2,2'-dinitrodiphenylmethane and bis(4-hydroxyphenylazo)-2,2'-dinitrodiphenylsulfone. The second-harmonic generation (SHG) efficiency of the polymers was experimentally verified by a powder-reflection technique with 2-methyl-4nitroaniline as a reference. The SHG efficiencies of the polymers were compared to those of the chromophores and explained as a function of the percentage of chiral composition. WAXD scans showed that with the increase in the percentage of the chiral unit, the packing order in the polymers increased. They also synthesized [140] several chiral PEs containing donor-acceptor substituted $\pi$-conjugated segments in the main chain by high-temperature polycondensation of biphenolic chromophores, bis(4-hydroxyphenylazo)-2,2'-dinitrodiphenylmethane and bis(4-hydroxyphenylazo)-2,2'-dinitrodiphenylsulfone with $(2 \mathrm{R}, 3 \mathrm{R})-(+)$-diethyl tartrate and terephthaloyl chloride. Results showed that the optical rotation increased with the increase in the composition of diethyl tartrate units. The temporal stability showed that the chiral organization and, hence, the dipole orientation are stable in these systems. The high $T_{\mathrm{g}}$ value of the polymers also supported the thermal stability of the orientation. Thus, chiral polymers incorporating donor-acceptor substituted $\pi$-conjugated segments can offer themselves as promising materials in the field of nonlinear optics. The same researchers reported on [141] the synthesis, characterization and solvatochromic behavior of a new series of optically active PEs. These polymers were prepared from polycondensation of diacid chlorides with biphenolic azo chromophores such as bis(4-hydroxyphenylazo)-2,2'dinitrodiphenylmethane and bis(4-hydroxyphenylazo)-2,2'-dinitrodiphenylsulphone with $\Lambda$-shaped conformation and isosorbide compound. The polymerizations were carried in different highly polar solvents like DMF and DMAc with Py as acid acceptor. The PEs were obtained with higher dipole moment in excited state than in ground state so that they were stabilized more in the excited state by an increase in solvent polarity. This shows that in all respects these PEs are suitable for NLO studies.

Nemoto et al. [142] prepared new types of PEs containing containing second-order NLO active chromophores with high density by the condensation polymerization between the isophthalic acid derivatives and the $\mathrm{N}$-substituted diethanolamines using TPP and diethyl azodicarboxylate as the condensing agents in DMSO or NMP. The obtained amorphous PEs exhibited good solubility in common organic solvents and provided optical-quality films by spin-coating. The weight average molecular weights of PEs estimated from gel permeation chromatography (GPC) were the magnitude of thousand, which indicates the DP was ca. 10-15. Mehl et al. [143] investigated a series of optically active PEs containing chiral groups in the main chain by polycondensation of chiral diol with several aromatic diacids. The DP for all the polymers lay between 13 and 15 repeat units. The polydispersity of the samples was more or less similar, and therefore comparisons between different polymers were possible. The comparatively low polydispersity was a result of the good solubility of the monomers and low molar mass oligomers in methanol. Synthesis and characterization of novel optically active biodegradable network PEs from L- and D-malic acid and various glycols with different number of methylene groups $\left(\mathrm{HO}\left(\mathrm{CH}_{2}\right)_{\mathrm{n}} \mathrm{OH}, \mathrm{nG}, \mathrm{n}=2-6,8-\right.$ 10, and 12) was studied by Nagata et al. [144]. The biodegradation experiments for the network PE films were carried out in enzymatic solution with Rhizopus delemar lipase and in an activated sludge. The stereochemistry between the L- and D-isomer of network PE films gave rise to the small differences in biodegradation rate: the rate of biodegradation for the network PE with L-isomer is higher than that with D-isomer. Bai et al. [145] synthesized a series of new liquid-crystalline PEs having the chiral centers and dipolar groups isoregically arranged along the polymer backbones. The physical properties such as molecular weights, intrinsic viscosities, elemental analyses, and thermal analy- 
ses of polymers were studied. The thermal stability for polymers was similar regardless the difference in spacer length and molecular weight, because they have same functional groups and linkages. Srinivasan and Radhakrishnan [146] reported on the synthesis, characterization, and examination of liquid-crystalline properties of thermotropic mainchain random coPEs based on 4,4'-biphenol using twin spacers-chiral and achiral-revealed that chiral spacers were able to transmit the twist direction and a tilt angle to the molecule (their ferroelectric properties were investigated). The number average molecular weights measured by GPC were between 6000 and 8000 with polydispersities ranging from 1 to 1.1. Liquid-crystalline PEs based on hexanediol or butanediol, dimethyl 4,4'-biphenyldicarboxylate, and a sugar-based diol, and and various levels of isosorbide or isomanide (Figure 11), were organized with conventional melt polycondensation by Lin et al. [147]. Modest molecular weights were obtained, although they were typically lower than those of PE analogues that did not include sugarbased diols. TGA confirmed that the insertion of isosorbide or isomanide units did not reduce the thermal stability in a nitrogen atmosphere.

Hilker et al. [148] reported on the examination of a novel concept for the synthesis of chiral PEs (Figure 12), a lipase-catalyzed dynamic kinetic resolution (DKR) polymerization of racemic monomers. In their investigation, a mixture of stereoisomers of a secondarydiol is enzymatically polymerized with a difunctional acyl donor (dicarboxylic acid derivative) in the presence the Noyori-type ruthenium catalyst $\mathrm{A}$ and an immobilized Candida Antarctica Lipase B (Novozym 435). Because of its enantioselectivity the Lipase B converts only the hydroxy
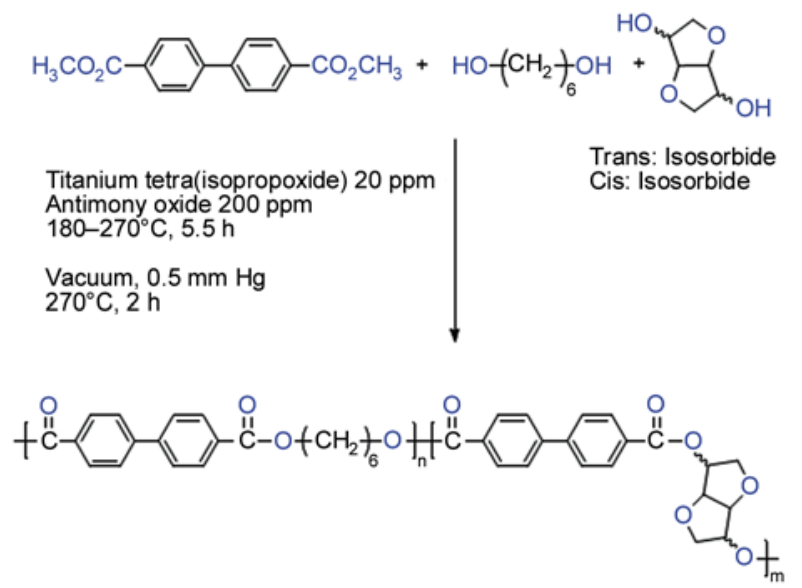

Figure 11. Synthesis of chiral liquid-crystalline PEs [147]

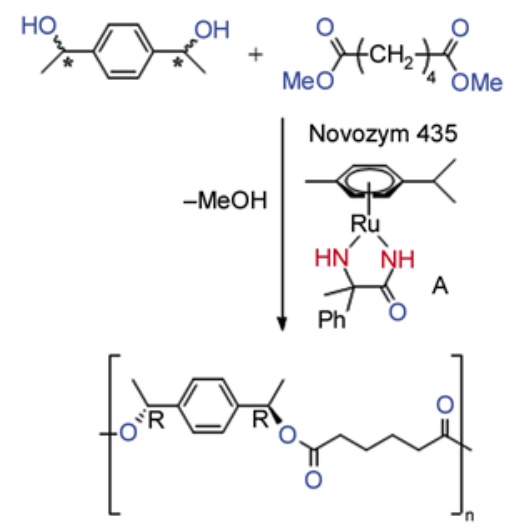

Figure 12. Reaction sequence for the one-pot DKR polymerization [148]

groups at the R-configured centers. In situ racemization of the hydroxysubstituted stereocenters from the $\mathrm{S}$ to the $\mathrm{R}$ configuration allows the polymerization to proceed to high conversion. They showed that DKR can be combined with enzymatic polymerization for the preparation of chiral PEs from racemic secondary diols. This notion offers an efficient method for the one-pot synthesis of chiral polymers from nonnatural monomers.

Under similar conditions DKR of secondary alcohols and esters was extended to secondary diols and diesters to afford chiral PEs by Van As et al. [149]. With these conditions, chiral polymers were obtained with peak molecular weights up to $15 \mathrm{kDa}$, enantiomeric excess (ee) values up to $99 \%$. At most, an ee of $46 \%$ was obtained with low molecular weights in the range of $3.3-3.7 \mathrm{kDa}$. This process is an example of iterative tandem catalysis, an effective method for synthesis of chiral polymers from a variety of optically inactive monomers. Gómez et al. [150] reported on the first synthesis of optically active PE containing 11,11,12,12-tetracyano-9,10-anthraquinodimethane (TCAQ) as an efficient electron acceptor in the main chain by polycondensation reaction of (S)-2,2'-bis(dodecyloxy)-1,1'-binaphthyl-6,6'-dicarboxylic acid chloride with 2,6-dihydroxy-TCAQ. The reaction was carried out at moderate temperature in an aprotic solvent and in the presence of TEA. Cyclic voltammetry investigations showed that TCAQ preserved its acceptor ability in the polymer system and preliminary photophysical investigations showed fluorescence quenching in mixtures containing the acceptor polymer and fluorescent conjugated polymers. 


\subsection{Poly(amide-imide)s}

Synthesis and characterization of a number of optically active poly(amide-imide)s (PAI)s were investigated by Mallakpour's group [151-154]. The polymerization reactions were carried out via polycondensation reaction of $\mathrm{N}$-trimellitylimidoleucine, N-trimellitylimidoisoleucine, N-trimellitylimidophenylalanine and N-trimellitylimido-DL and Lalanine with several diamines in the presence of TPP, NMP, Py, and $\mathrm{CaCl}_{2}$ under various conditions for different periods of time, and in another method (Figure 13). These aromatic PAIs showed optical rotations, were readily soluble in various organic solvents, and had moderate thermal stability. This could be due to the formation of some cyclic polymers instead of linear polymers.

Mallakpour and coworkers $[155,156]$ reported on some of preparation of chiral PAIs via direct solution polycondensation of different aliphatic and aromatic diisocyanates with a chiral diacid monomer. The optically active N-trimellitylimido-L-isoleuceine as a monomer was reacted with some aromatic as well as aliphatic diisocyanates according to isocyanate route. This method was a convenient technique for the preparation of novel optically active PAIs. In addition, in this method use of diamines was eliminated and there was no need to activate diacid monomer. Mallakpour et al. [157159] have also investigated the synthesis of PAIs from the polycondensation reaction of $\mathrm{N}_{2} \mathrm{~N}^{\prime}$ -

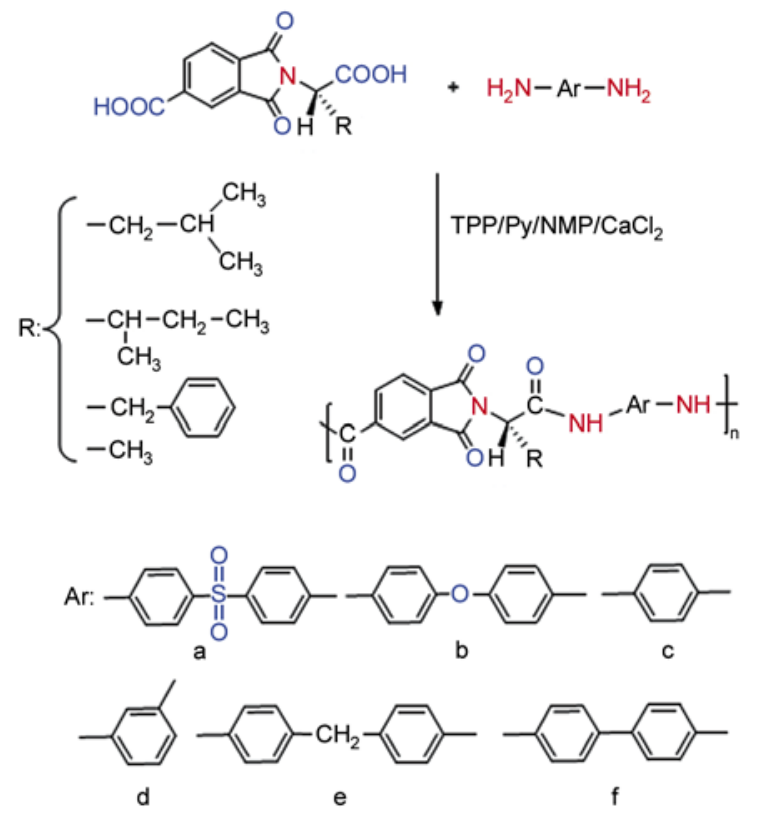

Figure 13. Synthesis route for optically active PAIs [151154]
(pyromellitoyl)-bis-L- $\alpha$-amino diacid chloride such as: L-leucine, L-isoleucine and L-valine with different aromatic diamines under microwave heating in a porcelain dish and the results were compare with those polymers obtained by conventional heating (Figure 14). The obtained aromatic PAIs were optically active and soluble in various organic solvents and have good thermal stability. Microwaveassisted step-growth polymerization reactions preceded rapidly compared to conventional solution polycondensation and it was almost completed within a short period of time. Several types of optically active PAIs were prepared by Mallakpour et al. [160-163] from polycondensation reaction of $\mathrm{N}, \mathrm{N}^{\prime}$-(4,4'-carbonyldiphthaloyl)-bis $\alpha$-amino diacid chloride such as: L-phenylalanine, L-alanine and Lleucine with several aromatic diamines in o-cresol or DMAc (Figure 15). Polymerization reactions were carried out using microwave irradiation and conventional solution polycondensation. The polycondensation proceeded rapidly, compared with the conventional melt polycondensation and solution polycondensation giving a series of PAIs with inherent viscosities about $0.22-0.85 \mathrm{dl} / \mathrm{g}$. All aromatic PAIs were optically active and readily soluble in various organic solvents and had good thermal stability. The inherent viscosities obtained from microwave assisted polycondensation reactions are much higher than those polymers obtained from solution polymerization. Furthermore, the above
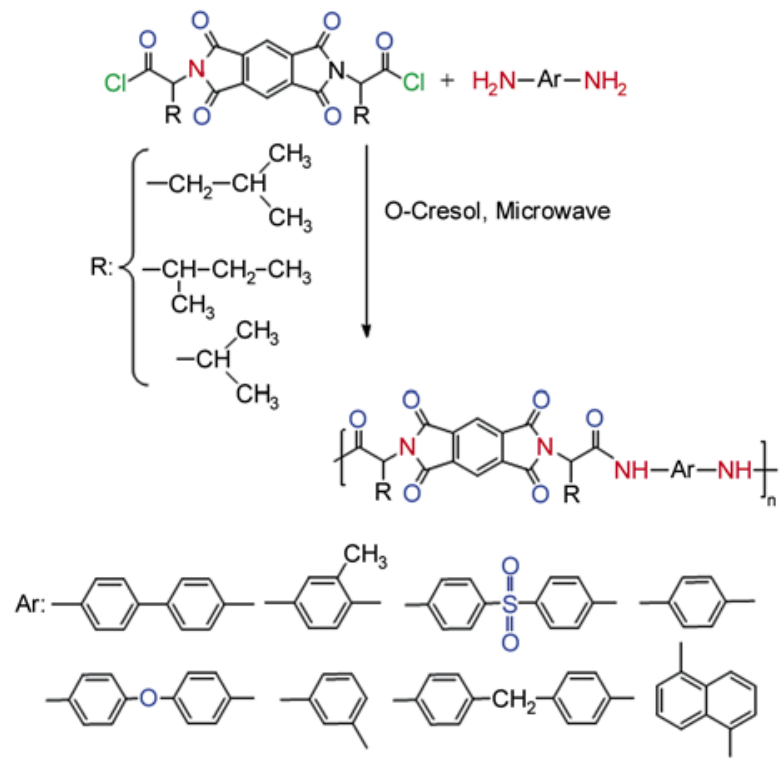

Figure 14. Synthesis of chiral PAIs by reaction of different $\mathrm{N}, \mathrm{N}^{\prime}$-(pyromellitoyl)-bis-L- $\alpha$-amino diacid chloride with aromatic diamines [157-159] 

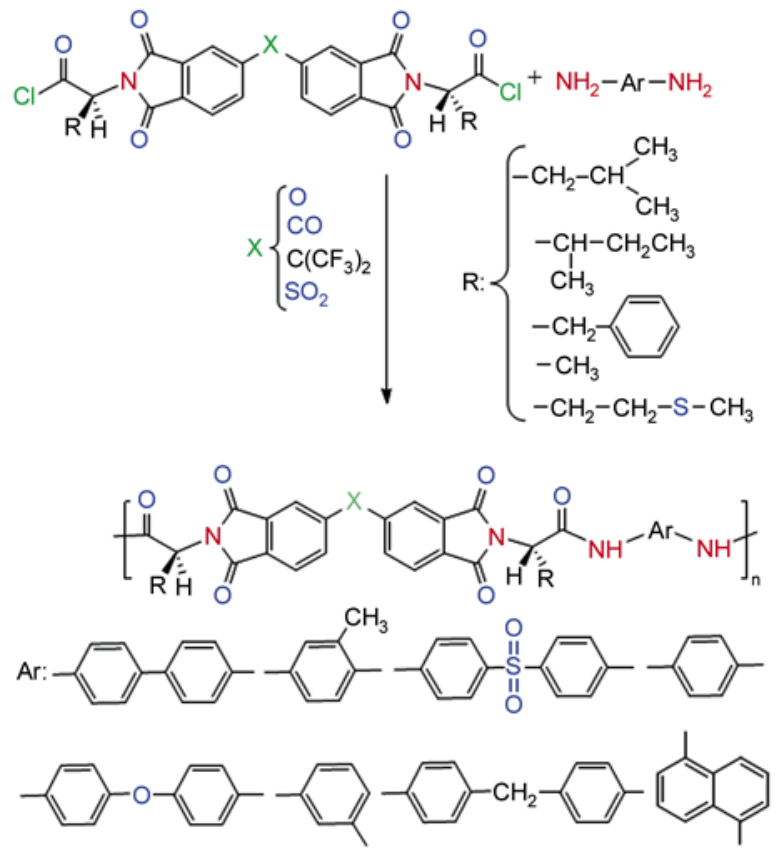

Figure 15. Reaction of several optically active diacid chlorides with different aromatic diamines [160172, 176-179]

results demonstrate that microwave heating is an efficient method (shorter reaction time and high efficiency of energy) for the polycondensation reactions. Polymerization reaction of several diamines with 4,4'-(hexafluoroisopropylidene)-N,N'-bis(phthaloylmethionine) diacid chloride and 4,4'(hexafluoroisopropylidene)-bis-(phthaloylleucine) diacid chloride were performed in polar aprotic solvents by Mallakpour's group [164, 165] (Figure 15). By applying different solution polycondensation methods, fluorine containing PAIs having inherent viscosities in a range of $0.09-0.45 \mathrm{dL} / \mathrm{g}$ (molecular weight ranging 15 000-25000 dalton) were synthesized. These polymers exhibit a higher thermal stability than non-fluorine bearing polymers with comparable structures. The presence of both amide and chiral imide groups into the polymer backbone, gives a good balance of properties with chiral centers; and introducing two $\mathrm{CF}_{3}$ groups into the monomer unit, giving a good solubility in comparison to the other PAIs.

This group have also investigated direct polycondensation of 4,4'-(hexafluoroiso-propylidene)$\mathrm{N}, \mathrm{N}^{\prime}$-bis(phthaloylleucine-p-amidobenzoic acid) and N, $\mathrm{N}^{\prime}-\left(4,4^{\prime}\right.$-hexafluo-roisopropylidendiphthaloyl)-bisisoleucine with aromatic diamines in a medium consisting of TPP, NMP, $\mathrm{Py}$, and $\mathrm{CaCl}_{2}$ or via Vilsmeier adduct derived from $\mathrm{TsCl}$ and $\mathrm{DMF}$
[166, 167] (Figure 15). The resulting PAIs were obtained in high yield and are optically active and thermally stable. Furthermore, the resulting optically active PAIs contain amino acid linkages, could be biocompatible and biodegradable. Mallakpour's group [168-172] studied the microwavepromoted as well as conventional heating polycondensation of N,N'-(4,4'-oxydiphthaloyl)-bis-methionine diacid chloride or diacid chlorides contain amino acids of (S)-valine, L-isoleucine or L-leucine with several aromatic diamines (Figure 15). They also investigated a series of optically active PAIs via step-growth polymerization reactions of bis (pamidobenzoic acid)-N-trimellitylimidoleucine monomer with different diisocyanates via direct step-growth polymerization under microwave irradiation, solution polymerization under gradual heating and reflux conditions in the presence of Py, DBTDL, and TEA as a catalyst and without a catalyst [173]. The optically active PAIs were obtained after a short time of $3 \mathrm{~min}$ in good yields (53-95\%) and inherent viscosities in the range of 0.17 to $0.61 \mathrm{dL} / \mathrm{g}$.

Moreover, this group [174, 175] studied the direct polyamidation of above monomer with different aromatic diamines in order to prepare another series of optically active PAIs with inherent viscosities of $0.22-0.52 \mathrm{dL} / \mathrm{g}$, based on L-leucine and L-methionine amino acids. Because of combination of aromatic backbone and aliphatic side chain in the presence of several functional groups, the solubility of these polymers was improved without significant loss in their thermal properties. In addition, because of the existence of amino acid in the polymer backbone, these polymers are expected to be biodegradable and therefore are classified under environmentally friendly polymers. Synthesis of optically active PAIs by the reactions of chiral diacid chlorides containing 3,3',4,4'-diphenylsulphonetetracarboxylic dianhydride and $\alpha$-amino acids (S-valine, L-phenylalanine, L-leucine or L-isoleucine) moieties with several aromatic diamines was reported by Mallakpour and coworkers [176-179] (Figure 15). The polymerization reactions were carried out in the presence of a small amount of o-cresol and polymers with high yields and moderate inherent viscosities were obtained within 6 min with $100 \%$ of radiation power. In order to compare this method with conventional solution polycondensation, PAIs 
were also synthesized by both low and high temperature solution step-growth polymerization reaction. The polyamidation reaction of $4,4^{\prime}$-carbonylbis(phthaloylalanine) diacid chloride with six different derivatives of tetrahydropyrimidinone and tetrahydro-2-thioxopyrimidine compounds were discussed earlier in the work of Mallakpour et al. [180] in the presence of a small amount of o-cresol. Under microwave irradiation power of $900 \mathrm{~W}$, a

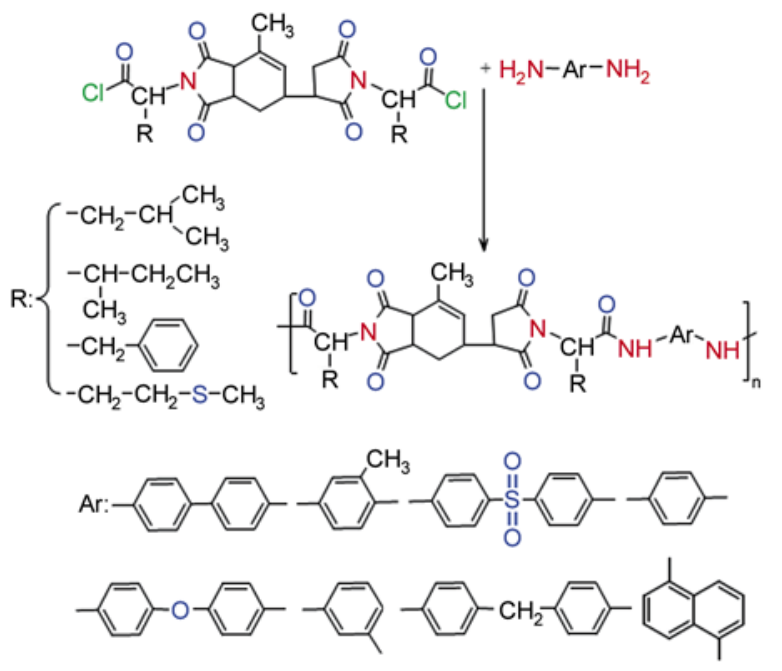

Figure 16. Synthesis of optically active PAIs containing epiclon and several amino acids [181-185]
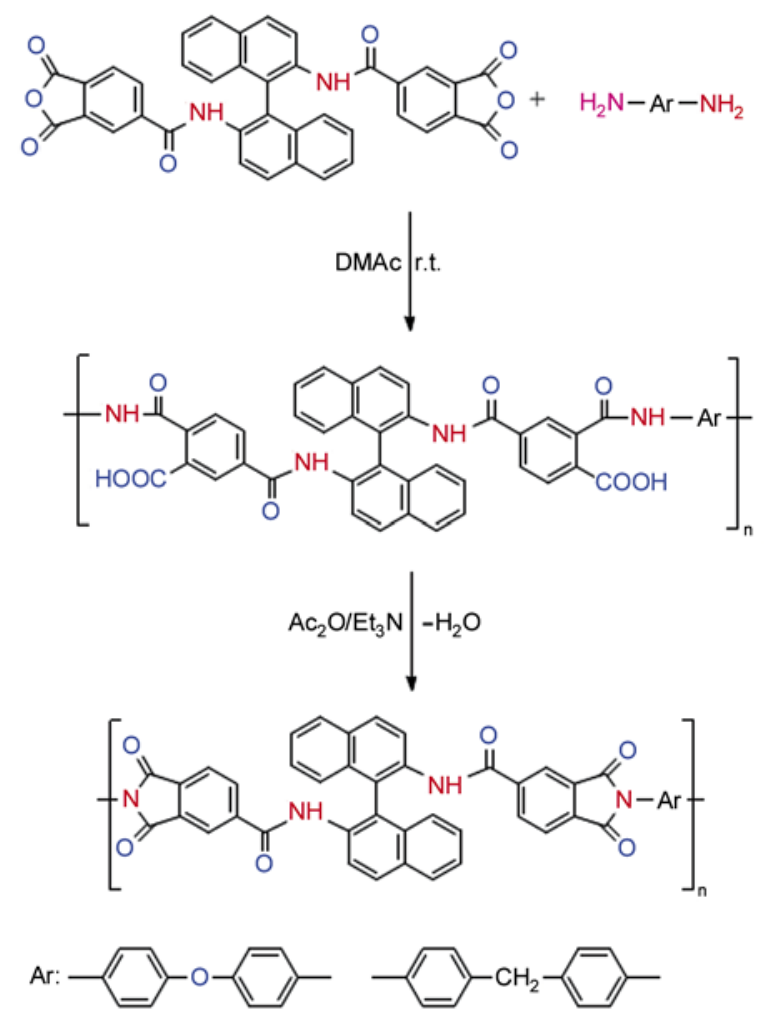

Figure 17. Synthesis of optically active PAIs derived from new chiral dianhydride and diamines [189] series of optically active and thermally stable PAIs were produced within $10 \mathrm{~min}$ with inherent viscosities in the range of about $0.25-0.45 \mathrm{dL} / \mathrm{g}$ and high yields. The syntheses and characterization of optically active PAIs derived from diacid chloride containing epiclon and several amino acids such as Lphenylalanine, L-isoleucine, L-methionine, L-valine or L-Leucine with different aromatic diamines in the presence of a small amount of a polar organic medium such as NMP under microwave irradiation (Figure 16) was studied by Mallakpour and coworkers [181-185]. To compare microwave irradiation polymerization with solution polymerization methods PAIs were also synthesized by both low temperature and high temperature classical solution polymerization. The results of these methods were comparable with the microwave method. But the microwave heating is a more efficient method for these step-growth polymerization reactions.

Faghihi et al. [186-188] studied synthesis and characterization of optically active PAIs with hydantoin and thiohydantoin derivatives in the main chain via polycondensation reaction of $\mathrm{N}, \mathrm{N}^{\prime}$-(pyromellitoyl)bis-1-phenylalanine diacid chloride and six different derivatives of 5,5-disubstituted hydantoin compounds in the presence of a small amount of ocresol as a polar organic media. Polymers were synthesized via two different methods: Classical heating and microwave irradiation method. The results showed that microwave heating is an efficient method for the polycondensation reactions. These PAIs exhibited excellent solubility in the organic solvents at room temperature.

Song et al. [189] prepared newly optically active aromatic PAIs from polycondensation reaction of 2,2'-bis(3,4-dicarboxybenzamido)-1,1'-binaphthyl dianhydride and different diamines in DMAc (Figure 17). Polymers with different ee $\%$ were investigated with respect to their structures and chiroptical properties. The results suggested that optically active PAIs posseed regular chiral conformations. They showed high glass transition temperatures of $287-290^{\circ} \mathrm{C}$ and $5 \%$ weight loss temperatures of $450-465^{\circ} \mathrm{C}$ in nitrogen.

\subsection{Poly(ester-amide)s}

Poly(ester-amide)s (PEA)s are emerging as promising materials for a wide range of biomedical applications due to their potential for both hydrolytic and 
enzymatic degradation as well as the ease with which their properties can be tuned by the choice of monomers. The architecture of the PEA polymers is a blend of PA and PE polymer character. This leads to a blend of the characteristic behavior and properties of these two distinct polymers as well. The thermal properties of PEAs include higher melt transitions and increased thermal stability versus PEs. Conversely, the characteristic thermal properties are lower for PEAs than for PAs. PAs tend to be high melting and thermally stable. These characteristics make PAs difficult to process. PAs also generally display better mechanical endurance than the corresponding PEs, thanks to the formation of strong hydrogen bonding between the amide linkages of individual chains. PEs, on the other hand, is generally superior in flexibility, solubility, and hydrolytic susceptibility, and can thus be designed to degrade within a reasonable time-scale. PEAs represent a mixture of PE and PA character and therefore the corresponding thermal properties are a blend of the two homopolymers. The lower melt transitions versus PAs mean that molding, shaping and extruding are all possible. As a consequence, it is preferentially cleaved by enzymes. In PEAs, the combination of the bonding from two parent polymer families can be used to tailor the final thermal and enzymatic properties of the synthesized PEA polymer. The blend of characteristics is accomplished by varying the ratio of amide to ester bonds in the final polymer. This can be accomplished via co-polymerization of monomers containing both types of bonds, but more frequently by the condensation of monomers with terminal amines and terminal acids. The biological degradation behavior for PEAs is generally less complete than for PEs but much more complete than PAs. This is due to the ester bond being more readily hydrolyzed than the corresponding amide bond. The structure of the PEA polymer backbone, in particular, provides a straightforward route to biodegradable materials because of the possibility of incorporating biologically related molecules. The incorporation of pendant functional handles along the PEA backbone has the potential to further expand their applications by allowing the charge and hydrophilicity of the polymers to be altered, and facilitating the conjugation of active molecules such as drugs, targeting groups, and cell signaling molecules [190-193].
Atkins et al. [190] described a simple and versatile approach based on orthogonal protecting groups, by which L-lysine and L-aspartic acid could be incorporated into several families of PEAs based on monomers including the diacids succinic and terephthalic acid, the diols 1,4-butanediol and 1,8octanediol, and the amino acids L-alanine and Lphenylalanine. Molina Pinilla et al. [194] reported on the synthesis and stereoregular high intrinsic viscosity chiral PEA derived from L-arabinose and succinic anhydride by using the active ester polycondensation method. The polymerization reaction was carried out in different polar solvents. The TGA thermogram indicated that this PEA was stable up to $250^{\circ} \mathrm{C}$ under nitrogen. Fan et al. [195] prepared several optically active PEAs derived from Lisoleucine. Polymers were synthesized from the ptoluenesulfonic acid salt of o,o'-bis(leucyl)-hexanediol (TS-+LHD+TS-) and p-phthaloyl chloride and styrene-2,5-dicarbonyl chloride styrene by interfacial polymerization. The resulting polymers were soluble in strong acids (formic, dichloroacetic and trifluoroacetic acid) and chlorinated polar solvents such as chloroform and dichloromethane. The synthesis of PEAs from the reaction of p-nitrophenyl esters of sebacic or adipic acids and diamines containing $\alpha$-amino acid ester groups was studied by Fan et al. [196] (Figure 18). The biodegradability of the resulting polymers was investigated by in vitro hydrolysis with proteases and a lipase as catalysts in borate buffer solutions. The results indicated that the polymers containing L-phenylalanine were hydrolyzed most effectively by $\alpha$-chymotrypsin $(\alpha$ $\mathrm{CT}$ ), subtilisin Carlsberg, and subtilisin $\mathrm{BPN}^{\prime}$. The PEAs containing other amino acid residues also underwent hydrolysis to different extents, reflecting the substrate specificity of the proteases. Lipase had almost no effect on the hydrolytic degradation of these PEAs. The polymers containing glycine residues were hardly decomposed by any of the enzymes used.

Several optically active PEAs were synthesized by interfacial polycondensation of the mixture of 1,6hexanediol diester of L- and D-alanine with sebacoyl chloride or terephthaloyl chloride by Nagata [197]. The enzymatic degradation of the PEAs was followed by the weight loss in a buffer solution $(\mathrm{pH}$ 7.2) of proteolytic enzymes (proteinase-K, papain and $\alpha-\mathrm{CT}$ ) and lipase enzymes (R. delemar, P. cepa- 


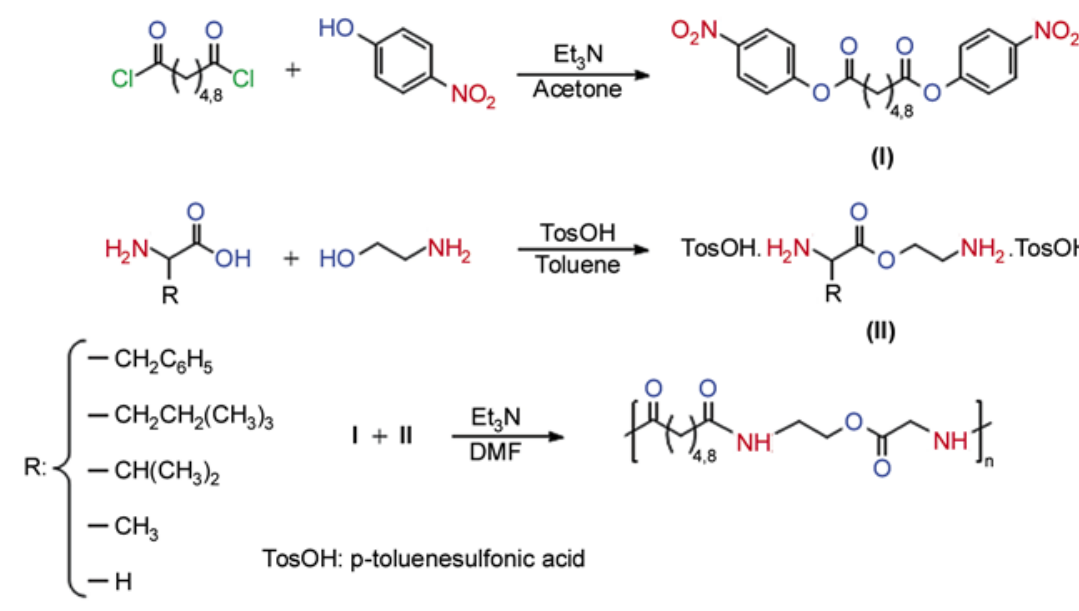

Figure 18. Synthesis of the optically active and biodegradable PEAs from amino acids, 2-aminoethanol, and dicarboxylic acid [196]

cia and C. rugosa) at $37^{\circ} \mathrm{C}$. It was found that the degradation with the proteolytic enzymes is not caused by hydrolysis of the semi-peptide linkage but of the ester linkage. The synthesis and characterization of a new series of chiral PEAs was reported by Philip and Sreekumar [198]. These PEAs were prepared by solution polycondensation of diacid chlorides of bismaleamic acid with biphenolic azo chromophores and optically active isosorbide in DMAc at $100^{\circ} \mathrm{C}$. The resulting polymers showed $T_{\mathrm{g}}$ between 100 and $190^{\circ} \mathrm{C}$ and were stable up to $400^{\circ} \mathrm{C}$.

Asín et al. [199] synthesized sequential chiral PEAs derived from glycine by a two-steps method, involving a final thermal polyesterification. They compared this method in detail with their previous reported on the basis of interfacial polymerization. Thermal synthesis of the indicated glycine derivatives was carried out with high yield and generally provided polymers with the right molecular weight $\left(M_{\mathrm{W}}\right)$ to render fiber- and film-forming properties. Thermal synthesis seems to be useful for preparing polymers derived from diacid chlorides such as oxaloyl or succinoyl chlorides and diols such as 1,4-butanediol because the interfacial synthesis of these polymers is highly deficient. Furthermore, the intrinsic viscosities of the other studied polymers with aliphatic or aromatic components were generally higher when thermal synthesis was used. The resulting PEAs appear to be susceptible to the proteolytic enzymatic attack with papain as a result of the presence of glycine units. Degradable polymers may still be obtained when oxaloyl or terephthaloyl units were incorporated. In another study by Pare- des et al. [200], a new kind of PEA derived from Lalanine was synthesized and the biodegradation and biocompatibility of the resulted polymer were investigated by them. The obtained polymer had good fiber and film-forming properties, as well as other characteristics like thermal stability and solubility in chloroform, which enhanced its processing facilities. Degradation studies showed that both $\mathrm{pH}$ and temperature influenced in the hydrolysis rate that took mainly place through the ester linkages. Degradation was also studied using different enzymes. Results indicated that papain was the most efficient of these, and that the hydrolysis to water-soluble products could be attained in a few days. The biocompatibility of the obtained polymer was investigated using cell culture techniques, because in vitro assessment of biocompatibility with permanent cell lines is a good screening method for detecting adverse effects.

Amino alcohols are easily obtained by the reduction of amino acids, which serve as useful chiral building blocks in organic synthesis. Step-growth polymerization of dicarboxylic acids with diols having amide moieties derived from optically active amino alcohols were carried out by Koyama et al. [201]. Polymers were obtained by the polycondensations using of 1-ethyl-3-(3-dimethylaminopropyl) carbodiimide hydrochloride in DMF at room temperature for $8 \mathrm{~h}$ in satisfactory yields. The $T_{\mathrm{g}}$ of the polymer rose with decrease of the methylene chain length of the dicarboxylic acid. Currently available synthetic biodegradable elastomers are primarily composed of crosslinked aliphatic PEs, which suffer from deficiencies including (1) high crosslink 
A<smiles>NCC(O)CN</smiles>

$\mathrm{P}$

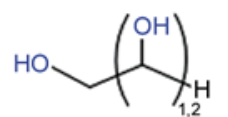<smiles>CC(C)(C(=O)O)C(=O)O</smiles>

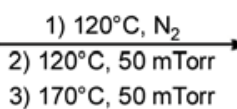

3) $170^{\circ} \mathrm{C}, 50 \mathrm{mTorr}$

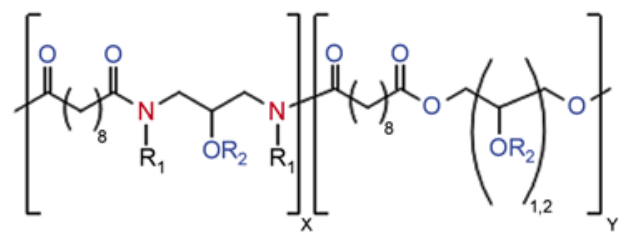

$\mathrm{R}_{1}=\mathrm{X}$ or $\mathrm{Y}$ (via amide), or $\mathrm{H}$

Figure 19. Synthesis scheme of APS polymers [202].

densities, which results in exceedingly high stiffness, (2) rapid degradation upon implantation, or (3) limited chemical moieties for chemical modification. Bettinger et al. [202] developed a new class of synthetic, biodegradable and chiral elastomeric PEAs, poly(1,3-diamino-2-hydroxypropane-copolyol sebacate)s, composed of crosslinked networks based on an amino alcohol (Figure 19). These crosslinked networks featured tensile Young's modulus on the order of $1 \mathrm{MPa}$ and reversable elongations up to $92 \%$. These polymers showed in vitro and in vivo biocompatibility and were projected degradation half-lives up to 20 months in vivo.

Kobayashi et al. [203] prepared several optically active PEAs from polycondensation of ester-containing chiral dicarboxylic acid and different aromatic diamines in the presence of TPP, Py, and $\mathrm{CaCl}_{2}$ in NMP. The resulting optically active polymers were obtained with inherent viscosities of $0.44-0.79 \mathrm{dl} / \mathrm{g}$, and specific rotations from -43.6 to $-78.5^{\circ}$. The $T_{\mathrm{g}} \mathrm{s}$ of the polymers were in the range from 129 to $169^{\circ} \mathrm{C}$, and their decomposition started at a temperature from 231 to $249^{\circ} \mathrm{C}$ to afford biscrotonamide and terephthalic acid.

A new class of optically active and biodegradable PEAs was prepared by Gomurashvili et al. [204]. Polymers were synthesized by two step method. At first isosorbide or isomannide were esterified with $\alpha$-amino acids in the presence of $\mathrm{p}$-toluenesulfonic acid, and the resulting esters bisammonium tosylates were isolated. Second, the amino groups were liberated and polycondensed with p-nitrophenyl esters of aliphatic dicarboxylic acids. Biodegradation of resulting polymers was studied by chymotrypsin or lipase.

Poly(lactic acid) (PLA) and its copolymers have received great interest in industrial and medical applications. It can be used in plastic and fiber grade. Some of applications of PLA are resorbable sutures, drug delivery systems, artificial skin, implants for orthopedics, surgical materials, thermoforms, injection-molded or blow-molded containers, oriented and blown films, nonwovens, scaffold for tissue engineering and renewable plastics $[205,206]$. To extend the use of LA-based polymers, functional group such as amide was introduced in the main chain. Most of the reports focus on the linear polymer, because they are easy to process, shape and manufacture. On the other hand, the attention was paid to the cross-linked polymers for enhancing the mechanical and thermal properties. A novel LA-based cross-linked PEA (LCPEA) with different cross-linking density was synthesized via polycondensation reaction of a dicarboxylic-terminated oligoester ELDA, a diacid derived from LA, TDI by Yue Ying et al. [205]. The tensile strength, elastic modulus and bend strength of the LCPEA of $65 \%$ gel fraction were $4.65,136.55$ and $39.63 \mathrm{MPa}$, respectively. The thermal decomposition temperature $(50 \mathrm{wt} \%)$ of the LCPEA was around $410^{\circ} \mathrm{C}$.

Although a number of PEAs of different compositions have been reported, there is a significant need for the incorporation of amino acids with functional side chains. This will allow for the conjugation of drugs or cell signaling molecules in tissue engineering scaffolds, thus expanding the potential applications of these materials. De Wit et al. [207] studied the synthesis, characterization and functionalization of novel PEAs. They reported on the incorporation of L-lysine into PEAs comprised of succinic acid, 1,4-butandiol, and L-phenylalanine to provide pendant amine functional groups for the first time in PEAs. The degradation of thin films of polymers was studied using scanning electron microscopy and the incorporation of lysine was found to signif- 
icantly accelerate both the hydrolytic and enzymatic degradation.

\subsection{Poly(ester-imide)s}

A series of optically active Poly(ester-imide)s (PEI)s were prepared through a facile and rapid polycondensation reaction of chiral $\mathrm{N}, \mathrm{N}$-(pyromellitoyl)-bis-L-leucine diacid chloride and N,N(pyromellitoyl)-bis-L-phenylalanine diacid chloride with several aromatic diols such as phenol phthalein, bisphenol-A, 4,4'-hydroquinone, 1,8dihydroxyanthraquinone, 1,5-dihydroxy naphthalene, 4,4'-dihydroxy biphenyl, and 2,4-dihydroxyacetophenone using a domestic microwave oven in the presence of a small amount of a polar organic medium such as o-cresol by Mallakpour et al. [208, 209] (Figure 20). The polymerization reactions proceeded rapidly and were completed within 10$20 \mathrm{~min}$, producing a series of optically active PEIs with good yield and moderate inherent viscosity of $0.10-0.27 \mathrm{dl} / \mathrm{g}$ and were compare with polymerization reaction under solution condition but the resulting materials were soluble in methanol probably due to formation of oligomers. Therefore microwave technique in this case was superior to the conventional solution method. These aromatic PEIs showed optical rotation and were readily soluble in various organic solvents and had good thermal stability. Fluorine containing PEIs having different $\alpha$-amino acid such as: L-leucine, L-isoleucine and L-methio-
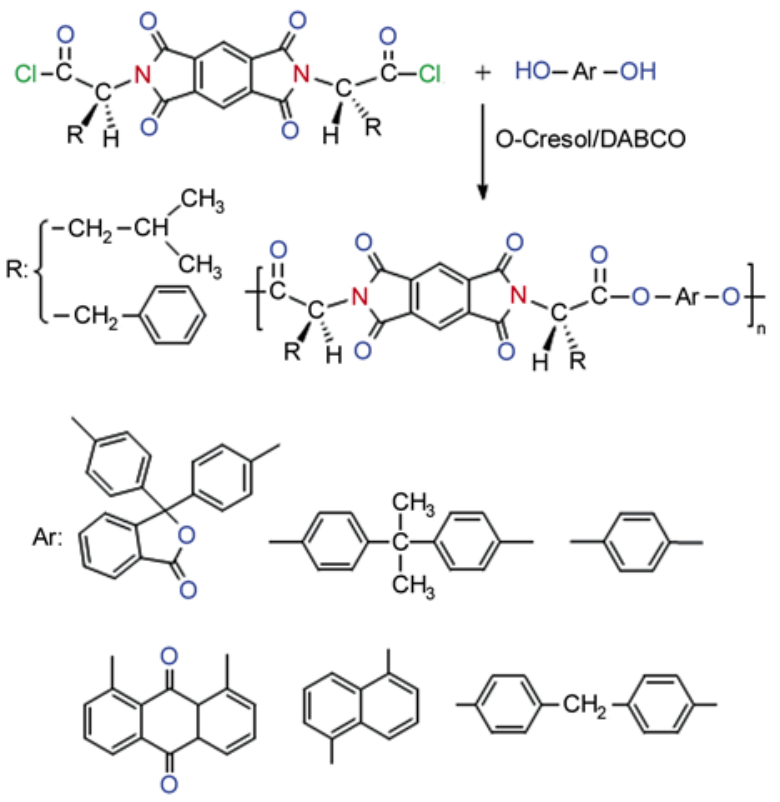

Figure 20. Polycondensation reaction of chiral N,N(pyromellitoyl)-bis-L-amino acid chloride with several aromatic diols [208, 209] nine in main chain were also prepared by Mallakpour and coworkers [210-213] (Figure 21).

The reactions with $\mathrm{TsCl}$ were significantly promoted by controlling alcoholysis with diols in the presence of the catalytic amounts of DMF to give a series of optically active PEIs with good yield, moderate to high inherent viscosity ranging 0.35 $1.12 \mathrm{dL} / \mathrm{g}$ and also showed optical rotation. Thermal stability of the PEIs with fluorine containing linkage was higher than a related polymer having non-fluorinated. Furthermore, the resulting optically active PEIs containing amino acid linkages so could be biocompatible and biodegradable.

Mallakpour's group reported on the direct polycondensation reactions of $\mathrm{N}, \mathrm{N}^{\prime}$-(4,4'-oxydiphthaloyl)bis-leucine diacid and N,N'-(4,4'-oxydiphthaloyl)bis-methionine diacid with several aromatic diols in a system of TsCl, Py and DMF (method I) or thionyl chloride/Py (method II) [214-216] (Figure 21). The influence of aging time, amount of DMF, concentration of monomers and condensing agents and reaction time on the physical properties of the resulting polymers was investigated by this group. Direct polyestrification in method II showed a series of advantages including improved reaction yield and higher $M_{\mathrm{W}}$ of the resulting PEIs and is very efficient in terms of cost and energy. The
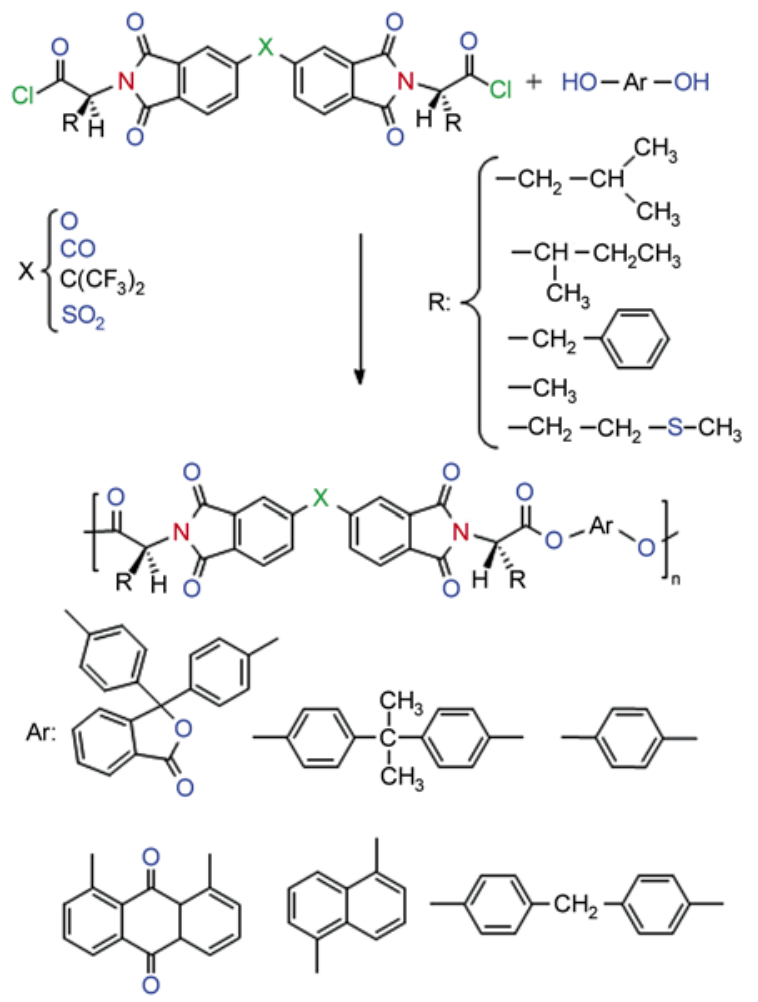

Figure 21. Preparation of different PEIs by reaction of several imide dicarboxylic acid and diols [210-219] 
resulting PEIs had good yield and moderate inherent viscosity. The obtained polymers were thermally stable and were readily soluble in common organic solvents. Optically active PEIs containing benzophenone tetracarboxylic and L-phenylalanine or L-alanine moieties were synthesized from $\mathrm{N}, \mathrm{N}^{\prime}$ (4,4'-carbonyldiphthaloyl)-bisphenylalanine or Lalanine diacid chloride with several aromatic diols by low-temperature solution polycondensation in $\mathrm{CHCl}_{3} / \mathrm{Et}_{3} \mathrm{~N}$ solution and under microwave irradiation in the presence of a small amount of a polar organic medium such as o-cresol [217, 218] (Figure 21). These PEIs showed optical rotation and were readily soluble in various organic solvents and had moderate thermal stability. The same researchers also used L-isoleucine amino acid as a biocompatible material as well as optically active pure and chemical functional group in the polymer backbone for the formation of a series of new PEIs by direct polyesterification from aromatic diols and imide dicarboxylic acid which was prepared from trimellitic anhydride and L-isoleucine amino acid in a system of TsCl/Py/DMF [219] (Figure 21). Mallakpour's group also reported on [220] the synthesis of optically active PEIs via direct polycondensation of N-trimellitylimido-L-methionine with various aromatic diols such as bisphenol A, phenolphthalein, 1,5-naphthalendiol, 2,6-dihydroxytoluene, hydroquinone, biphenyl-2,2'-diol, 1,4-dihydroxyanthraquinone. The resulting PEIs were obtained in good yields and exhibited low to moderate inherent viscosities ranging from 0.15 to $0.40 \mathrm{dL} / \mathrm{g}$. All of the PEIs showed good solubility and readily dissolved in aprotic polar solvents. Recently, this group [221] synthesized several novel chiral and potentially biodegradable PEIs bearing natural amino acids in the main chain as well as in the side chain via direct polyesterification of $\mathrm{N}, \mathrm{N}^{\prime}$-(pyromellitoyl)-bis-(L-tyrosine dimethyl ester) as a biodegradable optically active phenolic diol and synthesized diacids containing different amino acids and phthalimide group in the side chain in $\mathrm{TsCl} / \mathrm{Py} / \mathrm{DMF}$ system as a condensing agent under conventional heating condition.

A series of axially chiral PEIs were prepared by the polycondensation reactions of new axially asymmetric dianhydrides, (R)-2,2'-bis(3,4-dicarboxybenzoyloxy)-1,1'-binaphthyl dianhydride and (S)2,2'-bis(3,4-dicarboxybenzoyloxy)-1,1'-binaphthyl dianhydride, and various diamines with aromatic, semiaromatic, and aliphatic structures by Song et al. [222]. The film-forming ability of PEIs was tested by the casting of $10 \%(\mathrm{w} / \mathrm{v})$ solutions in DMAc onto a glass slide. All the polymers were able to form tough, flexible, and transparent films with 6$10 \mu \mathrm{m}$ thick.

Kricheldorf's group [223] prepared a series of chiral PEIs by polycondensation of acid chloride of 4aminocinnamic acid trimellitimide with various chiral diols at low or moderate temperature $(0$ $60^{\circ} \mathrm{C}$ ) in the presence of Py as $\mathrm{HC} 1$ acceptor. They also synthesized [224] several cholesteric PEIs from (S)-pentyloxyterephthalic acid or (S,S)-2,5bispentyloxyterephthalic acid and N-(4'-hydroxyphenyl)-4-hydroxyphthalimide. 2,5-bis(dodecyloxy)terephthalic acid and 2-(4'-ch1orophenoxy) terephthalic acid were used as comonomer.

\subsection{Poly(amide-ester-imide)s}

A series of optically active poly(amide-esterimide)s (PAEI)s based on bis(p-aminobezoic acid)$\mathrm{N}$-trimellitylimido-S-valine or L-isoleucine were prepared via polyesterification reaction of synthetic chiral diacids and different aromatic diols using $\mathrm{TsCl} / \mathrm{Py} /(\mathrm{DMF})$ as a condensing agent by Mallakpour and coworkers (Figure 22) [225, 226]. The effect of the amount of DMF, aging time, reaction temperature, and reaction time was studied on the reaction yields and polymer viscosities. The resulting novel optically active PAEIs with inherent viscosities ranging $0.10-0.71 \mathrm{dL} / \mathrm{g}$ were obtained in high yield.

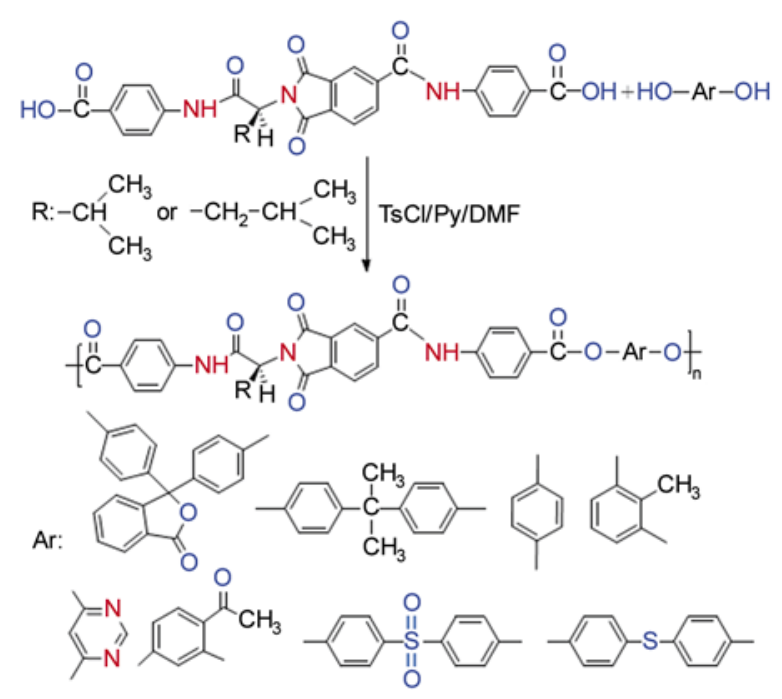

Figure 22. Preparation of optically active PAEIs [225, 226] 
Li et al. [227] prepared PAEIs from amino acid (4aminobenzoic acid, 3-aminobenzoic acid, or 6aminohexanoic acid) and N-(4-hydroxyphenyl) phthalimide-4-carboxylic acid, N-(3-hydroxyphenyl) phthalimide-4-carboxylic acid, or N-(2methyl-4-hydroxyphenyl) phthalimide-4-carboxylic acid in the presence of diphenylchlorophosphate and Py as direct condensation agents. The inherent viscosities of PAEIs were in the range of 0.13$0.95 \mathrm{dl} / \mathrm{g}$. Thermotropic liquid crystalline behavior of these polymers was examined by DSC and optical polarizing microscopy. These PAEIs showed thermotropic liquid crystalline behavior in the range of $190-426^{\circ} \mathrm{C}$.

\subsection{Polyurethanes}

Polyurethanes (PU)s, having a relatively short history, of slightly more than 65 years, became one of the most dynamic groups of polymers, and their use covers practically all the fields of polymer applications such as foams, elastomers, thermoplastics, thermorigids, adhesives, coatings, sealants, fibres and so on. PUs are used in nearly every aspect of daily life, changing the quality of human life. Furniture, bedding, seating for cars, shoe soles, thermoinsulation for refrigerators and buildings, wood substitutes, packaging, and coatings, are only a few common examples of PU use in every day life [228]. Because of importace of PUs and optically active polymers, many studies have been performed in the synthesis of optically active PUs by researchers. Chen et al. [229] synthesized an optically active PU by the step-growth polymerization of (2R,3R)-(+)-diethyl L-tartrate, MDI and polyeth- ylene glycol (PEG) with various molecular weights at $60^{\circ} \mathrm{C}$ in DMSO. Chirackal Varkey and Sreekumar [230] prepared the TDI based optically active PUs consist of chiral units (diethyl- $(2 \mathrm{R}, 3 \mathrm{R})(+)$-tartrate) and donor-acceptor building blocks in the main chain with a helical conformation in the macromolecular chain by using DBTDL catalyst by incorporating the amido diols which were obtained by the aminolysis of $\varepsilon$-caprolactone by using the diamines, diaminoethane, diaminobutane, and diaminohexane, respectively. The effect of incorporation of the chiral molecule diethyl-(2R,3R)-(+)tartrate on the properties of PUs was studied by changing the chromophores and also by varying the chiral-chromophore composition. An azobenzene PU containing chiral units with high thermal stability was synthesized by Qiu et al. [231] via stepgrowth polymerization of a chiral diol derived from diethyl-(2R,3R)-(+)-tartrate and 4-(4'-nitrophenylazo) phenylamine with TDI in the presence of the catalyst T-12 (Figure 23). It was a levopolymer whose optical rotation and melting point were -18.06 and $302^{\circ} \mathrm{C}$, respectively. They investigated optical parameters, including the refractive index (n) and thermo-optic coefficient $(\mathrm{d} n / \mathrm{d} T)$; the dielectric constant $(\varepsilon)$ and its variation with temperature; and the thermal volume expansion coefficient and its variation with temperature of PU. These parameters are of great significance for the optical application of the material, particularly for the development of optical materials because of the control of their $n$ values. The results indicated that the PU could be used in the design of high-performance thermo-optic polymer devices. Nagai et al. [232]
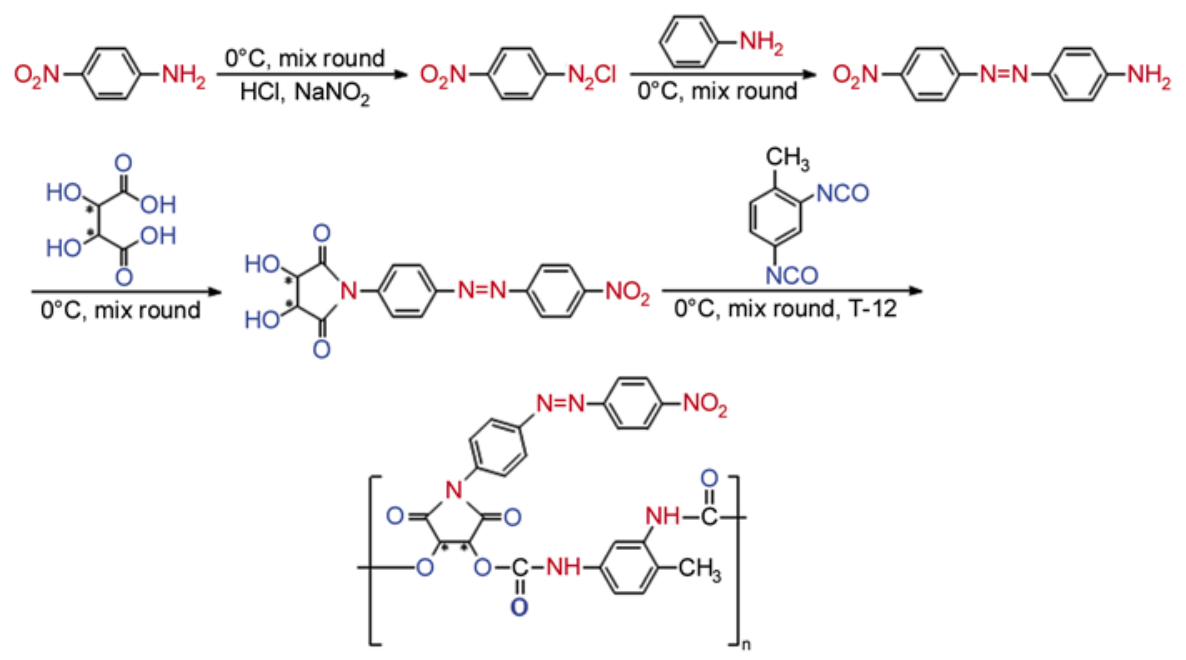

Figure 23. Synthesis of the chiral azobenzene PU containing [231] 
reported on the synthesis and self-step-growth polymerization of optically active monomers having both isocyanate and hydroxyl groups derived from tyrosine. The resulting PUs had specific head-to-tail structures and some regulated, higher order structures such as helical conformation because of its asymmetric carbon. A series of optically active PUs were prepared by Chen et al. [233] from stepgrowth polymerization of chiral 1,1'-binaphthyl and TDI and the high-intensity ultrasonic was applied to the preparation of $\mathrm{PU} / \mathrm{TiO}_{2}$ nanocomposites. TGA studies indicated that thermal stability of the nanocomposites has improved with increasing nanoparticles content. Infrared emissivity study showed that the nanocomposites possessed lower emissivity value than those of $\mathrm{PU}$ and $\mathrm{TiO}_{2}$, respectively. The ultrasonic method is a simple and inexpensive route to synthesize the polymer/nanoparticles, which can be extended to prepare a novel low infrared emissivity material. Zhou's group [234] also described the synthesis and the properties of novel optically active PUs based on chiral binaphthol via direct step-growth polymerization. The effect of optical purity on the specific rotation of the polymers was studied and results showed that the specific rotation of the polymer kept increasing with the optical purity, it may be explained that the increment of the optical purity caused a bigger chiral groups density. The resulting polymers displayed low infrared emissivity, which were expected to have potential application in the field of steals materials.

\subsection{Polyureas}

Diamines are frequently used to cure diisocyanates, especially isocyanate prepolymers, to give polyureas. The reaction has the advantages that no by-products are produced and that it can be carried out at low tempratures. Optically active polyureas have been reported to be prepared from optically active diisocyanate (L-lysinediisocyanatemethyl ester) and optically inactive linear diamine $\mathrm{H}_{2} \mathrm{~N}\left(\mathrm{CH}_{2}\right)_{\mathrm{n}}$, where $n=2-6$ and 9. Polymerization reaction was carried out by step-growth polymerization method [235]. The values of optical rotation of obtained polyureas were dependent on the methylene number of diamines. Asymmetric selective polyaddition of Llysinediisocyanatemethylester for racemic 1,2diaminopropane was unsuccessful.
A series of chiral polyureas having chiral diamine unity as part of the backbone were synthesized via step-growth polymerization of two chiral diamines and several aromatic and aliphatic diisocyanates by Dunjic et al. [236]. The resulting polymers were complexed with rhodium and used as catalysts in asymmetric hydride transfer $\mathrm{C}=\mathrm{O}$ bond reduction.

\subsection{Poly(imide-urethane)s}

A series of poly(imide-urethane)s (PIU)s derived from $\mathrm{N}, \mathrm{N}^{\prime}$-(pyromellitoyl)-bis-(L-leucine) diisocyanate and aromatic diols were synthesized via solution polycondensation by Mallakpour and Shahmohammadi [237]. Polymers were obtained in good yield and moderate inherent viscosity in the range $0.18-0.28 \mathrm{dl} / \mathrm{g}$. The resulting PIUs have potential to be used as packing materials in column chromatography. Wang et al. [238] reported on the synthesis and characterization of optically active helical PIU with optical activity based on R-1,1'binaphthyl-2',2-diol and racemic PIU based on racemic 1,1'-binaphthyl-2',2-diol. The thermal stability of R-PUI was higher than that of racemic-PUI due to the higher degree of hydrogen bond for RPUI. In another study, this group prepared [239] helical PIU@attapulgite composite based on the surface modification of attapulgite. The results indicated that helical PIU has been grafted onto the surfaces of the modified attapulgite without destroying the original crystalline structure of attapulgite. The infrared emissivity of result composite was also investigated. The infrared emissivity value of PIU@attapulgite composite (0.628) was lower than that of bare attapulgite (0.934) due to the interfacial interactions between organics and inorganics. This work opened up a possibility for the preparation of infrared low-emissive materials.

\subsection{Poly(urea-urethane)s}

The synthesis and characterization of five new optically active poly(urea-urethane)s (PUU)s by solution step-growth polymerization of $(1 \mathrm{~S}, 2 \mathrm{~S})-(+)-2-$ amino-3-methoxy-1-phenyl-1-propanol with diisocyanates (MDI, TDI, HDI, IPDI, m-xylylene diisocyanate) was reported by Chen and Tseng [240]. The conformation of the polymers in film state was studied by CD spectra, by comparison with the corresponding model compounds which 
were synthesized from $(1 \mathrm{~S}, 2 \mathrm{~S})-(+)-2$-amino-3methoxy-1-phenyl-1-propanol and phenyl isocyanate or propyl isocyanate. Polymers derived from aromatic diisocyanates formed as ordered conformation in the film state, while those from aliphatic diisocyanates did not. After packing as chiral stationary phases of HPLC, the polymers showed selective resolution to trans-stilbene oxide and trans-1,2-cyclopentanedicarboxanilide. Wang et al. [241] prepared several helical R/S- PUUs with R/S-1,1'-binaphthyl-2',2-diol, TDI, and 1,4diaminobenzene by a simple step-growth polymerization reaction. R-PUU and S-PUU were two enantiomorphs with wonderful mirror-image symmetry. The optical rotation values were +54.7 and $-60.7^{\circ}$, respectively. The left-handed rotation structure was more stimulative for thermal stability than the righthanded rotation below $250^{\circ} \mathrm{C}$ because of both conformation and interchain hydrogen bonds, and they were reversed above $250^{\circ} \mathrm{C}$; this can be attributed to the breaking of hydrogen bonds. The crystallizability of S-PUU was better than that of R-PUU because of the more orderly hydrogen bonds resulting in the interchain effects of S-PUU. The interchain hydrogen bonds were the planebifurcated structures, which are more stable and inlocked to the helical structures. In another study, this group also synthesized an optically active helical PUU with single-handed helical conformation by step-growth polymerization of chiral binaphthyl compound with MDI [242]. The interchain hydrogen bonds were controlled and changed in the synthesized progress, and they were affected by the helical conformation and the optical activity.

\subsection{Poly(amide-imide-urethane)s}

A series of optically active poly(amide-imide-urethane)s (PAIUs) based on PEG and MDI were prepared by Mallakpour's group [243-247] by the chain extension reaction of $\mathrm{NCO}$ terminated oligoamide prepared from the reaction of a chiral amino acid based dicarboxylic acid having a preformed imide ring according to diisocyanate route, with different $M_{\mathrm{W}}$ of PEG polyols by the two-step methods. The synthetic procedure referred to as two-step method, is effective for the synthesis of the multiblock copolymers having high structural regularity. Systematic study of PAIUs based PEGMDI obtained in the presence of different solvents and catalysts under different reaction time and temperatures demonstrated the influence of reaction condition on the efficiency of the polymer chain growth, viscosity, solubility and therefore porocessability of PAIUs. Best condition for the preparation of these optically active PAIUs was NMP as a solvent in the absence of any catalyst. They also synthesized [248] a new class of optically active PAIUs via a two-step diisocyanate route. In the first step, MDI was reacted with different diacids to produce an isocyanate-terminated oligo(amide imide). The chain extension of the previous hard segment with PEG with a $M_{\mathrm{W}}$ of 400 dalton was the second step for furnishing a series of new PAIUs. N-Trimellitylimido-L-leucine was used as a diacid monomer for polycondensation reactions. Polymerization reactions were performed without any catalyst or with Py or DBTDL as a catalyst. The optimized reaction conditions were used for the reaction of $\mathrm{N}$ trimellitylimidoisoleucine, N-trimellitylimidomethionine, $\mathrm{N}$-trimellitylimido-S-valine, and $\mathrm{N}$-trimellitylimidophenyl-alanine as diacid monomers with MDI. In another study by Mallakpour et al. [249], a new series of optically active PAIUs were synthesized via two-step reactions. In the first step, MDI reacted with several PEGs such as PEG-400, PEG600, PEG-2000, PEG-4000, and PEG-6000 to produce the soft segment parts. On the other hand, 4,4'(hexafluoroisopropylidene)-N,N'-bis(phthaloylleuc ine-p-amidobenzoic acid) was prepared from the reaction of 4,4-(hexafluoroisopropylidene)-N, $\mathrm{N}^{\prime}$ bis(phthaloylleucine) diacid chloride with paminobenzoic acid to produce hard segment part. The chain extension of the above soft segment with the amide-imide is the second step to give a homologue series of PAIUs.

\subsection{Poly(amide-imide-ether-urethane)s}

Mallakpour's researcher group [250] used mathematical method for the optimization of some of the reaction parameters, that can influence viscosity and polymer chain growth of thermally stable optically active poly(amide-imide-ether-urethane)s (PAIEU)s based on a reaction component, bis(pamidobenzoic acid)-N-trimellitylimidoleucine. It was shown that, the temperature of $85^{\circ} \mathrm{C}$ and the reaction time of $2 \mathrm{~h}$ gives the highest viscosity for any PEG $M_{\mathrm{W}}$. It means that, in spite of what they assumed, the constructed correlation in this study 
showed there was no significant difference between the viscosities of polymers based on different $M_{\mathrm{W}}$ of PEGs. Another series of optically active PAIEUs based on polytetrahydrofuran (PTHF), of numberaverage molecular weights $\left(M_{\mathrm{n}}\right)=1000$ dalton as soft segment were synthesized by Mallakpour and Rafiemanzelat [251]. These copolymers were prepared via direct polycondensation reaction of an aromatic diacid based on L-leucine with preformed imide ring, MDI and PTHF-1000. The effect of the introduction of bis(p-amidobenzoic acid)-N-trimellitylimidoleucine (BPABTL) into PU back-bone on their properties was also studied. It was shown that BPABTL is an interesting candidate to incorporate amide, imide and amino acid moieties into segmented PUs and prepare them with more thermal stability, induced more crystallinity as well as good solubility.

\subsection{Poly(amide-imide-ether-urea)s}

Mallakpour and Seyedjamali [252] have also investigated the synthesis and characterization of a new multifunctional diamine containing L-leucine moieties in the structure and its polymerization with various diisocyanates to afford corresponding optically active poly(amide-imide-ether-urea)s. These components supplied several functional groups which showed some regulation effects on the properties of final polymers. The incorporation of stiff functions (imide, amide and urea groups) and flexible functions (aliphatic and ether moieties) made polymer chains flexible enough to be soluble in the common aprotic organic solvents as well as preservation of good thermal stability especially when aromatic diisocyanates were employed. The existence of isobutyl moieties in the structure of Lleucine may be the source of the increase of the free inter-chain volumes, suppressing the usual attraction of polymer chains as well as inducing the asymmetric character.

\section{Synthesis of optically active polymers by Suzuki-Miyaura coupling reaction}

The palladium-catalyzed cross-coupling reaction between organoboron compounds and organic halides or triflates provides a powerful and general methodology for the formation of carbon-carbon bonds. Recently, this reaction has been called the Suzuki coupling, Suzuki reaction, or SuzukiMiyaura coupling [253]. Lately, many optically active conjugated polymers were synthesized by this reaction. Hu et al. [254] synthesized an optically active conjugated poly(arylenevinylene). They selected 1,1'-bi-2-naphthol, and its derivatives as building blocks in the construction of main chain chiral polymers because of their outstanding asymmetric differentiation properties. This polymer was soluble in common organic solvents and could be cast into self-standing films. This researcher group also prepared [255] an optically active polyarylene from the palladium-catalyzed Suzuki cross-coupling of an optically active binaphthyl molecule, 2'bis(hexyloxy)-1,1'-binaphthyl-6,6'-diboronic acid, with 1,4-dibromobenzene. GPC analysis of this

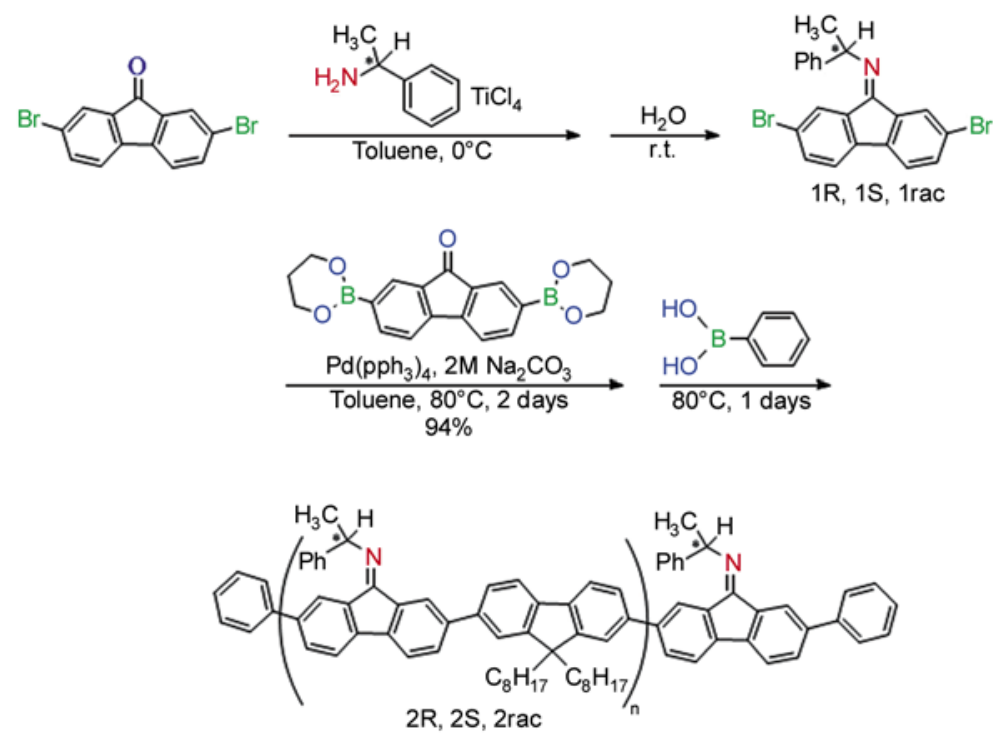

Figure 24. Synthesis of optically active polyfluorenes with chiral Schiff bases in the side chain by the palla-dium-catalyzed Suzuki-Miyaura coupling polymerization [258] 
polymer showed $M_{\mathrm{W}}=41000$ and $M_{\mathrm{n}}=20000$. The specific optical rotation of resulting polymer was $-289.4^{\circ}$. In another study Pu's group [256] synthesized a series of binaphthyl-based chiral poly(aryleneethynylene)s with different $M_{\mathrm{W}}$ by Suzuki coupling rection of an optically active binaphthyl molecule, (R)-2,2'-bis(octadecyloxy)6,6'-diethynyl-1,1'-binaphthyl, with 1,4-diiodobenzene in the presence of tetrakis(triphenylphosphine)palladium( $(0)$ and cuprous iodide catalysts. The synthesis of the first optically active 1,1'-bi-2naphthol and 2,2'-bis(diphenylphosphino)-1,1'binaphthyl copolymer by Suzuki coupling reaction was reported by Yu et al. [257]. The resulting polymer showed $M_{\mathrm{W}}=11600$ dalton and $M_{\mathrm{n}}=7500$ dalton as was measured by GPC relative to polystyrene standards. They utilized this polymer in a tandem catalytic asymmetric diethylzinc addition and asymmetric hydrogenation of p-acetylbenzaldehyde to generate a chiral diol.

The synthesis of optically active poly(fluorene-altchiral iminofluorene)s using 1-phenylethylamine as a chiral auxiliary was described by Asai et al. [258]. Optically active polyfluorenes were synthesized by the palladium-catalyzed Suzuki-Miyaura coupling polymerization of 9,9'-dioctylfluorene-2,7bis(trimethyleneborate) with a chiral Schiff base monomer (imino group modified-fluorene) (Figure 24). The obtained polymers showed intense green emission with high quantum efficiency.

\section{Synthesis of optically active polymers by Sonogashira reaction}

In 1975, Sonoghashira et al. reported [259] for the first time a coupling reaction of terminal alkynes with aryl or vinyl halides. Recently, this reaction has been used for the synthesis of different optically active polymers. Block and Hecht [260] used this reaction for the synthesis of a series of block copolymers composed of a highly isotactic and nonracemic poly(propylene oxide) segment joined to a poly(phenylene ethynylene) segment, with either meta or para connectivity. Two regioregular poly(pphenyleneethynylene-alter-mphenyleneethynylene)s bearing (-)-trans-myrtanoxyl side groups with different substitution patterns were designed and synthesized by Li et al. [261] via Sonogashira reaction. These two polymers have the same chemical com- ponent and main chain structure, but the substitution pattern of the chiral groups was different from each other. The effects of annealing temperature and time on the properties of the films were investigated by ultraviolet-visible absorption, fluorescence and CD spectra. The observations indicated that the substitution pattern of the chiral side groups had significant effect on the chiroptical properties of chirally substituted conjugated polymers.

\section{Conclusions}

In this paper, synthesis of various optically active condensation polymers was reviewed. There is currently intense interest in the synthesis and control of optically active polymers. Many of the condensation polymers reviewed here are prepared by polycondensation reaction of chiral monomers, which is more versatile, inexpensive and generally poor in control than addition polymerization. Optically active polymers often play important roles as key fundamental materials for welldefined polymers with specific secondary and/or tertiary structures. Optically active polymers have stimulated wide interest from synthetic, structural, and functional viewpoints. They have been extensively studied aiming at the application in optoelectronic devices and chiral recognition materials including asymmetric catalyst, chiral stationary phase in HPLC, enantioselective permeation membrane, chiral adsorbent for separation of racemates and in liquid crystals. Nature uses chirality as one of the key structural factors to perform a series of complicated functionalities such as molecular recognition and catalytic activities and can be saying that chirality is important for life.

\section{Acknowledgements}

We wish to express our gratitude to the Research Affairs Division Isfahan University of Technology (IUT), Isfahan, for partial financial support. Further financial support from National Elite Foundation (NEF) and Center of Excellency in Sensors and Green Chemistry Research (IUT) is gratefully acknowledged.

\section{References}

[1] Okamoto Y.: Chiral polymers. Progress in Polymer Science, 25, 159-162 (2000). DOI: $10.1016 /$ S0079-6700(99)00034-9 
[2] Nakano T.: Optically active synthetic polymers as chiral stationary phases in HPLC. Journal of Chromatography A, 906, 205-225 (2001).

DOI: 10.1016/S0021-9673(00)00944-4

[3] Okamoto Y.: Chiral polymers for resolution of enantiomers. Journal of Polymer Science Part A: Polymer Chemistry, 47, 1731-1739 (2009).

DOI: $10.1002 /$ pola.23215

[4] Fujiki M.: Optically active polysilylenes: State-ofthe-art chiroptical polymers. Macromolecular Rapid Communications, 22, 539-563 (2001).

DOI: $10.1002 / 1521-3927(20010501) 22: 8<539::$ AIDMARC539>3.0.CO;2-K

[5] Takata T., Furusho Y., Murakawa K. I., Endo T., Matsuoka H., Hirasa T., Matsuo J., Sisido M.: Optically active poly(aryl carbonates) consisting of axially chiral units. Chiral binaphthyl group induced helical polymer. Journal of the American Chemical Society, 120, 4530-4531 (1998).

DOI: $10.1021 /$ ja9743371

[6] Abdul Rahim E., Sanda F., Masuda T.: Synthesis and properties of optically active amino acid based polyacetylenes bearing eugenol and fluorene moieties. Journal of Polymer Science Part A: Polymer Chemistry, 44, 810-819 (2006).

DOI: $10.1002 /$ pola.21215

[7] Lee H. S., Hong J.: Chiral and electrokinetic separation of amino acids using polypyrrole-coated adsorbents. Journal of Chromatography A, 868, 189-196 (2000).

DOI: $10.1016 / \mathrm{S} 0021-9673(99) 01246-7$

[8] Guo H. S., Knobler C. M., Kaner R. B.: A chiral recognition polymer based on polyaniline. Synthetic Metals, 101, 44-47 (1999).

DOI: $10.1016 / \mathrm{S} 0379-6779(98) 00301-4$

[9] Hoffmann P., Wagner H., Weber G., Lanz M., Caslavska J., Thormann W.: Separation and purification of methadone enantiomers by continuous- and interval-flow electrophoresis. Analytical Chemistry, 71, 1840-1850 (1999).

DOI: $10.1021 / \mathrm{ac} 981178 \mathrm{v}$

[10] Lemaire M., Delabouglise D., Garreau R., Guy A., Roncali J.: Enantioselective chiral poly(thiophenes). Journal of the Chemical Society, Chemical Communications, 658-661 (1988).

DOI: $10.1039 / \mathrm{C} 39880000658$

[11] Chen Z., Takei Y., Deore B. A., Nagaoka T.: Enantioselective uptake of amino acid with overoxidized polypyrrole colloid templated with L-lactate. Analyst, 125, 2249-2254 (2000).

DOI: $10.1039 / \mathrm{b} 005745 \mathrm{~m}$

[12] Kane-Maguire L. A. P., Norris I. D., Wallace G. G.: Properties of chiral polyaniline in various oxidation states. Synthetic Metals, 101, 817-818 (1999). DOI: 10.1016/S0379-6779(98)01117-5

[13] Pu L.: The study of chiral conjugated polymers. Acta Polymerica, 48, 116-141 (1997).

DOI: $10.1002 /$ actp.1997.010480402
[14] Kozlovsky M. V.: Chiral polymers with photoaffected phase behaviour for photo-optical and optoelectronic applications. Synthetic Metals, 127, 67-70 (2002). DOI: 10.1016/S0379-6779(01)00595-1

[15] Wulff G.: Main-chain chirality and optical activity in polymers consisting of $\mathrm{C}-\mathrm{C}$ chains. Angewandte Chemie International Edition, 28, 21-37 (1989). DOI: 10.1002/anie.198900211

[16] Liaw D. J., Liaw B. Y., Kang E. T.: Synthesis and characterization of new cardo polyamide-imides containing ether and tricyclo[5.2.1.02,6]decane groups. Macromolecular Chemistry and Physics, 200, 24022406 (1999).

DOI: $10.1002 /(\mathrm{SICI}) 1521-3935(19991001) 200: 10<$ 2402::AID-MACP2402>3.0.CO;2-C

[17] Feng L., Hu J., Liu Z., Zhao F., Liu G.: Preparation and properties of optically active poly $(N$-methacryloyl L-leucine methyl ester). Polymer, 48, 3616-3623 (2007).

DOI: 10.1016/j.polymer.2007.04.064

[18] Sanda F., Yukawa Y., Masuda T.: Synthesis and properties of optically active substituted polyacetylenes having carboxyl and/or amino groups. Polymer, 45, 849-854 (2004).

DOI: 10.1016/j.polymer.2003.11.044

[19] Takei F., Yanai K., Onitsuka K., Takahashi S.: Screwsense-selective polymerization of isocyanides by dinuclear $\mu$-ethynediyl complexes. Angewandte Chemie International Edition, 35, 1554-1556 (1996). DOI: 10.1002 /anie. 199615541

[20] Ute K., Hirose K., Kashimoto H., Hatada K., Vogl O.: Haloaldehyde polymers. 51. Helix-sense reversal of isotactic chloral oligomers in solution. Journal of American Chemical Society, 113, 6305-6306 (1991). DOI: $10.1021 / \mathrm{ja} 00016 \mathrm{a} 076$

[21] Okamoto Y., Suzuki K., Ohta K., Hatada K., Yuki H.: Optically active poly(triphenylmethyl methacrylate) with one-handed helical conformation. Journal of the American Chemical Society, 101, 4763-4765 (1979). DOI: $10.1021 / \mathrm{ja} 00510 \mathrm{a} 072$

[22] Chen L., Chen Y., Yao K., Zhou W., Li F., Chen L., Hu R., Tang B. Z.: A novel type of optically active helical liquid crystalline polymers: Synthesis and characterization of poly( $p$-phenylene)s containing terphenyl mesogen with different terminal groups. Journal of Polymer Science Part A: Polymer Chemistry, 47, 4723-4735 (2009).

DOI: $10.1002 /$ pola.23526

[23] Bouman M. M., Meijer E. W.: Stereomutation in optically active regioregular polythiophenes. Advanced Materials, 7, 385-387 (1995).

DOI: 10.1002/adma.19950070408

[24] Suzuki Y., Shiotsuki M., Sanda F., Masuda T.: Chiral 1-methylpropargyl alcohol: A simple and powerful helical source for substituted polyacetylenes. Macromolecules, 40, 1864-1867 (2007).

DOI: $10.1021 / \mathrm{ma} 0629642$ 
[25] Aoki T., Kaneko T., Maruyama N., Sumi A., Takahashi M., Sato T., Teraguchi M.: Helix-sense-selective polymerization of phenylacetylene having two hydroxy groups using a chiral catalytic system. Journal of the American Chemical Society, 125, 63466347 (2003).

DOI: $10.1021 / \mathrm{ja0212330}$

[26] Li B. S., Cheuk K. K. L., Ling L., Chen J., Xiao X., Bai C., Tang B. Z.: Synthesis and hierarchical structures of amphiphilic polyphenylacetylenes carrying L-valine pendants. Macromolecules, 36, 77-85 (2003). DOI: $10.1021 / \mathrm{ma} 0213091$

[27] Cheuk K. K. L., Lam J. W. Y., Chen J., Lai L. M., Tang B. Z.: Amino acid-containing polyacetylenes: Synthesis, hydrogen bonding, chirality transcription, and chain helicity of amphiphilic poly(phenylacetylene)s carrying L-leucine pendants. Macromolecules, 36, 5947-5959 (2003).

DOI: $10.1021 / \mathrm{ma} 0344543$

[28] Lam J. W. Y., Tang B. Z.: Functional polyacetylenes. Accounts of Chemical Research, 38, 745-754 (2005). DOI: $10.1021 / \operatorname{ar} 040012 \mathrm{f}$

[29] Okoshi K., Sakurai S. I., Ohsawa S., Kumaki J., Yashima E.: Control of main-chain stiffness of a helical poly(phenylacetylene) by switching on and off the intramolecular hydrogen bonding through macromolecular helicity inversion. Angewandte Chemie International Edition, 48, 8173-8176 (2006).

DOI: $10.1002 /$ anie. 200603663

[30] Wu S., Yang N., Yang L., Cao J., Liu J.: A novel type of optically active helical polymers: Synthesis and characterization of $\operatorname{poly}(\alpha, \beta$-unsaturated ketone). Journal of Polymer Science Part A: Polymer Chemistry, 48, 1441-1448 (2010).

DOI: $10.1002 /$ pola.23915

[31] Torma V., Gyenes T., Szakács Z., Noszál B., Némethy A., Zrínyi M.: Novel amino acid-based polymers for pharmaceutical applications. Polymer Bulletin, 59, 311-318 (2007).

DOI: $10.1007 / \mathrm{s} 00289-007-0774-9$

[32] Sogawa H., Terada K., Masuda T., Sanda F.: Synthesis and properties of amino acid-derived optically active photo-responsive polymers. Polymer Bulletin, 63, 803-813 (2009).

DOI: $10.1007 / \mathrm{s} 00289-009-0121-4$

[33] Terada K., Sanda F., Masuda, T.: Polycondensation of diketopiperazine-based dicarboxylic acids with diamines and dibromoxylenes. Journal of Macromolecular Science Part A: Pure and Applied Chemistry, 44, 789-794 (2007).

DOI: $10.1080 / 10601320701406971$
[34] Chankvetadze B., Yamamoto C., Kamigaito M., Tanaka N., Nakanishi K., Okamoto Y.: High-performance liquid chromatographic enantioseparations on capillary columns containing monolithic silica modified with amylose tris(3,5-dimethylphenylcarbamate). Journal of Chromatography A, 1110, 46-52 (2006). DOI: 10.1016/j.chroma.2006.01.076

[35] Okamoto Y., Yashima E., Hatada K., Mislow K.: Chromatographic resolution of perchlorotriphenylamine on (+)-poly(triphenylmethyl methacrylate). Journal of Organic Chemistry, 49, 557-558 (1984). DOI: $10.1021 /$ jo00177a037

[36] Zheng J., Bragg W., Hou J., Lin N., Chandrasekaran S., Shamsi S. A.: Sulfated and sulfonated polysaccharide as chiral stationary phases for capillary electrochromatography and capillary electrochromatography-mass spectrometry. Journal of Chromatography A, 1216, 857-872 (2009).

DOI: $10.1016 /$ j.chroma.2008.11.082

[37] Lao W., Gan J.: High-performance liquid chromatographic separation of imidazolinone herbicide enantiomers and their methyl derivatives on polysaccharide-coated chiral stationary phases. Journal of Chromatography A, 1117, 184-193 (2006).

DOI: $10.1016 /$ j.chroma.2006.03.094

[38] Zhong Q., Han X., He L., Beesley T. E., Trahanovsky W. S., Armstrong D. W.: Chromatographic evaluation of poly (trans-1,2-cyclohexanediyl-bis acrylamide) as a chiral stationary phase for HPLC. Journal of Chromatography A, 1066, 55-70 (2005).

DOI: $10.1016 /$ j.chroma.2004.12.088

[39] Corley L. S., Vogl O.: Optically active polychloral. Polymer Bulletin, 3, 211-217 (1980).

DOI: $10.1007 / \mathrm{BF} 00291959$

[40] Chiellini E., Senatori L., Solaro R.: A new chiral poly(alkyl vinyl ether): Synthesis and chiroptical properties. Polymer Bulletin, 20, 215-220 (1988).

DOI: $10.1007 / \mathrm{BF} 00261971$

[41] Miyabe T., Hase Y., Iida H., Maeda K., Yashima E.: Synthesis of functional poly(phenyl isocyanide)s with macromolecular helicity memory and their use as asymmetric organocatalysts. Chirality, 21, 44-50 (2009).

DOI: $10.1002 /$ chir.20604

[42] Cao J., Yang N-F., Wang P-D., Yang L-W.: Optically active polyethers from chiral terminal epoxides with bulky group. Polymer International, 57, 530-537 (2008).

DOI: $10.1002 /$ pi.2380

[43] Pino P., Ciardelli F., Lorenzi G. P., Natta G.: Optically active vinyl polymers. VI. chromatographic resolution of linear polymers of $(\mathrm{R})(\mathrm{S})-4-\mathrm{methyl}-1-$ hexene. Journal of the American Chemical Society, 84, 1487-1488 (1962).

DOI: $10.1021 / \mathrm{ja} 00867 \mathrm{a} 028$ 
[44] Marvel C. S., Overberger C. G.: An optically active styrene derivative and its polymer. Journal of the American Chemical Society, 66, 475-477 (1944). DOI: $10.1021 / \mathrm{ja} 01231 \mathrm{a} 051$

[45] Bailey W. J., Yates E. T.: Polymers. III. Synthesis of optically active stereoregular polyolefins. Journal of Organic Chemistry, 25, 1800-1804 (1960). DOI: $10.1021 /$ jo01080a033

[46] Rogers M. E., Long T. E.: Synthetic methods in stepgrowth polymers. Wiley, New Jersey (2003). DOI: $\underline{10.1002 / 0471220523}$

[47] Selegny E.: Optically active polymers. Springer, Dordrecht (1979).

[48] Morikawa A., Kakimoto M-A., Imai Y.: Preparation and properties of optically active aromatic polyamides derived from newly prepared chiral phenylindanediamine. High Performance Polymers, 7, 149-156 (1995).

DOI: 10.1088/0954-0083/7/2/002

[49] Iribarren I., Alemán C., Bou J. J., Muñoz-Guerra S.: Crystal structures of optically active polyamides derived from di- $O$-methyl-1-tartaric acid and 1,n-alkanediamines: A study combining energy calculations, diffraction analysis, and modeling simulations. Macromolecules, 29, 4397-4405 (1996).

DOI: $10.1021 / \mathrm{ma} 951394 \mathrm{v}$

[50] Bueno M., Zamora F., Molina I., Orgueira H. A., Varela O., Galbis J. A.: Synthesis and characterization of optically active polyamides derived from carbohydrate-based monomers. Journal of Polymer Science Part A: Polymer Chemistry, 35, 3645-3653 (1997).

DOI: 10.1002/(SICI)1099-0518(199712)35:17<3645:: AID-POLA4>3.0.CO;2-R

[51] Varela O., Orgueira H. A.: Synthesis of chiral polymides from carbohydrate-derived monomers. Advances in Carbohydrate Chemistry and Biochemistry, 55, 137-174 (2000). DOI: $10.1016 / \mathrm{S} 0065-2318(00) 55005-7$

[52] Orgueira H. A., Erra-Balsells R., Nonami H., Varela P.: Synthesis of chiral polyhydroxy polyamides having chains of defined regio and stereoregularity. Macromolecules, 334, 687-695 (2001).

DOI: $10.1021 / \mathrm{ma} 000016+$

[53] Orgueira H. A., Varela O.: Stereocontrolled synthesis of stereoregular, chiral analogs of nylon 5,5 and nylon 5,6. Tetrahedron: Asymmetry, 8, 1383-1389 (1997).

DOI: 10.1016/S0957-4166(97)00121-3

[54] Orgueira H. A., Bueno M., Funes J. L., Galbis J. A., Varela O.: Synthesis and characterization of chiral polyamides derived from glycine and (S)-5-amino-4methoxypentanoic acid. Journal of Polymer Science Part A: Polymer Chemistry, 36, 2741-2748 (1998). DOI: 10.1002/(SICI)1099-0518(19981115)36:15<2741 $\because:$ AID-POLA10>3.0.CO;2-E
[55] de Gracia García-Martín M., De Paz Báñez M. V., Galbis J. A.: Preparation of 3-amino-3-deoxy-2,4,5,6tetra-o-methyl-D-altronic acid hydrochloride, a precursor in the preparation of a chiral $\beta$-polyamide (nylon 3 analog). Journal of Polymer Science Part A: Polymer Chemistry, 19, 805-815 (2000). DOI: $10.1080 / 07328300008544119$

[56] Overberger C. G., Shimokawa Y.: Synthesis and optical properties of asymmetric polyamides derived from optically active cyclic dicarboxylic acids. Macromolecules, 4, 718-725 (1971).

DOI: $10.1021 / \mathrm{ma} 60024 \mathrm{a} 010$

[57] Overberger C. G., Okamoto Y., Bulacovschi V.: Synthesis and optical properties of asymmetric polyamides derived from optically active dicarboxylic acids and spirodiamine. Macromolecules, 8, 31-36 (1975).

DOI: $10.1021 / \mathrm{ma} 60043 \mathrm{a} 007$

[58] Lu C. X., Ji A., Overberger C. G.: Synthesis of polyamide containing optically active thymine derivative as a grafted pendant. Journal of Polymer Science Part A: Polymer Chemistry, 24, 269-278 (1986).

DOI: $10.1002 /$ pola.1986.080240206

[59] Overberger C. G., Lu C. X., Chen C. C.: Syntheses of stereoregular and optically active polyamides from active 4-chloro-1-benzotriazolyl diesters and diamines. Journal of Polymer Science Part A: Polymer Chemistry, 24, 75-85 (1986).

DOI: 10.1002/pola.1986.080240106

[60] Li B., Yang X., Yang K., Fu E.: Synthesis of novel chiral macrocyclic polyamides derived from L-/D-tartaric acid. Synthetic Communications, 35, 2603-2608 (2005).

DOI: $10.1080 / 00397910500214235$

[61] Marqués M. S., Regaño C., Nyugen J., Aidanpa L., Muñoz-Guerra S.: Hydrolytic and fungal degradation of polyamides derived from tartaric acid and hexamethylenediamine. Polymer, 41, 2765-2772 (2000). DOI: $10.1016 / \mathrm{S} 0032-3861(99) 00422-\mathrm{X}$

[62] Esquivel D., Bou J. J., Muñoz-Guerra S.: Synthesis, characterization and degradability of polyamides derived from tartaric acid and diaminoethers. Polymer, 44, 6169-6177 (2003).

DOI: $10.1016 / \mathrm{S} 0032-3861(03) 00651-7$

[63] Bou J. J., Rodriguez-Galan A., Muñoz-Guerra S.: Optically active polyamides derived from L-tartaric acid. Macromolecules, 26, 5664-5670 (1993). DOI: $10.1021 / \mathrm{ma} 00073 \mathrm{a} 020$

[64] Majó M. A., Alla A., Bou J. J., Herranz C., MuñozGuerra S.: Synthesis and characterization of polyamides obtained from tartaric acid and L-lysine. European Polymer Journal, 40, 2699-2708 (2004). DOI: 10.1016/j.eurpolymj.2004.07.020

[65] Alla A., Oxelbark J., Rodriguez-Galan A., MuñozGuerra S.: Acylated and hydroxylated polyamides derived from L-tartaric acid. Polymer, 46, 2854-2861 (2005).

DOI: 10.1016/j.polymer.2005.02.046 
[66] Cianga L.: Synthesis and characterization of optically active polymers containing azo groups and (L)- $\alpha$ amino acid moieties. European Polymer Journal, 39, 2271-2282 (2003).

DOI: 10.1016/S0014-3057(03)00140-X

[67] Carlini C., Fissi A., Galletti A. M. R., Sbrana G.: Optically active polymers bearing side-chain photochromic moieties: synthesis and chiroptical properties of methacrylic homopolymers with pendant trans-azobenzene chromophores bound through L-leucine, Lvaline and L-proline amino acid spacers. Macromolecular Chemistry and Physics, 201, 1540-1551 (2000). DOI: 10.1002/1521-3935(20000801)201:13<1540:: AID-MACP1540>3.0.CO;2-8

[68] Wang L., Wang Y., Cao D.: Synthesis and characterization of novel biodegradable polyamides containing $\alpha$-amino acid. Journal of Macromolecular Science Part A: Pure and Applied Chemistry, 46, 312-320 (2009).

DOI: $10.1080 / 10601320802637441$

[69] Ikeuchi Y., Nakagawa M., Yoshikawa M., Yoshida H., Sakurai S.: Chiral polyamides consisting of N- $\alpha$-benzoyl-L-glutamic acid as a diacid component. Journal of Polymer Science Part A: Polymer Chemistry, 47, 2530-2538 (2009).

DOI: $10.1002 /$ pola.23335

[70] Nakagawa M., Ikeuchi Y., Yoshikawa M.: Chiral separation of racemic amino acids with novel polyamides having $N$ - $\alpha$-acetyl-L-glutamyl residue as a diacid component. Polymer, 49, 4612-4619 (2008). DOI: $10.1016 /$ j.polymer.2008.08.018

[71] Katasarava R., Kharadze D., Kirmelashvili L., Medzmariashvili N., Goguadze T., Tsitlanadze G.: Polyamides from 2,2'-p-phenylenebis $\left(\Delta^{2}-5\right.$-oxazolone $) \mathrm{s}$ and $N, N^{\prime}$-bistrimethylsilylated diamines. Synthesis of polyamides containing dipeptide links in the main chains. Die Makromolekulare Chemie, 194, 143-150 (1993).

DOI: 10.1002/macp.1993.021940111

[72] Mansour M. E., Kandil S. H., Hassan H. H. A. M., Shaban M. A. E.: Synthesis of carbohydrate-containing polyamides and study of their properties. European Polymer Journal, 26, 267-276 (1990).

DOI: 10.1016/0014-3057(90)90240-5

[73] Bachmann F., Thiem J.: Synthesis of hydrophilic carbohydrate-derived polyamides. Journal of Polymer Science Part A: Polymer Chemistry, 30, 2059-2062 (1992).

DOI: 10.1002/pola.1992.080300934

[74] Zamora F., Bueno M., Molina I., Orgueira H. A., Varela O., Galbis J. A.: Synthesis of carbohydratebased monomers that are precursors for the preparation of stereoregular polyamides. Tetrahedron: Asymmetry, 7, 1811-1818 (1996).

DOI: $\underline{10.1016 / 0957-4166(96) 00216-9}$
[75] Mancera M., Roffé I., Al-Kass S. S. J., Rivas M., Galbis J. A.: Synthesis and characterization of new stereoregular AABB-type polyamides from carbohydratebased monomers having D-manno and L-ido configurations. Macromolecules, 36, 1089-1097 (2003).

DOI: $10.1021 / \mathrm{ma} 021307 \mathrm{~g}$

[76] Zamora F., Bueno M., Molina I., Iribarren J. I., Muñoz-Guerra S., Galbis J. A.: Stereoregular copolyamides derived from $\mathrm{D}$-xylose and L-arabinose. Macromolecules, 33, 2030-2038 (2000).

DOI: $10.1021 / \mathrm{ma9916436}$

[77] Fernández C. E., Bermúdez M., Alla A., Mancera M., Garcia-Martín M. G., Benito E., Roffe I., Galbis J. A., Muñoz-Guerra S.: Crystallization studies on linear aliphatic polyamides derived from naturally occurring carbohydrates. Journal of Applied Polymer Science, 116, 2515-2525 (2010). DOI: $10.1002 / a p p .31759$

[78] Mallakpour S., Dinari M.: Microwave step-growth polymerization of 5-(4-methyl-2-phthalimidylpentanoylamino)isophthalic acid with different diisocyanates. Polymers for Advanced Technologies, 19, 1334-1342 (2008).

DOI: $10.1002 /$ pat.1142

[79] Mallakpour S., Taghavi M.: A facile, microwaveassisted synthesis of novel optically active polyamides derived from 5-(3-methyl-2-phthalimidylpentanoylamino)isophthalic acid and different diisocyanates. European Polymer Journal, 44, 87-97 (2008).

DOI: 10.1016/j.eurpolymj.2007.10.027

[80] Mallakpour S., Sepehri S.: Preparation of new optically active polyamides containing a L-phenylalanine, phthalimide side-chain via the diisocyanate route by microwave energy: Comparison with conventional heating. Designed Monomers and Polymers, 11, 535546 (2008).

DOI: $10.1163 / 156855508 X 363825$

[81] Mallakpour S., Dinari M.: Soluble new optically active polyamides derived from 5-(4-methyl-2-phthalimidylpentanoylamino)isophthalic acid and different diisocyanates under microwave irradiation in molten ionic liquid. Journal of Applied Polymer Science, 112, 244-253 (2009).

DOI: $10.1002 / a p p .29410$

[82] Mallakpour S., Sepehri S.: Polycondensation of new optically active diacid with diisocyanates in the presence of tetrabutylammonium bromide as a green media under microwave heating. Reactive and Functional Polymers, 68, 1459-1466 (2008).

DOI: $10.1016 /$ j.reactfunctpolym.2008.07.004

[83] Mallakpour S., Taghavi M.: Efficient and rapid synthesis of optically active polyamides in the presence of tetrabutylammonium bromide as ionic liquids under microwave irradiation. Journal of Applied Polymer Science, 109, 3603-3612 (2008).

DOI: $10.1002 /$ app. 28263 
[84] Mallakpour S., Zadehnazari A.: Fast synthesis, using microwave induction heating in ionic liquid and characterization of optically active aromatic polyamides. Journal of Macromolecular Science Part A: Pure and Applied Chemistry, 46, 783-789 (2009).

DOI: $10.1080 / 10601320903004541$

[85] Mallakpour S., Taghavi M.: Direct polyamidation in green media: Studies on thermal degradation of novel organosoluble and optically active flame retardant polyamides. Reactive and Functional Polymers, 69, 206-215 (2009).

DOI: $10.1016 /$ j.reactfunctpolym.2008.12.023

[86] Mallakpour S., Rafiee Z.: Expeditious synthesis of novel aromatic polyamides from 5-[3-phenyl-2-(9,10dihydro-9,10-ethanoanthracene-11,12-dicarboximido) propanoylamino]isophthalic acid and various diamines using microwave-assisted polycondensation. Reactive and Functional Polymers, 69, 252-258 (2009). DOI: $10.1016 /$ j.reactfunctpolym.2009.01.003

[87] Mallakpour S., Taghavi M.: Microwave heating coupled with ionic liquids: Synthesis and properties of novel optically active polyamides, thermal degradation and electrochemical stability on multi-walled carbon nanotubes electrode. Polymer, 49, 3239-3249 (2008).

DOI: $10.1016 /$ j.polymer.2008.06.001

[88] Liu Y., Hua J., Sang W.: Dielectric properties in ferroelectric optically active polyamides. Journal of Macromolecular Science Part B: Physics, 39, 349-358 (2000).

DOI: $10.1081 / \mathrm{MB}-100100390$

[89] Chen Y., Siago K., Yonezawa N., Tachibana K., Hasegawa M.: Optically active polyamides having (-)-anti head-to-head coumarin dimer component. 3 . Chiral recognition ability. Bulletin of the Chemical Society of Japan, 60, 3341-3345 (1987).

DOI: $10.1246 /$ bcsj.60.3341

[90] Liou G-S., Maruyama M., Kakimoto M-A., Imai Y.: Preparation and properties of aromatic polyamides from 2,2'-bis( $p$-aminophenoxy) biphenyl or 2,2'bis(p-aminophenoxy)-1, $1^{\prime}$-binaphthyl and aromatic dicarboxylic acids. Journal of Polymer Science Part A: Polymer Chemistry, 31, 2499-2506 (1993).

DOI: 10.1002/pola.1993.080311010

[91] Liou G-S., Kakimoto M-A., Imai Y.: Preparation and properties of aromatic polyamides from $2,2^{\prime}$-bis(pcarboxyphenoxy) biphenyl or 2,2'-bis( $p$-carboxyphenoxy)-1,1'-binaphthyl and aromatic diamines. Journal of Polymer Science Part A: Polymer Chemistry, 31, 3265-3272 (1993).

DOI: $10.1002 /$ pola.1993.080311314

[92] Nozaki K., Terakawa T., Takaya H., Hiyama T.: Cyclic polyamides consisting of 1,1'-binaphthyls. 'Chiral twist' of glycine residues. Tetrahedron: Asymmetry, 8, 3431-3436 (1997).

DOI: $10.1016 / \mathrm{S} 0957-4166(97) 00460-6$
[93] Hsiao S-H., Yang C-P., Tsai C-Y., Liou G-S.: A novel class of organosoluble and light-colored fluorinated polyamides derived from 2,2'-bis(4-amino-2-trifluoromethylphenoxy)biphenyl or 2,2'-bis(4-amino-2-trifluoromethylphenoxy)-1,1'-binaphthyl. European Polymer Journal, 40, 1081-1094 (2004). DOI: 10.1016/j.eurpolymj.2004.01.001

[94] Agata Y., Kobayashi M., Kimura H., Takeishi M.: Synthesis and photoinduced transformation of helical aromatic polyamides containing atropisomeric biphenylene units and azobenzene segments in the main chain. Polymer International, 54, 260-266 (2005).

DOI: $10.1002 /$ pi.1664

[95] Liou G-S., Fang Y-K., Yen H-J.: Synthesis and properties of noncoplanar rigid-rod aromatic polyamides containing phenyl or naphthyl substituents. Journal of Polymer Research, 14, 147-155 (2007).

DOI: 10.1007/s10965-006-9094-2

[96] Korshak V. V., Rogozhin S. V., Davankov V. A., Davidovich Y. A., Makarova T. A.: Advances in the synthesis of polypeptides. Russian Chemical Reviews, 34, 329-366 (1965).

DOI: 10.1070/RC1965v034n05ABEH001449

[97] Dickinson H. R., Hiltner A.: Biodegradation of a poly( $\alpha$-amino acid) hydrogel. II. In vitro. Journal of Biomedical Materials Research, 15, 591-603 (1981).

DOI: $10.1002 / \mathrm{jbm} .820150413$

[98] Deming T. J.: Synthetic polypeptides for biomedical applications. Progress in Polymer Science, 32, 858875 (2007).

DOI: 10.1016/j.progpolymsci.2007.05.010

[99] Yang D. J., Li C., Nikiforow S., Gretzer M. B., Kuang L-R., Lopez M. S., Vargas K., Wallace S.: Diagnostic and therapeutic potential of poly(benzyl L-glutamate). Journal of Pharmaceutical Sciences, 83, 328-331 (1994). DOI: 10.1002/jps.2600830312

[100] Anson M. L., Edsall J. T., Bailey K.: Advances in protein chemistry, Volume 6. Academic Press, New York (1951).

[101] Frankel M., Neufeld O., Katchalski E.: Carbamates of $\alpha$-amino-acid esters and their polycondensation. Nature, 144, 832-833 (1939).

DOI: $10.1038 / 144832 b 0$

[102] Frankel M., Katchalski E.: Poly-condensation of $\alpha$ amino acid esters. I. Poly-condensation of glycine esters. Journal of the American Chemical Society, 64, 2264-2268 (1942).

DOI: $10.1021 / \mathrm{ja} 01262 \mathrm{a} 011$

[103] Frankel M., Katchalski E.: Poly-condensation of $\alpha$ amino acid esters. II. Poly-condensation of alanine ethyl ester. Journal of the American Chemical Society, 64, 2268-2271 (1942). DOI: $\underline{10.1021 / \mathrm{ja} 01262 \mathrm{a} 012}$ 
[104] Katchalski E., Grossfeld I., Frankel M.: Poly-condensation of $\alpha$-amino acid derivatives. III. Poly-lysine. Journal of the American Chemical Society, 70, 2094 2101 (1948).

DOI: $10.1021 / \mathrm{ja} 01186 \mathrm{a} 032$

[105] Frankel M., Berger A.: Synthesis of poly-aspartic acid. Nature, 163, 213-214 (1949). DOI: $10.1038 / 163213 b 0$

[106] Fasman G. D., Blout E. R.: The synthesis and the conformation of poly-L-serine and poly-O-acetyl-L-serine. Journal of the American Chemical Society, 82, 2262-2267 (1960). DOI: $10.1021 / \mathrm{ja} 01494 \mathrm{a} 041$

[107] Kim J-H., Son C. M., Jeon Y. S., Choe W-S.: Synthesis and characterization of poly(aspartic acid) derivatives conjugated with various amino acids. Journal of Polymer Research, in press, (2010).

DOI: 10.1007/s10965-010-9485-2

[108] Yuki H., Okamoto Y., Kobayashi Y.: Poly( $\beta$-amino acids). VI. Synthesis and conformational properties of poly[(r)-3-pyrrolidinecarboxylic acid]. Journal of Polymer Science: Polymer Chemistry Edition, 17, 3867-3878 (1979). DOI: $10.1002 /$ pol.1979.170171207

[109] Mittal K. L.: Polyimides and other high temperature polymers: Synthesis, charactherization and applications, Volume 2. VSP, Utrecht (2003).

[110] Barikani M.: Polyimides derived from diisocyanates. Iranian Polymer Journal, 11, 215-236 (2002).

[111] Mi Q., Gao L., Ding M.: The synthesis of a 1,1'-bi-2naphthol-based bis(ether anhydride) and aromatic polyimides derived therefrom. Polymer, 38, 36633668 (1997).

DOI: 10.1016/S0032-3861(96)00912-3

[112] Gao C., Zhang S., Gao L., Ding M.: Syntheses of biphenyl polyimides via nickel-catalyzed coupling polymerization of bis(chlorophthalimide)s. Macromolecules, 36, 5559-5565 (2003).

DOI: $10.1021 / \mathrm{ma} 034036 \mathrm{y}$

[113] Yan J., Liu C., Wang Z., Xing W., Ding M.: Water resistant sulfonated polyimides based on 4,4'-binaphthyl-1,1',8,8'-tetracarboxylic dianhydride (BNTDA) for proton exchange membranes. Polymer, 48, 62106214 (2007).

DOI: 10.1016/j.polymer.2007.07.026

[114] Mi Q., Gao L., Ding M.: Optically active aromatic polyimides having axially dissymmetric $1,1^{\prime}$-binaphthalene-2,2'-diyl units. Macromolecules, 29, 57585759 (1996).

DOI: $10.1021 / \mathrm{ma9606667}$

[115] Mi Q., Ma Y., Gao L., Ding M.: New optically active aromatic polyimides II: Synthesis and properties of optically active aromatic polyimides based on (R)(+)-2,2'-bis(trifluoro-4-aminophenoxy)-1,1'-binaphtyl. Chinese Journal of Polymer Science, 17, 87-90 (1999).
[116] Mi Q., Ma Y., Gao L., Ding M.: Synthesis and characterization of optically active aromatic polyimides derived from 2,2'-bis(2-trifluoro- 4-aminophenoxy)$1,1^{\prime}$-binaphthyl and aromatic tetracarboxylic dianhydrides. Journal of Polymer Science Part A: Polymer Chemistry, 37, 4536-4540 (1999).

DOI: $10.1002 /($ SICI) 1099-0518(19991215)37:24< $4536::$ AID-POLA10>3.0.CO;2-Y

[117] Liou G-S.: Synthesis and properties of soluble aromatic polyimides from 2,2'-bis(3,4-dicarboxyphenoxy)-1,1'-binaphthyl dianhydride and aromatic diamines. Journal of Polymer Science Part A: Polymer Chemistry, 36, 1937-1943 (1998).

DOI: 10.1002/(SICI)1099-0518(199808)36:11<1937:: AID-POLA29>3.0.CO;2-E

[118] Yigit M., Seçkin T., Koytepe S., Çetinkaya E.: Synthesis and characterization of polyimides prepared from optically active $(\mathrm{R}, \mathrm{R})$ and $(\mathrm{S}, \mathrm{S})-1,3-\mathrm{bis}\left(\mathrm{p}-\mathrm{N}, \mathrm{N}^{\prime}-\right.$ dimethylaminobenzyl)-perhydrobenzimidazol-2-thion. Turkish Journal of Chemistry, 31, 113-124 (2007).

[119] Kudo K., Li J., Nonokawa D., Yoshizawa T., Kishida Y., Takayama T., Shiraishi S.: Synthesis and properties of structurally ordered alicyclic polyimides. Journal of Photopolymer Science and Technology, 15, 215-218 (2002).

[120] Kudo K., Nonokawa D., Li J., Shiraishi S.: Synthesis of optically active alicyclic polyimides from a chiral, nonracemic dianhydride. Journal of Polymer Science Part A: Polymer Chemistry, 40, 4038-4044 (2002). DOI: $10.1002 /$ pola.10497

[121] Li J., Kudo K., Shiraishi S.: Synthesis and properties of novel soluble polyimides having an unsymmetric spiro tricyclic dianhydride unit. Macromolecular Chemistry and Physics, 201, 2289-2297 (2000).

DOI: 10.1002/1521-3935(20001101)201:17<2289:: AID-MACP2289>3.0.CO;2-F

[122] Kudo K., Yoshizawa T., Hamada T., Li J., Sakamoto S., Shiraishi S.: One-pot synthesis of an alternating copolyimide based on regioselective reaction of a non-symmetrical alicyclic dianhydride. Macromolecular Rapid Communications, 27, 1430-1436 (2006). DOI: $10.1002 /$ marc. 200600319

[123] Li J., Kudo K., Shiraishi S.: A study on the effect of spirocyclic structures in the main chain on the physical properties of copolyimides. Macromolecular Rapid Communications, 21, 1166-1170 (2000). DOI: $10.1002 / 1521-3927(20001101) 21: 16<1166:$ : AID-MARC1166>3.0.CO;2-M

[124] Barikani M., Mehdipour-Ataei S., Yeganeh H.: Synthesis and properties of novel optically active polyimides. Journal of Polymer Science Part A: Polymer Chemistry, 39, 514-518 (2001).

DOI: 10.1002/1099-0518(20010215)39:4<514::AIDPOLA1020>3.0.CO;2-4 
[125] Yeganeh H., Tamami B., Ghazi I.: Synthesis and properties of novel diisocyanate based optically active polyimides. European Polymer Journal, 38, 21792185 (2002).

DOI: 10.1016/S0014-3057(02)00115-5

[126] Yeganeh H., Tamami B., Ghazi I.: Synthesis and properties of novel optically active and soluble aromatic/ aliphatic polyimides via reaction of dianhydrides and diisocyanates. Iranian Polymer Journal, 14, 277-285 (2005).

[127] Mallakpour S., Kolahdoozan M.: Synthesis and properties of thermally stable and optically active novel wholly aromatic polyesters containing a chiral pendent group. European Polymer Journal, 43, 33443354 (2007).

DOI: 10.1016/j.eurpolymj.2007.06.006

[128] Mallakpour S., Seyedjamali H.: Synthesis and characterization of novel organosoluble and optically active aromatic polyesters containing L-methionine and phthalimide pendent groups. Amino Acids, 34, 531538 (2008).

DOI: $10.1007 / \mathrm{s} 00726-007-0005-6$

[129] Mallakpour S., Rafiee Z.: Synthesis and characterization of novel organosoluble, thermal stable and optically active polyesters derived from 5-(2-phthalimidiylpropanoylamino)isophthalic acid. Polymer Journal, 39, 1185-1192 (2007).

DOI: 10.1295/polymj.PJ2007061

[130] Mallakpour S., Sepehri S.: Synthesis and characterization of new optically active polyesters by stepgrowth polymerization of novel aromatic (2S)-4-[(4methyl-2-phthalimidyl-pentanoylamino)benzoylamin o]isophthalic acid with aromatic diols. Journal of Applied Polymer Science, 110, 2942-2949 (2008). DOI: $10.1002 /$ app. 28897

[131] Mallakpour S., Tirgir F.: Preparation and characterization of new thermally stable and optically active polyesters by direct polycondensation reaction promoted by Vilsmeier adduct. e-Polymers, no.108, 1-10 (2009).

[132] Mallakpour S., Hashemi E.: Synthesis and characterization of novel optically active and photoactive aromatic polyesters containing 1,8-naphthalimidyl pendant group by step-growth polymerization. Polymer Bulletin, 65, 551-563 (2010).

DOI: $10.1007 / \mathrm{s} 00289-009-0226-9$

[133] Fujishiro K., Lenz R. W.: Main-chain cholesteric liquid crystalline polyesters with chiral pendant groups. 2. Cholesteric copolyesters containing chiral and achiral substituted hydroquinones. Macromolecules, 25, 88-95 (1992).

DOI: $10.1021 / \mathrm{ma} 00027 \mathrm{a} 015$
[134] Schwarz G., Kricheldorf H. R.: New polymer synthesis. LXXXIII. Synthesis of chiral and cholesteric polyesters from silylated 'sugar diols'. Journal of Polymer Science Part A: Polymer Chemistry, 34, 603-611 (1996).

DOI: 10.1002/(SICI)1099-0518(199603)34:4<603:: AID-POLA6>3.0.CO;2-R

[135] Stumpe J., Ziegler A., Berghahn M., Kricheldorf H. R.: Photoreactive cholesteric polyesters derived from 4-carboxycinnamic acid and novel chiral spacers. Macromolecules, 28, 5306-5311 (1995).

DOI: $10.1021 / \mathrm{ma} 00119 \mathrm{a} 021$

[136] Kricheldorf H. R., Wulff D. F.: Layer structures 12. Chiral sanidic polyesters derived from 2,5-bis(hexadecyloxy)terephthalic acid, 2,5-bis((S)-2-methylbutoxy)terephthalic acid and 4,4'-dihydroxybiphenyl. Polymer, 39, 2683-2692 (1996). DOI: 10.1016/S0032-3861(97)00580-6

[137] Kricheldorf H. R., Wulff D. F., Wutz C.: Layer structures, 13. Chiral sanidic polyesters derived from 2,5bis(alkylthio)terephthalic acids. Macromolecular Chemistry and Physics, 200, 799-809 (1999). DOI: 10.1002/(SICI)1521-3935(19990401)200:4< 799::AID-MACP799>3.0.CO;2-S

[138] Bahulayan D., Sreekumar K.: Chiral polyesters with azobenzene moieties in the main chain, synthesis and evaluation of nonlinear optical properties. Journal of Materials Chemistry, 9, 1425-1429 (1999). DOI: $10.1039 / \mathrm{a} 900567 \mathrm{f}$

[139] Philip B., Sreekumar K.: Second-harmonic response of a series of chiral polyesters: A joint experimental and theoretical study. Journal of Polymer Science Part A: Polymer Chemistry, 40, 2868-2877 (2002).

DOI: $10.1002 /$ pola.10371

[140] Philip B., Sreekumar K.: Studies on second harmonic generation efficiency by a series of chiral polyesters. Journal of Applied Polymer Science, 89, 2468-2473 (2003).

DOI: 10.1002/app.12477

[141] Philip B., Sreekumar K.: Synthesis and characterization of chiral main chain polyesters with polar segments tailored for second harmonic generation. Journal of Materials Science, 38, 1573-1577 (2003). DOI: 10.1023/A:1022949320834

[142] Nemoto N., Miyata F., Nagase Y., Abe J., Hasegawa M., Shirai Y.: Novel types of polyesters containing second-order nonlinear optically active chromophores with high density. Macromolecules, 29, 2365-2371 (1996).

DOI: $10.1021 / \mathrm{ma} 951032 \mathrm{n}$

[143] Mehl G. H., Valvo F., Lacey D., Goodby J. W., DasGupta D. K.: Properties of side chain liquid crystal polyesters containing chiral groups in the main chain. Polymer Engineering and Science, 36, 2921-2931 (1996).

DOI: $10.1002 /$ pen.10693 
[144] Nagata M., Kono Y., Sakai W., Tsutsumi N.: Preparation and characterization of novel biodegradable optically active network polyesters from malic acid. Macromolecules, 32, 7762-7767 (1999).

DOI: $10.1021 / \mathrm{ma9909071}$

[145] Bai F., Chien L-C., Li C. Y., Cheng S. Z. D., Petschek R.: Synthesis and characterization of isoregic chiral smectic polyesters. Chemistry of Materials, 11, 16661671 (1999).

DOI: $10.1021 / \mathrm{cm} 990159 \mathrm{e}$

[146] Srinivasan R., Radhakrishnan G.: Synthesis and characterization of liquid-crystalline polyesters with chiral and achiral twin spacers. Journal of Polymer Science Part A: Polymer Chemistry, 39, 1743-1752 (2001). DOI: $10.1002 /$ pola.1152

[147] Lin Q., Pasatta J., Long T. E.: Synthesis and characterization of chiral liquid-crystalline polyesters containing sugar-based diols via melt polymerization. Journal of Polymer Science Part A: Polymer Chemistry, 41, 2512-2520 (2003).

DOI: $10.1002 /$ pola. 10787

[148] Hilker I., Rabani G., Verzijl G. K. M., Palmans A. R. A., Heise A.: Chiral polyesters by dynamic kinetic resolution polymerization. Angewandte Chemie International Edition, 45, 2130-2132 (2006).

DOI: 10.1002/anie.200503496

[149] Van As B. A. C., Buijtenen J. V., Mes T., Palmans A. R. A., Meijer E. W.: Iterative tandem catalysis of secondary diols and diesters to chiral polyesters. Chemistry-A European Journal, 13, 8325-8332 (2007). DOI: $10.1002 /$ chem.200700818

[150] Gómez R., Segura J. L., Martín N.: Synthesis of an optically active electron-acceptor tetracyanoanthraquinodimethane (TCAQ) main-chain polyester. Tetrahedron Letters, 47, 6445-6448 (2006).

DOI: $10.1016 /$ j.tetlet.2006.06.112

[151] Mallakpour S. E., Hajipour A. R., Roohipour-fard R.: Direct polycondensation of $\mathrm{N}$-trimellitylimido-Lleucine with aromatic diamines. European Polymer Journal, 36, 2455-2462 (2000).

DOI: $10.1016 / \mathrm{S} 0014-3057(00) 00018-5$

[152] Mallakpour S. E., Hajipour A-R., Shahmohammadi M. H.: Direct polycondensation of $N$-trimellitylimido-L-isoleucine with aromatic diamines. Journal of Applied Polymer Science, 89, 116-122 (2003). DOI: 10.1002/app.12075

[153] Mallakpour S. E., Hajipour A-R., Habibi S.: Synthesis of novel poly(amide-imide)s containing trimellitylimido-DL/L-alanine moieties via direct polycondensation. Journal of Applied Polymer Science, 80, 1312 1318 (2001). DOI: $10.1002 / a p p .1218$

[154] Mallakpour S. E., Hajipour A. R., Habibi S.: Synthesis of new poly(amide-imide)s derived from trimellitylimido-L-phenylalanine. Polymer International, 50, 331-337 (2001). DOI: $10.1002 /$ pi.633
[155] Mallakpour S., Rafiemanzelat F.: Diisocyanate route as a convenient method for the preparation of novel optically active poly(amide-imide)s based on $\mathrm{N}$ trimellitylimido- $S$-valine. European Polymer Journal, 41, 2945-2955 (2005).

DOI: $10.1016 /$ j.eurpolymj.2005.05.037

[156] Mallakpour S., Khani M.: Novel optically active poly(amide-imide)s derived from $\mathrm{N}$-trimellitylimidolL-isoleucine and different diisocyanates. Polymer Bulletin, 59, 587-596 (2007).

DOI: 10.1007/s00289-007-0802-9

[157] Mallakpour S. E., Hajipour A. R., Habibi S.: Facile synthesis of new optically active poly(amide-imide)s derived from $N, N^{\prime}$-(pyromellitoyl)-bis-L-leucine diacid chloride and aromatic diamines under microwave irradiation. European Polymer Journal, 37, 2435-2442 (2001). DOI: 10.1016/S0014-3057(01)00151-3

[158] Mallakpour S., Shahmohammadi M. H.: Microwavepromoted rapid synthesis of new optically active poly(amide imide)s derived from $N, N^{\prime}$-(pyromellitoyl)-bis-L-isoleucine diacid chloride and aromatic diamines. Journal of Applied Polymer Science, 92, 951-959 (2004). DOI: 10.1002/app.13720

[159] Mallakpour S., Shahmohammadi M. H.: Synthesis of new optically active poly(amide-imide)s derived from $N, N^{\prime}$-(pyromellitoyl)-bis- $S$-valine diacid chloride and aromatic diamines under microwave irradiation and classical heating. Iranian Polymer Journal, 14, 473483 (2005).

[160] Mallakpour S. E., Hajipour A-R., Zamanlou M. R.: Novel optically active poly(amide-imide)s from $N, N^{\prime}$ (4,4'-carbonyldiphthaloyl)-bis-L-phenylalanine diacid chloride and aromatic diamines by microwave irradiation. European Polymer Journal, 38, 475-485 (2002). DOI: 10.1016/S0014-3057(01)00199-9

[161] Mallakpour S. E., Hajipour A-R., Faghihi K.: Microwave-assisted synthesis of optically active poly(amide-imide)s with benzophenone and L-alanine linkages. European Polymer Journal, 37, 119124 (2001).

DOI: $10.1016 / \mathrm{S} 0014-3057(00) 00097-5$

[162] Mallakpour S. E., Hajipour A-R., Zamanlou M. R.: Synthesis of optically active poly(amide-imide)s derived from $N, N^{\prime}$-(4,4'-carbonyldiphthaloyl)-bis-Lleucine diacid chloride and aromatic diamines by microwave radiation. Journal of Polymer Science Part A: Polymer Chemistry, 39, 177-186 (2001).

DOI: $10.1002 / 1099-0518(20010101) 39: 1<177::$ AIDPOLA200>3.0.CO;2-L

[163] Mallakpour S. E., Dabbagh A. H., Faghihi K.: Synthesis of novel optically active poly(amide-imide)s with benzophenone and L-alanine moieties. Iranian Polymer Journal, 9, 41-48 (2000). 
[164] Mallakpour S., Kowsari E.: Thermally stable and optically active poly(amide-imide)s derived from 4,4'(hexafluoroisopropylidene)- $N, N^{\prime}$-bis-(phthaloyl-Lmethionine) diacid chloride and various aromatic diamines: synthesis and characterization. Polymer Bulletin, 57, 169-178 (2006).

DOI: $10.1007 / \mathrm{s} 00289-006-0549-8$

[165] Mallakpour S. E., Hajipour A-R., Khoee S.: Synthesis and characterization of novel optically active poly (amide-imide)s. Polymer International, 48, 11331140 (1999).

DOI: 10.1002/(SICI)1097-0126(199911)48:11<1133:: AID-PI275>3.0.CO;2-\#

[166] Mallakpour S., Moghadam E.: Direct polyamidation of $N, N^{\prime}$-(4,4'-hexafluoroisopropy-lidendiphthaloyl)bis-L-isoleucine with different aromatic diamines via vilsmeier adduct derived from tosyl chloride and $\mathrm{N}, \mathrm{N}$ dimethylformamide. Polymer Bulletin, 56, 339-347 (2006).

DOI: $10.1007 / \mathrm{s} 00289-006-0504-8$

[167] Mallakpour S. E., Hajipour A. R., Khoee S.: Rapid synthesis of optically active poly(amide-imide)s by direct polycondensation of aromatic dicarboxylic acid with aromatic diamines. European Polymer Journal, 38, 2011-2016 (2002).

DOI: 10.1016/S0014-3057(02)00099-X

[168] Mallakpour S., Kowsari E.: Synthesis and properties of novel soluble and thermally stable optically active poly(amide-imide)s from $N, N^{\prime}$-(4,4'-oxydiphthaloyl)bis-L-phenylalanine diacid chloride and aromatic diamines. Polymer Bulletin, 54, 147-155 (2005).

DOI: $10.1007 / \mathrm{s} 00289-005-0374-5$

[169] Mallakpour S., Kowsari E.: Ionic liquids as novel solvents and catalysts for the direct polycondensation of $N, N^{\prime}$-(4,4'-oxydiphthaloyl)-bis-L-phenylalanine diacid with various aromatic diamines. Journal of Polymer Science Part A: Polymer Chemistry, 43, 6545-6553 (2005).

DOI: $10.1002 /$ pola.21100

[170] Mallakpour S., Kowsari E.: Soluble novel optically active poly(amide-imide)s derived from $N, N^{\prime}-\left(4,4^{\prime}\right.$ oxydiphthaloyl)-bis-L-leucine diacid chloride and various aromatic diamines: Synthesis and characterization. Journal of Applied Polymer Science, 96, 435442 (2005).

DOI: $10.1002 / a p p .21462$

[171] Mallakpour S., Kowsari E.: Polycondensation reaction of $N, N^{\prime}$-(4,4'-oxydiphthaloyl)-bis-1-methionine diacid chloride with aromatic diamines: Synthesis and properties. Journal of Applied Polymer Science, 99, 1038-1044 (2006).

DOI: $10.1002 / a p p .22616$

[172] Mallakpour S., Kowsari E.: Preparation and characterization of new optically active poly(amide-imide)s derived from $N, N-\left(4,4^{\prime}-O x y d i p h t h a l o y l\right)-b i s-(s)-(+)-$ valine diacid chloride and aromatic diamines. Polymer Engineering and Science, 46, 558-565 (2006). DOI: $10.1002 /$ pen.20490
[173] Mallakpour S., Rafiemanzelat F.: Microwave-assisted and classical heating polycondensation reaction of bis(p-amido benzoic acid)- $N$-trimellitylimido- $L$-leucine with diisocyanates as a new method for preparation of optically active poly(amide imide)s. Journal of Applied Polymer Science, 93, 1647-1659 (2004). DOI: 10.1002 /app.20603

[174] Mallakpour S., Hajipour A-R., Vahabi R.: Synthesis and characterization of novel poly(amide imide)s based on bis( $p$-amidobenzoic acid)- $n$-trimellitylimido-L-leucine. Journal of Applied Polymer Science, 84, 35-43 (2002). DOI: 10.1002/app.10181

[175] Mallakpour S., Kolahdoozan M.: Preparation of new poly(amide-imide)s with chiral architectures via direct polyamidation reaction. Journal of Applied Polymer Science, 104, 1248-1254 (2007). DOI: $10.1002 / a p p .25747$

[176] Mallakpour S., Kowsari E.: Preparation and characterization of new optically active poly(amide imide)s derived from $N, N^{\prime}$-(4,4'-sulphonediphthaloyl)-bis-(s)$(+)$-valine diacid chloride and aromatic diamines under microwave irradiation. Polymer Bulletin, 53, 169-180 (2005).

DOI: 10.1007/s00289-004-0331-8

[177] Mallakpour S., Kowsari E.: Synthesis and characterization of novel, optically active poly(amide-imide)s from $N, N^{\prime}$-(4,4'-sulfonediphthaloyl)-bis-L-phenylalanine diacid chloride and aromatic diamines under microwave irradiation. Journal of Applied Polymer Science, 41, 3974-3988 (2003).

DOI: $10.1002 /$ pola.10998

[178] Mallakpour S., Kowsari E.: Microwave-assisted and conventional polycondensation reaction of optically active $N, N^{\prime}$-(4,4'-sulphonediphthaloyl)-bis-L-leucine diacid chloride with aromatic diamines. Journal of Applied Polymer Science, 91, 2992-3000 (2004). DOI: 10.1002/app.13515

[179] Mallakpour S., Kowsari E.: Preparation and characterization of optically active and organosoluble poly (amide-imide)s from polycondensation reaction of $N, N^{\prime}$-(4,4'-sulphonediphthaloyl)-bis-L-isoleucine diacid with aromatic diamines. Polymers for Advanced Technologies, 16, 466-472 (2005).

DOI: $10.1002 /$ pat. 603

[180] Mallakpour S. E., Hajipour A-R., Faghihi K., Foroughifar N., Bagheri J.: Novel optically active poly (amide-imide)s with tetrahydropyrimidinone and tetrahydro-2-thioxopyrimidine moieties by microwaveassisted polycondensation. Journal of Applied Polymer Science, 80, 2416-2421 (2001). DOI: $10.1002 /$ app. 1348 
[181] Mallakpour S., Kowsari E.: Application of microwave irradiation for synthesis of novel optically active poly(amide imides) derived from diacid chloride containing epiclon and L-isoleucine with aromatic diamines. Journal of Applied Polymer Science, 93, 2218-2229 (2004).

DOI: $10.1002 / a p p .20738$

[182] Mallakpour S. E., Hajipour A-R., Zamanlou M. R.: Microwave-assisted synthesis of optically active poly(amide imide)s derived from diacid chloride containing epiclon and L-leucine with aromatic diamines. Journal of Polymer Science Part A: Polymer Chemistry, 41, 1077-1090 (2003).

DOI: $10.1002 /$ pola.10652

[183] Mallakpour S., Kowsari E.: Synthesis and characterization of new optically active poly(amide-imide)s containing epiclon and L-methionine moieties in the main chain. Polymers for Advanced Technologies, 16, 732-737 (2005).

DOI: $10.1002 /$ pat.648

[184] Mallakpour S., Zamanlou M. R.: Synthesis of new optically active poly(amide-imide)s containing EPICLON and L-phenylalanine in the main chain by microwave irradiation and classical heating. Journal of Applied Polymer Science, 91, 3281-3291 (2004). DOI: $10.1002 / a p p .13517$

[185] Mallakpour S., Kowsari E.: Synthesis and properties of organosoluble and optically active poly(amideimide)s based on epiclon and (S)-(+)-valine under microwave irradiation. Iranian Polymer Journal, 14, 81-90 (2005).

[186] Faghihi K., Zamani K., Mallakpour S. E.: Synthesis and characterization of optically active poly(amideimide)s with hydantoin and thiohydantoin derivatives in the main chain. Iranian Polymer Journal, 11, 339347 (2002).

[187] Faghihi K., Foroughifar N., Mallakpour S. E.: Facile synthesis of novel optically active poly(amide-imide)s derived from $N, N$-(pyromellitoyl)-bis- $l$-alanine diacid chloride, tetrahydropyrimidinone and tetrahydro-2thioxopyrimidine by microwave-assisted polycondensation. Iranian Polymer Journal, 13, 93-99 (2004).

[188] Faghihi K., Zamani K., Mirsamie A., Mallakpour S. E.: Facile synthesis of novel optically active poly (amide-imide)s containing $N, N^{\prime}$-(pyromellitoyl)-bis-1phenylalanine diacid chloride and 5,5-disubstituted hydantoin derivatives under microwave irradiation. Journal of Applied Polymer Science, 91, 516-524 (2004).

DOI: $10.1002 / a p p .13161$

[189] Song N., Gao L., Ding M.: Optically active poly (amide-imide)s containing axially dissymmetric $1,1^{\prime}$ binaphthyl moieties. Journal of Polymer Science Part A: Polymer Chemistry, 37, 3147-3154 (1999).

DOI: 10.1002/(SICI)1099-0518(19990815)37:16< 3147::AID-POLA12>3.3.CO;2-Q
[190] Atkins K. M., Lopez D., Knight D. K., Mequanint K., Gillies E. R.: A versatile approach for the syntheses of poly(ester amide)s with pendant functional groups. Journal of Polymer Science Part A: Polymer Chemistry, 47, 3757-3772 (2009).

DOI: $10.1002 /$ pola.23429

[191] Shi R., Chen D., Liu Q., Wu Y., Xu X., Zhang L., Tian W.: Recent advances in synthetic bioelastomers. International Journal of Molecular Sciences, 10, 42234256 (2009).

DOI: $10.3390 /$ ijms 10104223

[192] Okada M., Tsunoda K., Tachikawa K., Aoi K.: Biodegradable polymers based on renewable resources. IV. Enzymatic degradation of polyesters composed of 1,4:3.6-dianhydro-D-glucitol and aliphatic dicarboxylic acid moieties. Journal of Applied Polymer Science, 77, 338-346 (2000).

DOI: 10.1002/(SICI)1097-4628(20000711)77:2<338:: AID-APP9>3.0.CO;2-C

[193] Armelin E., Paracuellos N., Rodríguez-Galán A., Puiggalí J.: Study on the degradability of poly(ester amide)s derived from the $\alpha$-amino acids glycine, and Lalanine containing a variable amide/ester ratio. Polymer, 42, 7923-7932 (2001).

DOI: 10.1016/S0032-3861(01)00315-9

[194] Pinilla I. M., Bueno Martinez M., Perez J. A. G.: Synthesis of a stereoregular poly(ester amide) derived from L-arabinose. Macromolecules, 28, 3766-3770 (1995). DOI: $10.1021 / \mathrm{ma} 00115 \mathrm{a} 003$

[195] Fan X-H., Zhou J-L., Chen X-F., Wan X-H., Zhou QF.: Synthesis, characterization of chiral poly(ester amide)s derived from L-isoleucine. Chinese Journal of Polymer Science, 22, 497-500 (2004).

[196] Fan Y., Kobayashi M., Kise H.: Synthesis and specific biodegradation of novel polyesteramides containing amino acid residues. Journal of Polymer Science Part A: Polymer Chemistry, 39, 1318-1328 (2001).

DOI: 10.1002/pola.1109

[197] Nagata M.: Synthesis and enzymatic degradation of poly(ester-amide) stereocopolymers derived from alanine. Macromolecular Chemistry and Physics, 200, 2059-2064 (1999).

DOI: $10.1002 /($ SICI)1521-3935(19990901)200:9< 2059::AID-MACP2059>3.0.CO;2-N

[198] Philip B., Sreekumar K.: Optically active poly(esteramide)s: Synthesis and characterization. Polymer International, 50, 1318-1323 (2001).

DOI: $10.1002 /$ pi.777

[199] Asín L., Armelin E., Montané J., Rodríguez-Galán A., Puiggalí J.: Sequential poly(ester amide)s based on glycine, diols, and dicarboxylic acids: Thermal polyesterification versus interfacial polyamidation. Characterization of polymers containing stiff units. Journal of Polymer Science Part A: Polymer Chemistry, 39, 4283-4293 (2001). DOI: $\underline{10.1002 / \text { pola. } 10082}$ 
[200] Paredes N., Rodríguez-Galán A., Puiggalí J., Peraire C.: Studies on the biodegradation and biocompatibility of a new poly(ester amide) derived from L-alanine. Journal of Applied Polymer Science, 69, 1537-1549 (1998).

DOI: $10.1002 /(\mathrm{SICI}) 1097-4628(19980822) 69: 8<$ 1537::AID-APP8>3.0.CO;2-D

[201] Koyama E., Sanda F., Endo T.: Polycondensations of dicarboxylic acids and diols derived from optically active amino alcohols. Journal of Polymer Science Part A: Polymer Chemistry, 35, 2925-2934 (1997).

DOI: 10.1002/(SICI)1099-0518(199710)35:14<2925:: AID-POLA13>3.0.CO;2-L

[202] Bettinger C. J., Bruggeman J. P., Borenstein J. T., Langer R. S.: Amino alcohol-based degradable poly (ester amide) elastomers. Biomaterials, 29, 23152325 (2008).

DOI: $10.1016 /$ j.biomaterials.2008.01.029

[203] Kobayashi T., Kakimoto M. A., Imai Y.: Synthesis and properties of optically active polyester-amides from ester-containing chiral dicarboxylic acid and aromatic diamines. Polymer Journal, 25, 65-73 (1993).

[204] Gomurashvili Z., Kricheldorf H. R., Katsarava R.: Amino acid based bioanalogous polymers. synthesis and study of new poly(ester amide)s composed of hydrophobic $\alpha$-amino acids and dianhydrohexitoles. Journal of Macromolecular Science Part A: Pure and Applied Chemistry, 37, 215-227 (2000).

DOI: 10.1081/MA-100101089

[205] Yue Ying H. E., Xiao M.: Synthesis and properties of lactic acid-based cross-linked poly(ester-amide). Chinese Chemical Letters, 17, 645-648 (2006).

[206] Agrawal A. K., Bhalla R.: Advances in the production of poly(lactic acid) fibers. A review. Journal of Macromolecular Science Part C: Polymer Reviews, 43, 479503 (2003).

DOI: $10.1081 / \mathrm{MC}-120025975$

[207] De Wit M. A., Wang Z., Atkins K. M., Mequanint K., Gillies E. R.: Syntheses, characterization, and functionalization of poly(ester amide)s with pendant amine functional groups. Journal of Polymer Science Part A: Polymer Chemistry, 46, 6376-6392 (2008). DOI: $10.1002 /$ pola.22915

[208] Mallakpour S. E., Hajipour A-R., Habibi S.: Microwave-assisted synthesis of new optically active poly(ester-imide)s containing $N, N^{\prime}$-(pyromellitoyl)bis- $L$-phenylalanine moieties. Journal of Applied Polymer Science, 86, 2211-2216 (2002).

DOI: $10.1002 / a p p .11219$

[209] Mallakpour S., Habibi S.: Microwave-promoted synthesis of new optically active poly(ester-imide)s derived from $N, N^{\prime}$-(pyromellitoyl)-bis-L-leucine diacid chloride and aromatic diols. European Polymer Journal, 39, 1823-1829 (2003).

DOI: $10.1016 / \mathrm{S} 0014-3057(03) 00079-\mathrm{X}$
[210] Mallakpour S. E., Hajipour A-R., Khoee S.: Microwave-assisted polycondensation of $4,4^{\prime}$-(hexafluoroisopropylidene)- $N, N^{\prime}$-bis(phthaloyl-L-leucine) diacid chloride with aromatic diols. Journal of Applied Polymer Science, 77, 3003-3009 (2000).

DOI: $10.1002 / 1097-4628(20000923) 77: 13<3003::$

$$
\text { AID-APP26>3.0.CO;2-6 }
$$

[211] Mallakpour S., Kowsari E.: Preparation and characterization of new thermally stable and optically active poly(ester-imide)s by direct polycondensation with thionyl chloride in pyridine. Polymers for Advanced Technologies, 17, 174-179 (2006). DOI: $10.1002 /$ pat. 711

[212] Mallakpour S., Kowsari E.: Synthesis of novel optically active poly(ester imide)s by direct polycondensation reaction promoted by tosyl chloride in pyridine in the presence of $N, N$-dimethyformamide. Journal of Applied Polymer Science, 101, 455-460 (2006). DOI: 10.1002/app.23289

[213] Mallakpour S., Moghaddam E.: Preparation of new poly(ester-imide)s from N,N'-(4,4'-hexafluoroisopropylidendiphthaloyl)-bis-isoleucine and aromatic diols with $\mathrm{TsCl} / \mathrm{Py} / \mathrm{DMF}$ as a condensing agent. Iranian Polymer Journal, 15, 547-554 (2006).

[214] Mallakpour S., Kowsari E.: Direct polycondensations of $N, N^{\prime}$-(4,4'-oxydiphthaloyl)-bis-L-leucine diacid by use of tosyl chloride in the presence of $N, N$-dimethylformamide. Polymers for Advanced Technologies, 16, 795-799 (2005).

DOI: $10.1002 /$ pat. 654

[215] Mallakpour S., Kowsari E.: Thionyl chloride/pyridine system as a condensing agent for the polyesterification reaction of $N, N^{\prime}$-(4,4'-oxydiphthaloyl)-bis- $L$ leucine and aromatic diols. Iranian Polymer Journal, 15, 457-465 (2006).

[216] Mallakpour S., Kowsari E.: Synthesis of organosoluble and optically active poly(ester-imide)s by direct polycondensation with tosyl chloride in pyridine and dimethylformamide. Polymer Bulletin, 55, 51-59 (2005). DOI: $10.1007 / \mathrm{s} 00289-005-0416-\mathrm{Z}$

[217] Mallakpour S. E., Hajipour A-R., Zamanlou M-R.: New optically active poly(ester-imide)s derived from $N, N^{\prime}$-(4,4'-carbonyldiphthaloyl)-bis-L-phenylalanine diacid chloride. Journal of Applied Polymer Science, 85, 315-320 (2002). DOI: $10.1002 /$ app. 10630

[218] Mallakpour S. E., Hajipour A-R., Faghihi K.: Synthesis of novel optically active poly(ester-imide)s with benzophenone linkages by microwave-assisted polycondensation. Polymer International, 49, 1383-1388 (2000).

DOI: 10.1002/1097-0126(200011)49:11<1383::AIDPI502>3.0.CO;2-D 
[219] Mallakpour S., Shahmohammadi M. H.: Direct polycondensation of $N$-trimellitylimido- $L$-isoleucine with aromatic diols. Iranian Polymer Journal, 14, 974-981 (2005).

[220] Mallakpour S., Meratian S. H.: Synthesis and characterization of organosoluble optically active poly(esterimide)s derived from trimellitic anhydride, L-methionine and bisphenols. High Performance Polymers, 20, 3-18 (2008).

DOI: $10.1177 / 0954008307078385$

[221] Mallakpour S., Asadi P.: Novel chiral poly(esterimide)s with different natural amino acids in the main chain as well as in the side chain: Synthesis and characterization. Colloid and Polymer Science, 288, 1341-1349 (2010).

DOI: $10.1007 / \mathrm{s} 00396-010-2269-8$

[222] Song N., Qi W., Qiu X., Gao L., Ding M.: Synthesis and chirooptical properties of optically active poly (ester imide)s based on axially asymmetric 1,1'-binaphthyls. Journal of Polymer Science Part A: Polymer Chemistry, 42, 4318-4326 (2004).

DOI: 10.1002/pola.20297

[223] Kricheldorf H. R., Probst N., Gurau M., Berghahn M.: Liquid-crystalline polyimides. 20. Photoreactive and cholesteric poly(ester-imide)s based on 4-aminocinnamic acid trimellitimide and chiral sulfide spacers. Macromolecules, 28, 6565-6570 (1995).

DOI: $10.1021 / \mathrm{ma} 00123 \mathrm{a} 025$

[224] Kricheldorf H. R., Wulff D. F.: LC polyimides. XXVII. Cholesteric poly(ester-imide)s derived from chiral $i$-pentyloxyterephthalic acids. Journal of Polymer Science Part A: Polymer Chemistry, 34, 35113518 (1996).

DOI: 10.1002/(SICI)1099-0518(199612)34:17<3511:: AID-POLA5 $>3$.0.CO;2-X

[225] Mallakpour S., Kolahdoozan M.: Preparation and characterization of novel optically active poly(amideester-imide)s based on bis(p-aminobezoic acid)- $N$ trimellitylimido- $S$-valine via direct polyesterification. Iranian Polymer Journal, 15, 307-315 (2006).

[226] Mallakpour S. E., Hajipour A. R., Vahabi R.: Synthesis and characterization of novel poly(amide-esterimide)s based on bis(p-amidobenzoyl chloride) ntrirnellitylimido-leucine. Iranian Polymer Journal, 10, 321-330 (2001).

[227] Li C-H., Jung A., Liang A-L., Chang T-C.: Studies on the synthesis and properties of thermotropic liquid crystalline copoly(amide-ester-imide) derived from $N$-(hydroxyphenyl)phthalimide-4-carboxylic acid with amino acid. Journal of Applied Polymer Science, 56, 1661-1666 (1995). DOI: 10.1002/app.1995.070561217

[228] Ionescu M.: Chemistry and technology of polyols for polyurethanes. Rapra, Shawbury (2005).
[229] Chen C. F., Su Q., Chen Y. M., Xi F.: A new optically active polyurethane derived from chiral $(2 \mathrm{R}, 3 \mathrm{R})(+)-$ diethyl L-tartrate and diisocyanate. Chinese Journal of Polymer Science, 17, 371-373 (1999).

[230] Varkey E. C., Sreekumar K.: Optical and thermal properties of diethyl-(2R, 3R) (+)-tartrate based chiral polyurethanes with main chain amido chromophores. Journal of Applied Polymer Science, 119, 111-119 (2010).

DOI: 10.1002/app.32593

[231] Qiu F., Zhang W., Yang D., Zhao M., Cao G., Li P.: Synthesis, characterization, and thermo-optical properties of azobenzene polyurethane containing chiral units. Journal of Applied Polymer Science, 115, 146151 (2010).

DOI: $10.1002 /$ app.30948

[232] Nagai A., Ishikawa J., Kudo H., Endo T.: Synthesis of optically active polyurethanes by self-polyaddition of tyrosine-based monomers. Journal of Polymer Science Part A: Polymer Chemistry, 42, 1143-1153 (2004).

DOI: $10.1002 /$ pola.11047

[233] Chen J., Zhou Y., Nan Q., Ye X., Sun Y., Zhang F., Wang Z.: Preparation and properties of optically active polyurethane $/ \mathrm{TiO}_{2}$ nanocomposites derived from optically pure 1,1'-binaphthyl. European Polymer Journal, 43, 4151-4159 (2007).

DOI: $10.1016 /$ j.eurpolymj.2007.07.006

[234] Chen J., Nan Q., Guo L., Sun Y., Zhou Y.: Preparation and characterization of novel optically active polyurethanes containing 1,1'-binaphthol. Journal of Applied Polymer Science, 115, 2190-2196 (2010). DOI: 10.1002/app.31355

[235] Yasuzawa T., Yamaguchi H., Minoura Y.: Synthesis and properties of optically active polyurea by interfacial polyaddition. Journal of Polymer Science: Polymer Chemistry Edition, 17, 3387-3396 (1979).

DOI: $10.1002 /$ pol.1979.170171027

[236] Dunjic B., Gamez P., Fache F., Lemaire M.: Synthesis and characterization of a new chiral polyurea-based catalyst. Journal of Applied Polymer Science, 59, 1255-1262 (1996).

DOI: 10.1002/(SICI)1097-4628(19960222)59:8<1255 :AID-APP8>3.0.CO;2-B

[237] Mallakpour S., Shahmohammadi M. H.: Synthesis and characterization of novel optically active poly (imide-urethane)s derived from $N, N^{\prime}$-(pyromellitoyl)bis-(L-leucine) diisocyanate and aromatic diols. Polymer International, 53, 184-190 (2004).

DOI: $10.1002 /$ pi.1416

[238] Wang Z., Zhou Y., Sun Y.: Helical polyurethane-imide with optical activity based on binaphthyl units: Preparation, characterization, and study of interchain hydrogen bonds. Polymer Bulletin, 63, 699-708 (2009). DOI: $10.1007 / \mathrm{s} 00289-009-0153-9$ 
[239] Wang Z., Zhou Y., Sun Y.: Helical polyurethaneimide@attapulgite composite: Preparation, characterization and infrared emissivity study. Materials Letters, 64, 908-911 (2010).

DOI: $10.1016 /$ j.matlet.2010.01.055

[240] Chen Y., Tseng H-H.: Synthesis, characterization, and chiroptical property of optically active poly (urea-urethane)s. Journal of Polymer Science Part A: Polymer Chemistry, 31, 1719-1727 (1993).

DOI: $10.1002 /$ pola.1993.080310710

[241] Wang Z-Q., Zhou Y-M., Ye X-Y., Chen J., Sun Y-Q.: Synthesis and characterization of novel optically active poly(urethane urea)s: Effect of left/right rotation conformation. Journal of Applied Polymer Science, 111, 2134-2140 (2009).

DOI: 10.1002/app.29220

[242] Wang Z. Q., Zhou Y., Sun Y., Yao Q.: Optically active helical polyurethane-urea with single-handed conformation for infrared low emissivity. Macromolecules, 42, 4972-4976 (2009).

DOI: $10.1021 / \mathrm{ma900763r}$

[243] Mallakpour S., Rafiemanzelat F.: Synthesis and characterization of new optically active poly(amideimide-urethane) thermoplastic elastomers, derived from bis( $p$-amido benzoic acid)- $N$-trimellitylimido-Lleucine and polyoxyethylene-MDI. Reactive and Functional Polymers, 62, 153-167 (2005).

DOI: $10.1016 /$ j.reactfunctpolym.2004.11.005

[244] Mallakpour S., Rafiemanzelat F.: New optically active poly(amide-imide-urethane) thermoplastic elastomers derived from poly(ethylene glycol diols), 4,4'-methylene-bis(4-phenylisocyanate), and a diacid based on an amino acid by a two-step method under microwave irradiation. Journal of Applied Polymer Science, 98, 1781-1792 (2005).

DOI: $10.1002 / a p p .22363$

[245] Mallakpour S., Rafiemanzelat F.: Synthesis and characterization of novel optically active poly(ether-urethane)s modified by copoly(amide-imide) segments based on amino acid through diisocyanate route: Influence of reaction parameters. Iranian Polymer Journal, 15, 79-90 (2006).

[246] Mallakpour S., Rafiemanzelat F.: Facile and rapid synthesis of novel optically active poly(amide-imideurethane)s derived from bis(p-amido benzoic acid)-Ntrimellitylimido- L-leucine and polyoxyethylene-MDI under microwave irradiation. Iranian Polymer Journal, 14, 909-919 (2005).

[247] Mallakpour S., Rafiemanzelat F.: Synthesis and properties of novel optically active poly(amide imide urethane) thermoplastic elastomers by the reaction of a L-leucine based diacid chain extender and PEG-terminated MDI. Iranian Polymer Journal, 14, 169-180 (2005).
[248] Mallakpour S., Khani M., Rafiemanzelat F.: Synthesis and characterization of new optically active segmented poly(amide imide urethane)s based on different diacids via an isocyanate route. Journal of Applied Polymer Science, 108, 2975-2982 (2008).

DOI: 10.1002/app.27925

[249] Mallakpour S., Khoee S.: Synthesis and characterization of new optically active poly(amide-imide-urethane) thermoplastic elastomers, derived from 4,4'(hexafluoroisopropylidene)- $N, N^{\prime}$-bis(phthaloyl-Lleucine- $p$-aminobenzoic acid) and PEG-MDI. Journal of Applied Polymer Science, 91, 2288-2294 (2004). DOI: 10.1002/app.13361

[250] Mallakpour S., Esteki M., Rafiemanzelat F., Khayamian T.: Application of factorial design method for the optimization of reaction conditions influencing viscosity of poly(amide-imide-ether-urethane)s based PEG and L-leucine. Iranian Polymer Journal, 16, 21-29 (2007).

[251] Mallakpour S., Rafiemanzelat F.: Preparation and Properties of new copoly(amide-imide-ether-urethane)s based on bis( $p$-amido benzoic acid)- $N$-trimellitylimido- $L$-leucine by two different polymerization methods. Polymer Bulletin, 58, 339-350 (2007).

DOI: $10.1007 / \mathrm{s} 00289-006-0674-4$

[252] Mallakpour S., Seyedjamali H.: Design and synthesis of novel organosoluble chiral poly(amide-ether-imideurea) containing L-leucine moieties in the main chain. Colloid and Polymer Science, 288, 703-710 (2010). DOI: $10.1007 / \mathrm{s} 00396-010-2202-1$

[253] Suzuki A.: Recent advances in the cross-coupling reactions of organoboron derivatives with organic electrophiles, 1995-1998. Journal of Organometallic Chemistry, 576, 147-168 (1999). DOI: $10.1016 / \mathrm{S} 0022-328 \mathrm{X}(98) 01055-9$

[254] Hu Q-S., Vitharana D., Liu G-Y., Jain V., Wagaman M. W., Zhang L., Lee T. R., Pu L.: Conjugated polymers with main chain chirality. 1 . Synthesis of an optically active poly(arylenevinylene). Macromolecules, 29, 1082-1084 (1996).

DOI: $10.1021 / \mathrm{ma951414t}$

[255] Hu Q-S., Vitharana D., Liu G., Jain V., Pu L.: Conjugated polymers with main chain chirality. 2. Synthesis of optically active polyarylenes. Macromolecules, 29, 5075-5082 (1996).

DOI: $10.1021 / \mathrm{ma960249u}$

[256] Ma L., Hu Q-S., Musick K. Y., Vitharana D., Wu C., Kwan C. M. S., Pu L.: Conjugated polymers with main chain chirality. 3 . Synthesis of optically active poly(aryleneethynylene)s. Macromolecules, 29, 50835090 (1996).

DOI: $10.1021 / \mathrm{ma960250t}$

[257] Yu H-B., Hu Q-S., Pu L.: The first optically active BINOL-BINAP copolymer catalyst: Highly stereoselective tandem asymmetric reactions. Journal of American Chemical Society, 122, 6500-6501 (2000). DOI: $10.1021 / \mathrm{ja} 000778 \mathrm{k}$ 
[258] Asai K., Konishi G., Sumi K., Kawauchi S.: Synthesis of optically active green fluorescent $\pi$-conjugated fluorene polymers having chiral Schiff bases in the side chain. Polymer Chemistry, 1, 321-325 (2010).

DOI: $10.1039 / \mathrm{b} 9$ py00268e

[259] Sonogashira K., Tohda Y., Hagihara N.: A convenient synthesis of acetylenes: Catalytic substitutions of acetylenic hydrogen with bromoalkenes, iodoarenes and bromopyridines. Tetrahedron Letters, 16, 44674470 (1975).

DOI: 10.1016/S0040-4039(00)91094-3
[260] Block M. A. B., Hecht S.: Poly(propylene oxide)poly(phenylene ethynylene) block and graft copolymers. Macromolecules, 41, 3219-3227 (2008).

DOI: $10.1021 / \mathrm{ma} 702844 \mathrm{w}$

[261] Li X., Li C., Lu J., Liang H.: Designed synthesis and chiroptical properties of regioregular poly $(p$-phenyleneethynylene-alter-m-phenyleneethynylene) bearing (-)-trans-myrtanoxyl side groups. Frontiers of Chemistry in China, 4, 93-103 (2009).

DOI: $10.1007 / \mathrm{s} 11458-009-0018-7$ 